\title{
CARACTERIZAÇÃO DA SECA AGRONÔMICA ATRAVÉS DE NOVO MODELO DE BALANCCO HIDRICO, NA REGIĀO DE LAGUNA, LITORAL SUL DO ESTADO DE SANTA CATARINA
}

HUGO JOSÉ BRAGA

Orientador: Dr. NILSON AUGUSTO VILLA NOVA

Dissertação apresentada à Escola Superior de Agricultura "Luiz de Queiroz", da Universidade de São Paulo, para obtenção do título de Mestre em Agronomia - Área de Concentração - Agrometeorologia.

PIRACICABA

Estado de São Paulo - Brasil

Dezembro, 1982 
A memória de meu pai

A minha mãe

A minha esposa Rosane

A meu filho Rodrigo

DEDICO 


\section{AGRADECIMENTOS}

o autor expressa os mais sinceros agradecimentos:

Ao Prof.Dr. Nilson Augusto Villa Nova, pela orientaçāo e dedicação no desenvolvimento do presente trabalho, a lém da amizade e colaboração durante todo o curso.

Aos demais professores do Departamento de Física e Meteorologia da ESALQ, que contribuiram para a minha formação profissional.

Ao Departamento de Matemática e Estatística da

ESALQ.

A Escola Superior de Agricultura "Luiz de Queiroz" - ESALQ/USP.

Ao Centro de Energia Nuclear na Agricultura-CENA/ /SP, atravēs do Setor de Física de Solos, em especial ao Dr. Paulo Leonel Libardi, pela colaboração e amizade.

A Empresa Catarinense de Pesquisa Agropecuária EMPASC, em especial ao seu presidente, Dr. José Oscar Kurtz pe la oportunidade e apoio na realização do Curso de Pós-Graduação.

A Empresa Brasileira de Pesquisa Agropecuária EMBRAPA.

Ao Instituto Nacional de Meteorologia - INMET/MA, através do 8? DISME. 
i i i .

Aos colegas, Arno Bernardo Heldwein, Antonio José Parente de Carvalho, Engler José Lobato, Ana Maria Gonzales e demais colegas do Curso de Agrometeorologia.

As funcionárias, Aurea Benedita Michelotto e Ana :i.ju Silva, do Departamento de Física e Meteorologia da ESALQ, peìa amizade e colaboração durante o Curso de Pōs-Graduação.

Aos demais funcionários deste e outros Departamentos da ESALQ, pela colaboração durante o Curso.

Agradecemos ainda a todos aqueles que, direta ou indiretamente, contribuiram para a realização desse trabalho. 
LISTA DE TABELAS $\ldots \ldots \ldots \ldots \ldots \ldots \ldots \ldots \ldots \ldots \ldots \ldots \ldots \ldots \ldots \ldots \ldots \ldots$

LISTA DE FIGURAS .........................

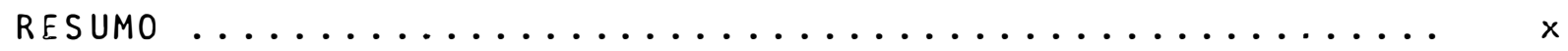

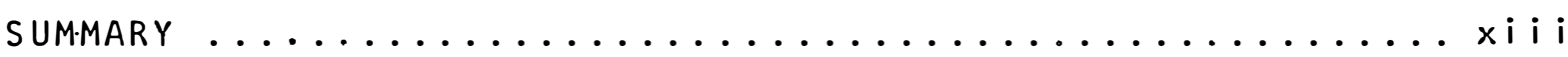

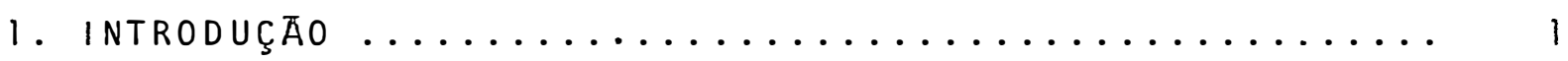

2. REVISÄO BIBLIOGRAFICA ..................... 4

3. MATERIAL E MÉTODOS ......................... 30

3.1. Local de Estudo ..................... 30

3.2. Dados Disponiveis .................. 30

3.2.1. Dados Climáticos ................ 30

3.2.2. Caracterização dos Solos ............ 32

3.3. Caracterização da Água Disponivel no Solo ...... 38

3.4. Determinação da Evapotranspiração Potencial (ETP) ou de Referência (ETo) ................. 38

3.5. Balanço de Água no Solo e Determinação dos "Dias Secos" .......................... 45

3.5.1. O Balanço Hídrico Seriado Diärio Modificado (BнM) .................... 46

3.6. Probabilidade de Ocorrência de "Dias Secos" .... 59

4. RESULTADOS E DISCUSSÃo ...................... 61

4.1. Local de Estudo e Dados Meteorológicos .........6 61

4.2. Caracterização dos Solos e Água Disponível ..... 62 
4.3. Evapotranspiração Potencial (ETP) ou de Referência (ETo) ................................ 71

4.3.1. Simplificação do Termo "Energia" da Equação de PENMAN (1948) ................. 7 I

4.3.2. Similificação do Termo "Aerodinämico" .... 74

4.3.3. A Equação Simplificada de PENMAN ........ 79

4.4. Contabilização dos :i ias Secos Consecutivos ...... 82

4.5. Sequéncias de Dias Secos por Períodos Anuais, Tri mestrais, Mensais, e Quinzenais .............. 89

4.6. Probabilidade Teōrica de Ocorrēncia de um "Nümero Mínimo de Dias Secos Consecutivos" por periodo Quinzenal, Mensal e Trimestral .............. 92

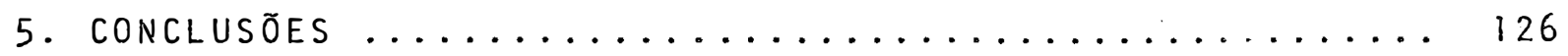

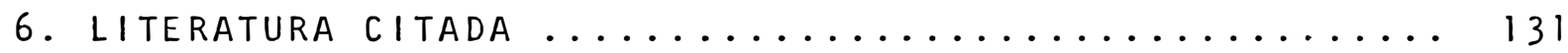

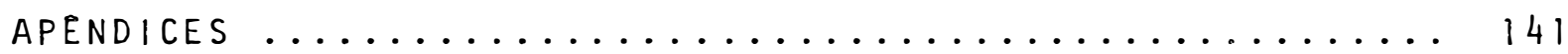




\section{LISTA DE TABELAS}

Tabela n?

Pāg •

1 Grupo de Culturas de acordo com a perda de Água do Solo (a) e Fração P para Grupos de Culturas e Evapotranspi ração Potencial-ETP (b) ........

2 Valores diversos de CAD e correspondentes Valores de Coeficientes angulares (b) da Equação 0riginal de THORNTHWAITE e MATHER (1955) para cál culo do Armazenamento de Agua no Solo ........

3 Exemplo Hipotético do Balanço Hídrico Seriado Diārio Modificado (BHM) utilizado para estudo e caracterização da Seca Agronômica, atraves de conceito de "dias secos".................

4 Densidade Global e Níveis de Umidade por Volume- $\left(\mathrm{cm}^{3} / \mathrm{cm}^{3}\right)$ nos solos "Tubarão", "J.Machado", "Morro da Fumaça" e "Ararangua" e nas camadas de $0-30 \mathrm{~cm} ; 30-60 \mathrm{~cm}$ e $60-100 \mathrm{~cm}$, para diferentes tensões de Umidade no Solo $\left(\psi_{m}\right) \ldots . . . \ldots$.

5 Capacidade de Agua Disponível Māxima-CAD em mm de altura d'água até as profundidades de $30 \mathrm{~cm}$, $60 \mathrm{~cm}$ e $100 \mathrm{~cm}$ para os Solos "Tubarão", "J. Machado", "Morro da Fumaça" e "Ararangua", entre as tensões de $0,1-15$ atm. e 0,3-15 atm .......

6 Valores do Fator $\beta$, para cada mês e ano, seus desvios padrões (DP), coeficientes de variação (CV\%) e Número de meses ou anos utilizados(N)..

7 Valoras do Fator B corrigidos, para cada mês e ano seus desvios padrões(DP), coeficientes de 
variação(CV\%) e nümero de meses ou anos utili-

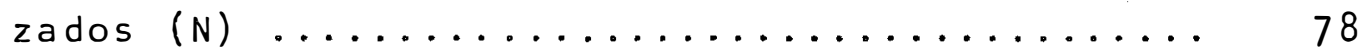

8 Valores da Evapotranspiração Potencial-ETP, cal culados pelo método simplificado $(X)$ e pelo de PENMAN (1948) ( $Y$ ), parāmetros a e b da equação de regressão entre ambos, coeficiente de determinação $\left(r^{2}\right)$ e Teste $T$, entre os meses de cada ano

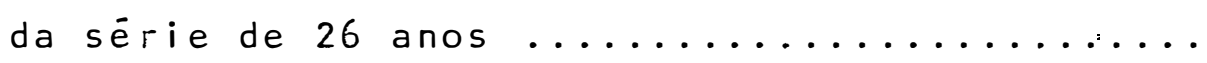

9 a 11 Valores dos coeficientes de determinaçāo $\left(r^{2}\right)$ das equąções $P L=a+b D$, onde $D$, significa o nümero mínimo de dias secos consecutivos observados e PL é a probabilidade empirica de ocorrência de $D$, marcada numa escala linear, probabilidade linear, paralela à escala do papel de probabili dade, para as CADs estudadas e por período quín zenal, mensal e trimestral ...............97a 98 
LISTA DE FIGURAS

Figura N?

Pàg.

1 Mapa com a localização da Região de Laguna, Li : toral sul, com suas delimitaçōes politicas e isolinhas de deficiència hídrica anual de 25 a

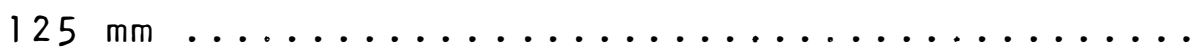

2 Mapa da Area abrangida do estudo com a ocorrência e localização dos principais solos. Baseado na Carta de Aptidão Agrícola das Terras do Estado de Santa Catarina $(1981) \ldots \ldots \ldots \ldots$

3 Relação entre o Armazenamento da Água no Solo e - Negativo Acumulado (N), pelo método de THORNTHWAITE e MATHER (1955) e o modificado neste tra balho, para uma $C A D$ de $50 \mathrm{~mm} \ldots \ldots \ldots \ldots$

4 Evapotranspiração Relativa(ETR/ETP), versus porcentagem de Água Disponível Māxima (CAD) no solo, em função de quatro valores do Fator P....

5 Curvas características das camadas 0-30 cm, 30-60 cm e 60-100 cm, para o solo "Tu-

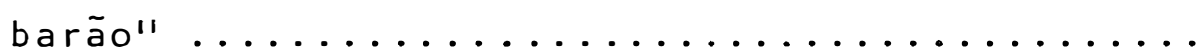

6 Curvas características das camadas $0-30 \mathrm{~cm}, 30-60 \mathrm{~cm}$ e 60-100 cm, para o solo "J.

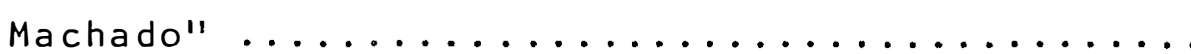

7 Curvas características das camadas 0-30 cm, 30-60 cm e 60-100 cm, para o solo "Mor

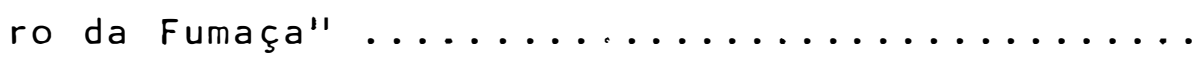


00-30 cm, 30-60 cm e 60-100 cm, para o solo "Ara

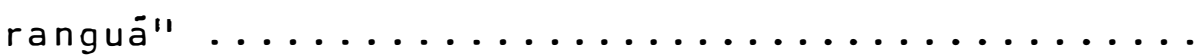

9 Papel de probabilidade onde foram marcados os números mínimos de dias secos consecutivos (abcissas) e suas probabilidades empíricas de ocor rência (ordenada à esquerda) e obtenção dos valores correspondentes às probabilidades em escala linear-PL (ordenada à direita) ..........

10 a 19 Probabilidade Teórica de ocorrer um dado número mínimo de dias secos consecutivos em cada quinzena de cada mês do calendário e para $18 \mathrm{~mm}$, $38 \mathrm{~mm}, 50 \mathrm{~mm}, 100 \mathrm{~mm}$ e $175 \mathrm{~mm}$ de Capacidade de Ågua Disponível Máxima-CAD ...............103 a 112

20 a 24 Probabilidade Teórica de ocorrer um dado número mínimo de dias secos consecutivos, para cada mês do calendário e para $18 \mathrm{~mm}, 38 \mathrm{~mm}, 50 \mathrm{~mm}, 100 \mathrm{~mm}$ e $175 \mathrm{~mm}$ de Capacidade de Āgua Disponível Máxi-

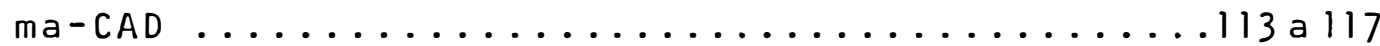

25 a 27 Probabilidade Teórica de 0correr um dado número mínimo de dias secos consecutivos, para cada trimestre do ano e para $18 \mathrm{~mm}, 38 \mathrm{~mm}, 50 \mathrm{~mm}, 100$ mm e $175 \mathrm{~mm}$ de Capacidade de Ågua Disponível Má.

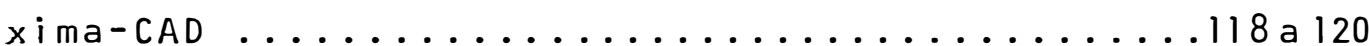

28 a 32 Número Mínimo de dias secos consecutivos esperados em cada quinzena de cada mês do calendário, aos niveis de 10\%, 20\%, 30\%, 40\%, $50 \%, 60 \%$ e $80 \%$ de Probabilidade Teórica, para $18 \mathrm{~mm}, 38 \mathrm{~mm}$, $50 \mathrm{~mm}, 100 \mathrm{~mm}$ e $175 \mathrm{~mm}$ de CAD ................. 12125 
CARACTERIZAÇÃO DA SECA AgRONOMICA ATRAVES DE NOVO MOdELO DE BALANÇO HIDRICO, NA REGIÃO DE LAGUNA, LITORAL SUL DO ESTADO DE SANTA CATARINA

Autor: Hugo José Braga

Orientador: Prof.Dr. Nilson Augusto Villa Nova

RESUMO

No presente trabalho estuda-se o problema da ocorrência da seca agronómica na Região de Laguna, Litoral Sul do Estado de Santa Catarina.

A caracterizaçāo da seca agronōmica efetivou-se pelo critērio de "dias secos consecutivos" determinados atravēs de um novo modelo de balanço hídrico, desenvolvido a partir da junção de diversos métodos, teorias e critérios existen tes, como aqueles utilizados por VAN BAVEL e WILSON(1952), VAN BAVEL (1953), THORNTHWAITE e MATHER (1955), DENMEAD e SHAW (1962) e FAO (1979).

Para aplicação desse modelo, utilizaram-se os ní veis de capacidade de āgua disponível mäxima de $18 \mathrm{~mm}, 38 \mathrm{~mm}$, $50 \mathrm{~mm}, 100 \mathrm{~mm}$ e $175 \mathrm{~mm}$, obtidos pela amostragem de quatro solos ocorrentes na região em estudo, em três profundidades bãs i cas, fazendo-se a determinação das suas curvas características de àgua.

O método desenvolvido, denominado de Balanço Hí- 
$x i$.

drico Modificado (BHM) e a caracterização da seca agronômica correspondente, levaram em consideração não apenas o teor de umidade no solo, mas tambēm o conceico de āgua livremente dís ponível, como função da demanda atmosfērica e da espécie vegetal.

Para a obtenção da evapotranspiração, potencial ETP, como elemento de estimativa da perda d'água da superfície vegetada para a atmosfera, utilizou-se da equação de PENMAN sim plificada, segundo metodologia usada por VILLA NOVA e OMETTO (1981), depois, de modificada e adaptada de acordo com os parámetros mensais pertinentes à região em estudo. Dessa forma, es timou-se a ETP média diāria para cada mês e ano da sērie de 26 anos utilizada (1955-1980).

Após verificar-se que as frequências do número mínimo de dias secos consecutivos apresentavam distribuição nor mal, a partir das contagens dos "dias secos consecutivos", obtiveram-se as probabilidades teóricas de ocorrência de um dado nủmero mínimo de dias secos consecutivos por períodos quinzenais, mensais e trimestrais.

De posse das relações entre as probabilidades teó ricas e o nümero mínimo de ocorrência de "dias secos consecuti

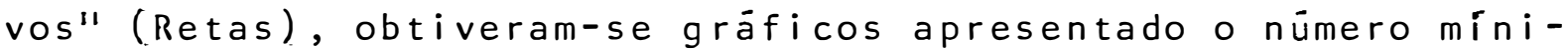
mo de dias secos possiveis de ocorrer em cada quinzena de cada més do calendārio, para cada CAD, aos níveis de $10 \%, 20 \%, 30 \%$, $40 \%, 50 \%, 60 \%$ e $80 \%$ de probabilidade teórica.

Verificou-se, assim, que os períodos que apresen 
$x i i$.

tam maior severidade quanto a seca agronómica, correspondemaos meses da primavera-verão, ou seja, outubro, novembro, dezembro, janeiro, fevereiro e março, mesmo para solos com uma capacidade de àgua disponível máxima-CAD de $175 \mathrm{~mm}$, na região estudada. 
$x i i i$

CHARACTERIZATION OF AGRICULTURAL DROUGHT THROUGH A NEW MODEL OF

WATER BALANCE, IN THE REGION OF LAGUNA, SOUTHERN COAST

OF THE STATE OF SANTA CATARINA, BRAZIL

Author: Hugo José Braga

Adviser: Prof.Dr. Nilson Augus to Villa Nova

SUMMARY

In the present work a study was made of the problem of occurrence of agriculturaldrought in the region of Laguna, southern coast of the State of Santa Catarina, Brazil.

The agricultural drought characterization was carried out by the criterion of "consecutive drought-days", determined through a new model of water balance, developed from several existing methods, theories and criteria, such as those utilized by VAN BAVEL and WILSON(1952), VAN BAVEL(1953),THORNTHWAITE and MATHER (1955), DENMEAD AND SHAW (1962) and FAO(1979). For the application of this model, the total available soil water storage levels of $18 \mathrm{~mm}, 38 \mathrm{~mm}, 50 \mathrm{~mm}, 100$ $\mathrm{mm}$ and $175 \mathrm{~mm}$ were utilized, which were obtained by sampling of 4 soils in the region under study, at 3 basic depths, through determination of the characteristic curves of soil water.

The method developed, denominated Modified Water Balance, and the characterization of the corresponding agricultural drought, considered the soil moisture and the concept of 
xiv.

freely available water, as a function of atmospheric demand and plant species.

For the obtention of Potential Evapotranspiration as a factor for estimating the loss of water of the vegetation-covered surface to the atmosphere, PENMAN'simplified equation was utilized, according to the methodology used by VILLA NOVA and OMETTO (1981) and adapted to the monthly parameters for the region under study. Thus, the mean daily of Potencial Evapotranspiration was estimated for each month and year in the 26 -year series utilized $(1955-1980)$.

After verifying that the frequencies of the minimum number of consecutive drought days showed a regular distribution, and from counts of consecutive drought days, the theoretical probabilities were obtained for occurrence of a given minimum number of consecutive drought days for periods of 15 days, 1 month and 3 months. Through the relations between the theoretical probabilities and the minimum occurrence of consecutive drought days (straights), graphs were obtained showing the minimum number of expected drought days in each 15-day period of every calendar month, for each CAD, at $10 \%, 20 \%, 30 \%, 40 \%, 50 \%, 60 \%$ and $80 \%$ levels of theoretical probability.

Thus, it was found that the periods in which agricultural drought was most severe correspond to the springsummer months, i.e., October, November, December, January, February and March, even for soils with $C A D=175 \mathrm{~mm}$ in the region studied. 
1. INTRODUÇĀO

Em função das condições climāticas assumirem ce ta variabilidade no tempo, as atividades agrícolas estarão sem pre sujeitas à altos riscos de insucessos. Aliado a esse fato, a modernização da nossa agricultura, impulsionada pela maior demanda de alimentos, é investida de pesadas aplicações de recursos aumentando ainda mais o risco de frustrações econōmicas.

Por essas razões, cresce a necessidade do estudo das condições agroclimāticas limitantes aos empreendimentos agrícolas, com objetivo principal de minimização desses riscos. Um dos fatores climāticos de maior importância $\underline{a}$ grícola e de alta variabilidade é a precipitação pluviométrica, principal supridor das necessidades hídricas das plantas. Mesmo em regiões úmidas e sub-ümidas a sua má distribuição pode causar seca agronómica com prejuízos variados, constituindo-se uma das principais fontes de risco agrícola.

Dessa maneira, a caracterização da seca agronômi ca, através de estudos de probabilidade, é de grande importân- 
cia para se definir as melhores épocas de plantio, escolha de cultivares adequadas, avaliação de riscos, necessidades de ägua para irrigação, previsão de colheitas, enfim como estudo bāsico para decisões de um melhor planejamento agrícola.

0 Zoneamento Agroclimático do Estado de Santa Cá tarina, realizado em 1978, atravēs do método do Balanço Hídrico de THORNTHWAITE e MATHER (1955), mostrou que o litoral sul desse Estado apresenta isolinhas de deficiência hídrica anual de até $125 \mathrm{~mm}$, para um solo com uma capacidade de armazenamento ou retenção de àgua māxima - CAD - de $75 \mathrm{~mm}$.

Embora a região, pela classificação climática de KÖEPPEN, mostre um clima mesotērmico úmido, sem estação seca, ocorrem deficiências hídricas em certas épocas do ano, seja pẹ la baixa capacidade de retenção dos solos, por má distribuição de chuvas ou também devido a alta demanda atmosférica.

Considerando que essa característica assume papel importante na limitação das atividades agrícolas, principalmente nas épocas de primavera e verão, estudos mais detalha dos sobre o balánço hídrico, nessa área, fazem-se necessários, pois os clássicos balanços hídricos mensais realizados em termos de normais climatológicas não parecem ser suficientes para fornecer uma visão mais realística deste processo.

0 presente trabalho tem por escepo a caracteriza ção da ocorrência da seca sob o aspecto agrícola, através da determinação das probabilidades (risco) de ocorrência da seca agronōmica, pelo critērio de "dias secos consecutivos" por pe- 
ríodos quinzenais, mensais, trimestrais e anual, na região de Laguna, Litoral Sul do Estado de Santa Catarina.

Para a caracterização da seca agronômica, desenvolveu-se um método de balanço de água no solo, através da jun ção de diversos métodos, teorias e critérios existentes, como os utilizados por VAN BAVEL e WILSON (1952), VAN BAVEL (1953), THORNTHWAITE e MATHER (1955), DENMEAD e SHAW (1962) e FAO (1979).

O método desenvolvido denominado de Balanço Hídrico Modificado (BHM) e a caracterização da seca agronômica correspondente, levam em consideração, não apenas o teor de umidade no solo, mas também o conceito de água livremente dispo nível como função da demanda atmosférica e da espécie de cultú tura.

Para a obtenção da Evapotranspiração Potencial (ETP), como elemento de estimativa da perda d'água da superfí cie vegetada para a atmosfera, utilizou-se da equação de PENMAN simplificada, segundo metodologia usada por VILLA NOVA e OMETTO (1981), depois de modificada e adaptada de acordo com os parâmetros específicos pertinentes à região em estudo. 
0 conhecimento da perda de água pelas superfícies naturais, seja por evaporação ou transpiração, é de extre ma importância nos diversos ramos do conhecimento científico. A água disponível no solo para a utilização das diversas plantas cultivadas é um dos principais elementos promotores decres cimento, desenvolvimento e produção final das mesmas. A avalia ção das quantidades deste elemento é de importância ímpar nos estudos dos regimes hidricos locais e regionais.

A principal fonte de suprimento de āgua para as plantas é, sem dūvida, advinda das precipitações pluviométricas, fenómeno este de grande variabilidade; dificultando sobre maneira seu estudo e predição.

Numerosos trabalhos têm sido conduzidos interna cionalmente no sentido de se determinar o consumo e utilização de água pelas plantas, seu armazenamento no solo e disponibili dade.

Segundo CHANG (1968), muitos métodos para a deter 
minação da umidade do solo foram desenvolvidos nos ültimos tem pos, podendo ser divididos em duas categorias:

a) Medidas de Tensão de Umidade

b) Medidas de Conteúdo de Agua

No primeiro grupo são incluídos os métodos elé tricos e os tensiōmetros. No segundo, o método de secagem em estufa (Gravimétrico) é usado, embora trabalhoso e o método de dispersão de Neutrons (Sonda de Neutrons).

Entretanto, nenhum dos métodos disponíveis pre sentemente, de medida de umidade do solo, é satisfatōrio para a rotina de campo usada pelo agricultor. Mesmo quando em traba lhos de pesquisa, os métodos em geral são dispendiosos e conso mem muito tempo de operação e interpretação, muitas amostras sendo necessários para a confiabilidade estatística.

Por essas razões, pelo progresso atingido na determinação e estimativas da evapotranspiração, conduziu ao de senvolvimento da técnica do balanço hídrico como um método de se estimar a umidade do solo. Esta metodologia apresenta baixo custo dos equipamentos envolvidos, simplicidade de medidas e razoāvel precisão dos resultados.

A metodologia do balanço hídrico, num volume de controle de solo, tem sido apresentada por vários autores ROSE, 1966; HOLMES et alii, 1967; BARROS FERRAZ, 1972; REICHARDT, 1975) onde seus componentes (precipitação, irrigação, deflūvio superficial, drenagem profunda e evapotranspiràção) são governa- 
dos pela lei da conservação das massas. Nessas condiçōes, a equação do Balanço Hídrico ê assim apresentada:

$\int_{t_{1}}^{t_{2}}\left(p+i-e \pm q_{L}-r\right) d t=\int_{0}^{L} \int_{t}^{t_{2}} \frac{\partial \theta}{\partial t} d t \cdot d z$

que desdobrada transforma-se em:

$\int_{t_{1}}^{t_{2}} p d t+\int_{t_{1}}^{t_{2}} i d t-\int_{t_{1}}^{t}{ }_{2} e d t \pm \int_{t_{1}}^{t^{2}} q_{L} d t-\int_{t_{1}}^{t^{2}} r d t=\int_{0}^{L} \int_{t_{1}}^{t_{2}} \frac{\partial \theta}{\partial t} d t \cdot d z$ onde $p, i, e, q_{L}$ e $r$ são fluxos $\left(L T^{-1}\right) ;$ e $\theta$, representa a umi dade volumétrica do solo $\left(\mathrm{cm}^{3}\right.$ de àgua. $\mathrm{cm}^{3}$ de solo).

Desenvolvendo fica:

$$
P+1-E T \pm Q_{L}-R=\Delta A
$$

onde:

P = precipitação pluviométrica por unidade de ārea e por tempo;

1 = quantidade de àgua por unidade de ārea que chega à super fície, em forma de irrigação;

$E T$ = quantidade de āgua por unidade de ārea que sai da superfí cie do solo, na forma de Evapotranspiração;

$Q_{L}=$ quantidade de āgua por unidade de ārea que passa através do limite inferior do volume de solo na profundidade $Z=L$, denominada de percolação ou drenagem profunda quando nega tivo e ascensão capilar quando positivo.

$R$ = quantidade de àgua que chega à superfície do solo,através da precipitação ou Irrigação, a qual não é infiltrada, de nominada de defluvio superficial.

$\Delta A=$ quantidáde de água armazenada no solo por unidade de àrea 
ou variação de armazenagem, durante um intervalo de tempo.

Se a capacidade de armazenamento de umidade de um solo é conhecida, a equação do balanço de água pode ser resolvida pela comparação da precipitação e da ãgua de irrigação com a evapotranspiração. Em se tratando de operação agrícola, o balanço hídrico diário é preferido, embora a computação sema nal possa apresentar, essencialmente, os mesmosresultados.

Conforme cita BERLATO e MOLION (1981), a evapotranspiração potencial, como um dos principais componentes do balanço dé água, é de grande utilidade em climatologia, querem classificações climáticas, quer para a quantificação das dispo nibilidades hidricas regionais, através de um cotejo com a pré cipitação e variação da água no solo.

A perda de água de um solo úmido ou de um reser vatório de āgua é um processo controlado por leis físicas, enquanto que a perda de água por uma planta é limitada por fenómenos biológicos. Conforme cita SHANG (1968), evapotranspiração é a combinação da evaporação da superfície do solo e da transpiração das plantas. Negligenciando-se a quantidade de água usada nas atividades metabólicas, evapotranspiração è o mesmo que o "uso conjuntivo" de água pelas plantas.

PENMAN (1956), citado por ShANG (1968), definiu a evapotranspiração potencial como a "quantidade de água transpirada na unidade de tempo por uma cultura verde, sombreando com pletamente o solo, de altura pequena e uniforme e nunca sofren do falta de água". 
Evapotranspiração potencial ou de referência é a evapotranspiração ocorrente de uma superfície vegetada com gra ma batatais (Paspalum notatum L.) bem provida de umidade, em fase de desenvolvimento ativo e com a bordadura adequada, con forme cita VILLA NOVA et alii (1980).

Existem muitos métodos de medidas ou de estimati vas da evaporação e evapotranspiração citados pela literatura. os métodos de medidas indiretas ou diretas de vaporação e evapotranspiração utilizam-se de vārios tipos de tanques (classe A, GGI-3000) e de lisímetros. Séries de medidas de evapotranspiração e evaporação, praticamente não existem entre nós, para cada região ou condição climática.

BERLATO e MOLION (1981), apresentaram uma série de métodos utilizados na estimativa da evaporação e evapotrans piração, assim classificando-os:

a) Método do Balanço Hídrico;

b) Método do Balanço Hídrico combinado com o Balanço de Energia;

c) Métodos Micrometeorológicos:

c.l. Método do Balanço de Energia;

c.2. Método do Transporte de Massa;

c.3. Mētodo Aerodinâmico;

c.4. Método da "correlação turbulenta" (Eddy Correlation Method);

c.5. Método de Resistências;

c.6. Método Combinado (PENMAN) 
d) Métodos Empíricos:

d. 1. Equação de THORNTHWAITE;

d.2. Equação de BLANEY e CRIDDLE;

d.3. Equação de TANNER e PELTON;

d.4. Equação de MAKKINK;

d.5. Equação de JENSEN-HAISE;

d.6. Equação de PRIESTLEY e TAYLOR;

d.7. Equação de LINACRE

Esses diversos métodos, muitos apresentam difi-

culdades inerentes, prestando-se apenas à trabalhos de pesqui sa.

Segundo VILLA NOVA et alii (1980), os principais métodos climatológicos de estimativa de evapotranspiração de referência ou potencial recomendados pela FAO são:

a) Método do Tanque Classe A;

b) Método da Radiação Solar;

c) Método Combinado (PENMAN).

o enfoque meteorológico para estimar a evapotranspiração potencial tem inūmeras vantagens. Os dados meteorológicos são mais disponíveis do que medidas de umidade do so lo e estimativas, a partir de dados meteorológicos, são facil mente realizáveis. Os máximos rendimentos das plantas cultivadas somente são obtidos quando não ocorrem limitações, principalmente no que tange ao suprimento de àgua e, consequentemen te, as estimativas de evapotranspiração potencial são valiosas para propormos a irrigação e para interpretar os resultados de 
muitos experimentos agronômicos, MOTA e BEIRSDORF (1976).

Para a estimativa da evapotranspiração potencial, os dois métodos mais largamente usados em todo o mundo, tem si do o de PENMAN (1948) e o de THORNTHWAITE (1948), segundo HOUNAM (1971), citado por MOTA e BIERSDORF (1976).

O método de PENMAN, tambēm chamado de método com binado, pois associa o balanço de energia com a aproximação aerodinâmica foi publicado pela primeira vez em 1948. A Equação de PENMAN (1948), é assim expressa:

$$
E T P=\frac{\frac{\Delta}{\gamma} \cdot \frac{R n}{59}+E a}{\frac{\Delta}{\gamma}+1}
$$

onde :

ETP = Evapotranspiração Potencial (mm/dia);

$R n$ = Saldo de radiação (Radiação líquida disponível ao meio), expresso em unidades de evaporação ( $\left.\cong 590 \mathrm{cal}^{\circ} \mathrm{g}^{-1}\right)$.

$\gamma=$ Constante psicrométrica (p/psicrometro ventilado $\cong 0,49$ $\left.\mathrm{mmHg} \quad{ }^{\circ} \mathrm{C}^{-1}\right)$.

$\Delta=\frac{d e}{d t}=$ Coeficiente angular da curva que relaciona tensão de saturação de vapor e temperatura $\left(\mathrm{mmHg}^{\circ} \mathrm{C}^{-1}\right)$.

$\mathrm{Ea}=$ Termo aerodinâmico, função do deficit de saturação do ar e da velocidade do vento dado por:

$$
\begin{aligned}
E a= & 0,35\left(1+0,54 v_{2}\right)\left(e_{s}-e_{a}\right) \\
v_{2}= & \text { velocidade do vento a dois metros de altura, em me } \\
& \text { tros por segundo; } \\
e_{s}= & \text { tensão de saturação do vapor d'ägua na temperatura } \\
& \text { do ar }(\mathrm{mmHg}) ;
\end{aligned}
$$


e = tensão atual de vapor (em $\mathrm{mmHg})$;

$e_{s}-e=$ deficit de saturação (em $\mathrm{mmHg}$ ).

0 método de THORNTHWAITE é baseado em equação em

pírica, derivada de dados de evapotranspiração medida em evapo transpirómetros e em bacias hidrogrāficas, com dados de tempe ratura média diāria e da duração do dia, CAMARGo (1966). E as sim apresentada:

$$
E T P=1,6(10 \mathrm{Ta} / 1)^{a}
$$

onde:

ETP = Evapotranspiração potencial para um mês de 30 dias de 12 horas cada um (cm)

Ta = Temperatura média mensal do ar $\left({ }^{\circ} \mathrm{C}\right)$;

1 = Tndice anual de calor, igual a soma de 12 indices "i"; onde $i=\left(\frac{T a}{5}\right) 1,514$

a = uma função cübica de 1 , dado por:

$a=675 \times 10^{-9} 1^{3}-771 \times 10^{-7} 1^{2}+179 \times 10^{-4} 1+0,492$

A ETP dada pela equação citada deve ser ajustada para o no de dias do mês e para o comprimento do dia, valores tabelados em função da latitude.

Conforme experimentos conduzidos por CHANG(1968)

e JENSEN (1973) demonstram que o método de PENMAN é o melhor na estimativa da ETP.

ORTOLANI et alii (1966), procederam correlações

entre valores decendiais de Evapotranspiração potencial es timados pelo método de PENMAN eTHORNTHWAITE com dados medidos em evapotranspirômetros em Ribeirão Preto, Estado de São Paulo. 
os dados resultantes demonstraram maior correlação para o méto do de PENMAN $(r=0,25)$ que para o de THORNTHWAITE $(r=0,84)$. Segundo MOTA (1975), a equação de THORNTHWAITE deve somente ser usada para periodos mensais, pois não fornece estimativas razoāveis para periodos menores. Funciona melhor em climas semelhantes, ao local em que ela foi definida, isto é, regiões continentais temperadas. Apesar das suas limitações e devido ao fato de usar apenas a temperatura média, que é univer salmente disponível, esta fōrmula é muito ütil em regiões desprovidas de outras informações meteorolōgicas.

Segundo CAMARGO (1966), a equação de THORNTHWAITE apresentou, nas condições do planalto paulista, resultados men sais muito prōximos dos obtidos por medição nos evapotranspirô metros (Lisímetros).

Evidências experimentais pelo mundo todo têm com Provado a superioridade da equação de PENMAN, PRUITT (1960) na California, PELTON e TANNER (1960) em Wisconsin, STANHILL(1960) em Israel, CHANG (1961) no Havai, DENMEAD e SHAW (1962)em lowa, CHAPAS e REES (1964) na Rodésia, MOTA e BEIRSDORF (1975) em Pe lotas/RS e DOOREMBOS e PRUITT (1975).

Segundo VAN BAVEL e WILSON (1952), a principal desvantagem da equação de PENMAN é que é complicada e que necessita de dados de clima disponíveis apenas em poucos locais. Esta fórmula, entretanto, esta baseada sobre uma exata teoria e pode ser usada como um controle independente sobre valores obtidos diferentemente. 
Alguns autores afirmam que o método de

PENMAN

não parece dar bons resultados para estimativas diårias, sendo recomendadas para períodos de 5 ou mais dias. Entretanto, TANNER e PELTON (1960), em anālises exaustivas de comparação do mé todo de PENMAN com o método do Balanço de Energia detalhado, concluiram que a aproximação de PENMAN é vālida para estimar a evapotranspiração potencial para períodos curtos, como um dia. Segundo VILLA NOVA (1973), a equação de PENMAN a a daptada para nível horārio permite uma muito boa estimativa de evapotranspiração nos períodos em que sejam observadas condições de evapotranspiração mínima.

A precisão do método de PENMAN para períodos cur tos depende em grande parte, da precisão comque émedido ou es timado o saldo da Radiação (Rn) e o Fluxo de calor para o solo (S), BERLATO E MOLION (1981).

De acordo ainda com PELTON et alii (1960), deter minações da (ETP) evapotranspiração potencial indicaram que não pode ser confiada, para uso geral, a média de temperatura na es timativa de evapotranspiração durante períodos curtos. Os mé todos que utilizam a temperatura média podem ser usados com li mitado sucesso para períodos longos, como estação de crescimen to e anual, na estimativa da ETP. 0 método que usam do Balanço de Energia são preferíveis, se dados de radiação forem dispon veis. A defasagem entre radiação liquida e temperatura ha ção são as principais fontes de erro no método de THORNTHWAITE e dos demais métodos que usam a temperatura média no cálculo da 
14.

ETP. As correlações entre radiação líquida e evaporação e entre radiação líquida e temperatura média deixam de existir por periodos curtos. Assim, a temperatura média não é uma medida a dequada de energia disponivel para ser usada na evapotranspira ção.

VILLA NOVA e OMETTO (1981), propuseram uma simplificação do método de PENMAN (1948), constando do seguinte:

a) Simplificação do termo "energia" atravēs de um estudo de correlação entre o balanço de energia diäria (H), a constan te solar (Qo) e a razão de insolação $(n / N)$;

b) Simplificação do termo aerodinâmico, estimando-o através da EVAPORAÇĀo PICHE, de maneira similar àquela proposta por STANHILL (1962), BROCHET e GERBIER (1972) e OMETTO (1974), eliminando o parámetro velocidade de vento, medida pouco usual.

c) Resolução gräfica da equação assim simplificada, tornando muito simples a sua utilização.

Encontraram as seguintes equações de estimativa da evapotranspiração potencial para o Estado de S.Paulo:

Período Primavera-Verão:

$E T P=\frac{\Delta}{\Delta+\gamma}[Q 0(0,19+0,23 \mathrm{n} / \mathrm{N})]+0,28 \mathrm{EP}$

Periodo Outono-Inverno:

$E T P=\frac{\Delta}{\Delta+\gamma}\left[Q_{0}(0,17+0,11 \mathrm{n} / \mathrm{N})\right]+0,28 \mathrm{EP}$ 
Sendo:

ETP = Evapotranspiração Potencial em $\mathrm{mm} / \mathrm{dia}$;

Qo = Radiação Solar no topo da atmosfera (ausência da atmosfe ra), dependendo da latitude e ëpoca do ano (mm/dia);

$\Delta=$ Tangente à curva de saturação de vapor $\left(m m H g /{ }^{\circ} \mathrm{C}\right)$;

$\gamma=$ Constante psicométrica $\left(\mathrm{mmHg}^{\circ} \mathrm{C}\right)$;

n = Insolação ou horas de brilho solar medida pelo heliografo do posto meteorológico (horas e décimos/dia);

$\mathbf{N}=$ Insolação teórica māxima, função da latitude e época do ano, obtida por tabelas (horas e décimos/dia);

EP = Evaporação Piche à Sombra (mm/dia).

Esta metodologia desenvolvida permite uma melhor adaptação do mētodo em regiões onde existem dados medidos de ba lanço de energia e evapotranspiração potencial. STANHILĹ(1962) para Israel, correlacionando, em base semanal, o termo aerodinámico $\left(\frac{\Delta}{\Delta+\gamma}\right.$. Ea) com a evaporação dada pelo evaporímetro de $\mathrm{Pi}$ che, constatou valor bastante alto $(r=0,89)$.

MOTA e BEIRSDORF (1976), utilizando a metodologia descrita por STANHILL (1962), determinaram, tambēm, correlações com a evaporação de Piche para o cālculo do termo aerodinâmico da equação de PENMAN.

Segundo LEMON et alii (1957) a evapotranspiração é função do solo, da planta e parámetros meteorológicos. 0s au tores demonstraram através de experimentos com algodão, que a evapotranspiração não pode ser predita estritamente sobre bases de variāveis meteorológicas; que a tensão de umidade do so 
lo não governa sozinha a ãgua perdida pelas plantas; que as prōprias plantas exercem, direta ou indiretamente, variāveis restrições sobre o sistema de transferència de āgua.

DENMEAD e SHAW (1962), trabalhando com a cultura do milho em experimentos de vaso e campo em lowa.(E.E.U.U.), sob condições de irrigação e evaporação mostraram que: sob condições de evapotranspiração potencial (ETP) de 3 a $4 \mathrm{~mm} /$ Idia a taxa de evapotranspiração atual (ETa) caiu abaixo da ETP para valores médios da tensão da água do solo de, aproximadamente, - 2 atm; para uma ETP de 6 a $7 \mathrm{~mm} / \mathrm{dia}$ a queda da $\underline{e}$ vapotranspiração atual ou real (ETa) verificou-se para uma ten são de apenas $-0,3$ atm; para uma ETP inferior a $1,4 \mathrm{~mm} / \mathrm{dia}$ a queda da ETa ocorreu somente por tensões superiores a -12 atm. ${ }^{\circ}$ A conclusão achada pelos experimentos conduzidos por estes a tores è de que a relação entre as taxas de evapotranspiração e a quantidade de umidade no solo, variam com diferentes deman das atmosféricas; resolvendo a controvérsia concernente ao pä pel da umidade do solo na evapotranspiração surgida com diversas teorias apresentadas por THORNTWAITE (1948), VEIHMEYER e HENDRICKSON (1955), PIERCE (1958) e BAHRANI e TAYLOR (1961). Muitos outros trabalhos foram desenvolvidos por diversos autores como: LEMON et alii (1957), LETEY e BLANK (1961), EAGLEMAN e DECKER (1965), GAVANDE e TAYLOR (1967), MIL LAR e GARDNER (1972) e AL-KHAFAF et alii (1978), os quais rea firmam as conclusões de DENMEAD e SHAW (1962). Segundo EAGLEMAN e DECKER (1965), a taxa de evapotranspiração potencial é 
governada apenas pelas condições meteorológicas.' A evapotranspiração real é, entretanto, influenciada pela disponibilidade rie água no solo e pela demanda evaporativa do ar.

Sabe-se, que a relação entre a evapotranspiração e a tensão de umidade no solo depende de muitos fatores, como:a textura do solo, profundidade do sistema radicular, condutividade hidráulica do solo, densidade da vegetação e condições atmosféricas, CHANG (1968).

Segundo DAKER (1973), apesar da disponibilidade

de água para as plantas ser função de um processo dināmico, en volvendo o complexo sistema solo-planta-atmosfera é, em muitos casos, necessário adotar-se critérios baseados em conceitos es táticos, como o teor de umidade e potencial da água no solo. os casos mais correntes da util lizaçãodo conceito estático de água no solo são para propósitos de irrigação de áreas, para projetos desta natureza, bem como definir estados de umidade do so lo, abaixo dos quais, as plantas têm sua produtividade altamen te comprometida.

o conceito de "capacidade de campo" é definido, segundo VEIHMEYER e HENDRICKSON (1949), como a quantidade de á gua armazenada no solo, apôs o seu excesso ter sido drenado e a taxa de movimento descendente de água ter praticamente cessa do, o que ocorre usualmente, 2 ou 3 dias após uma chuva ou ir rigação em solos permeáveis de estrutura e textura uniformes, citado por DAKER (1973).

o Ponto de Murcha Permanente (PMP) ē definidopor 
PETERS (1965), como a percentagem de água de um solo, quando as plantas desenvolvidas neste solo atingem uma condição de murcha e não mais recobram a turgidez, quando colocadas em uma atmosfera saturada.

Segundo RICHARDS (1955), a umidade retida pelo solo ao potencial de -15 atmosferas é igual ao limite inferior da faixa de umidade do solo, onde é possivel o crescimen to vegetativo das plantas.

GATES e HANKS (1967), citados por RITCHIE e BUR NETT (1971), apresentaram os fatores especificos que influenciam a evapotranspiração de comunidades de plantas, como sen do: espécie de planta, refletividade da luz pelas plantas, po pulação de plantas, espaçamento e orientação de plantas nas fileiras, altura, profundidade e extensão das raízes e estädio de crescimento.

RITCHIE e BURNETT (1971), em experimentos com algodão e sorgo granífero, durante a estação de crescimento, concluiram que a relação entre a evapotranspiração real e a ETP (ETR/ETP) aumenta com o incremento do indice de ärea foliar (IAF).

Experimentos com milho conduzidos por FRITSCHEN e SHAW (1961), mostraram que a taxa de evapotranspiração é pe quena no estabelecimento da cultura, aumentando até a planta ter atingido $1,30 \mathrm{~m}$, aproximadamente; permanecendo com uma mes ma taxa até atingir a maturação.

NANKEN et alii (1968), trabalhando com a cultu- 
ra do algodão, observaram que, em 3 níveis diferentes de umidade do solo (ûmido, moderado e seco), a taxa de evapotranspira ção manteve-se no mesmo nível ou com pouco incremento até a tingir 20 a $30 \%$ da estação de crescimento. Deste ponto, aumentam significativamente até atingir um máximo em torno de $70 \%$, decrescendo, então para valor mínimo. Verificaram, também, que os tratamentos mais ūmidos consumiram mais ägua. Outros trabalhos desta natureza, conduzidos por SCARDUA (1970) e por MATZE NAUER (1980) com a altura do milho, chegaram a seguinte conclu são: "A taxa de evapotranspiração é menor no início do ciclo, aumenta progressivamente até atingir valores máximos durante o subperíodo - $50 \%$ do período do pendoamento $-75 \%$ do espigamento, de clinando, após, até a maturação fisiológica".

JENSEN (1973) afirma que, quando a cultura atinge a maturação, a taxa de transpiração pode decrescer rapidamente, especialmente em culturas cujas folhas e caules secam rapidamente. Quando isto ocorre, a relação entre ETR/ETP decresce a 0,2 ou menos.

o crescimento vegetal, a transpiração e a resistência à perda de āgua pelos vegetais, tem grande importância nos estudos de balanço hídrico e consumo de água pelos vegetais, sendo regulados pelos elementos climáticos e pela dispo nibilidade de ägua no solo, BRUNINI (1975).

KRAMER (1963) afirma que o crescimento dos vegetais é controlado diretamente pelos potenciais de água no solo; essa afirmativa é compartillhada por VAN BAVEL (1967), oqual ob- 
servou que as mudanças na resistência à perda de água pelos ve getais, são regulados pelo teor e potencial da ãgua no solo e pela demanda atmosférica.

KOWAL e KASSAN (1973), analisando o consumo de ägua por plantas de milho, concluiram que a eficiência de uso da àgua por esse vegetal é função do consumo de água pelas plantas e do potencial de àgua no solo. Afirmam ainda, que a taxa de crescimento foi reduzida quando o potencial de água no solo estava abaixo de $-0,5$ bar.

Note-se que a bibliografia é bastante extensa no que tange a caracterização da umidade do solo e, consequentemente, a seca agrícola é tarefa que envolve diversos parâmetros de solo, planta e condições atmosféricas.

Segundo LEVITT et alii (1960), seca é a potencia lidade do ambiente para influenciar a perda d'água da planta.

Muitos trabalhos têm sido conduzidos nos diversos continentes, no sentido de desenvolver uma metodologia pa ra caracterização do déficit de umidade no solo ou de secalcon ceito agronómico).

Devido a complexidade da interação solo/plantal latmosfera, o estudo da umidade do solo fica difícil, trabalhoso e envolvendo equipamentos sofisticados, sendo normalmente, conduzidos em pequenas āreas ou mesmoanível de laboratório.

Desta forma, grandes simplificações foram introduzidas nos diversos métódos no intuito de ter-se resultados razoáveis e de poucos recursos envolvidos. 
Assim, muitos autores tem caracterizado a seca por meio, simplesmente, da precipitação pluviométrica.

BLUMENSTOCK (1942), citado por BARGER e THOM (1949.a), considerou que uma sērie de dias secos terminava. no momento que $2,5 \mathrm{~mm}$ de chuva ou mais fosse registrada, durante um período menor do que 48 horas.Para a agricultura, esta defi nição de seca ou estiagem tem pouca ou nenhuma significāncia, pois a ocorrência de $2,5 \mathrm{~mm}$ de chuva não muda apreciavelmente as condições de umidade do solo.

BARGER e THOM (1949.a), desenvolveram um critério para caracterização da intensidade da seca em milho basea do na associação de certa quantidade mínima total de chuva com o intervalo de tempo de um estágio da altura, ou seja, a quantidade de precipitação mínima que permitirá o normal desenvol vimento do milho, durante um período do ciclo da cultura. Cor relações entre a máxima deficiência de chuvas e desvio da pro dução normal de milho nos locais estudados mostraram que, para anos no qual, condições deseca ocorreram, de 25 a $60 \%$ do total da variação na produção foi explicado por este critério. 0 termo seca empregado neste estudo refere-se ao período específico de tempo durante o qual a quantidade total de chuva registrada è insuficiente para promover uma produção normal para o local em cultivo. Para avaliar a intensidade de seca para cada localida de (Região)basta saber-se a probabilidade de ocorréncia da quan tidade de precipitações, durante o período estudado.

LAWRENCE (1957), trabalhando com equações matemā 
ticas, estimou a seqUência de "Chuvas e Dias Secos". Definiu "Dias Secos" como sendo a sequéncia de dias com zero, traços ou $0,1 \mathrm{~mm}$ de precipitação registrada.

DECKER (1957), definiu como dia seco (climatologicamente) como um dia com menos de $5 \mathrm{~mm}$ de chuva. 0 mesmo,faz uma distinção entre dia seco encarado climatologicamente, como sendo o dia sem precipitação ou uma insignificante quantida de e dia seco encarado sob o aspecto da planta, como sendo a exaustão da quantidade de suplemento para a planta da àgua do solo. 0 limite de $5 \mathrm{~mm}$, foi escolhido arbitrariamente, pois re presenta a aproximada quantidade de āgua usada rapidamente pe la evapotranspiração da planta em um dia de verão.

AMIR et alii (1977), usaram como critério para ca racterizar dia seco, quando a quantidade de chuva foi menor do que $2,5 \mathrm{~mm}$.

Muitos autores tem-se utilizado apenas do parâme tro precipitação para tentarem caracterizar a seca, como: BARGER e THOM (1949.b), MALLIK (1959), HARGREAVES (1974) e MEDH I $(1976)$.

A utilização dos métodos climatológicos de balan ço de ägua no solo para estimativa das necessidades de íga ção e os estudos de ocorrências de secas, tem facilitado suas de terminações, principalmente em àreas de grandes extensões e ca rentes de informações e recursos. 0 conceito de planejamento de irrigação e de ocorrência de dias secos (sob aspecto agríco la) usando dados climáticos não é novo, THORNTHWAITE (1946), 
PENMAN (1949.a, 1949.b e 1952), SCHOFIELD (1950), VAN BAVEL e WILSON (1952), VAN BAVEL (1953), BAVER (1954), MATHER (1954), PRUIT e JENSEN (1955), PIERCE (1960), MORETTI (1965), JENSEN et alii (1971) e SCÅRDUA (1979).

Entretanto, este método não tem sido adotado para uso prático geral ou extensivamente testado previamente, JEN SEN et alii (1971).

VAN BAVEL e WILSON (1952), baseando-se em método proposto inicialmente por THORNTHWAITE (1946) e trabalhos simi lares de PENMAN (1949.a e 1949.b) e SCHOFIELD (1950), definiram um critério para estimar o momento de irrigação para a cultura do fumo. A metodologia consistia de um simples balanço climato lógico da āgua no solo, determinando-se a sua umidade em um da do tempo através de meios indiretos da contagem da diferença entre a adição de àgua no solo e sua perda. A perda da umida de pelo solo seria advinda da evapotranspiração potencial. Os autores definiram o problema da seguinte forma: "Se a quantida de de água adicionada para o solo for conhecida e se a quanti dade total de evapotranspiração potencial diāria for conhecida tambēm, um simples procedimento de cálculo pode ser usado para determinação do suprimento disponível da água no solo, em qual quer tempo". Quando este suprimento reduz-se ou aproxima-se de zero, valores estes correspondentes à tensões de água no solo que as plantas apresentam um apreciável decréscimo no crescí mento, desenvolvimento e produção final, há necessidade de for necimento de água. 
Um ano mais tarde, VAN BAVEL (1953), trabalhando com a cultura do Fumo, utilizando-se da mesma metodologia de balanço de água no śolo, definiu um critério para avaliação de incidência de "dias secos".

Definiu "Dia Seco" como sendo o período de 24 ho ras, começando na hora do dia anterior no qual a precipitação foi registrada, no qual o "Stress" de umidade do solo excedia um certo limite, definido sobre bases de evidéncias experimentais, sendo tomado como um ponto no qual o processo produtivo da planta é apreciavelmente diminuído. A caracterização dos "dias secos" $\Gamma$ a a estação de crescimento da cultura do Fumo', seguiram os sc. intes critérios:

- Considerou i rofundidade média das raízes do Fumo de 20 :cm e um limite inferior de tensão de àgua no solo de $800 \mathrm{~cm}$;

- Para as condições médias do solo até $20 \mathrm{~cm}$, foi assumido que o solo continha $43 \mathrm{~mm}$ d'água disponível entre a capacidade de campo e tensão de $800 \mathrm{~cm}$ de àgua;

- A evapotranspiração potencial foi determinada através da equação de THORNTHWAITE (1948) com ajuda da média mensal diāria da temperatura do ar para o período estudado ( 105 dias);

- Assumiu que no primeiro dia do período estudado, o solo encontrava-se com a máxima disponibilidade de água (43 mm). Des te valor, a evapotranspiração potencial média diāria para o período foi sendo subtraída diariamente e a precipitação soma da ;

- Valores de precipitação que excederam a capacidade de armaze 
namento do solo $(43 \mathrm{~mm})$ foram canceladas, bem como uma even tual quantidade negativa, não sendo subtraída do dia subsequente;

- o dia em que o valor do armazenamento foi zero ou negativo, foi marcado como "dia seco" e registrado;

- Depois de determinado o total de "dias secos" para o perío do estudado, definiu a frequência destas ocorrências, dos quais, traçou curvas de probabilidade empírica de ter mais de certo número de dias secos.

- 0 limite inferior de tensão de água no solo, assumido como $800 \mathrm{~cm}$, foi definido experimentalmente como o valor ou limi te no qual uma redução apreciāvel no desenvolvimento e crescimento e produção da planta foi verificada.

A àgua disponível ou armazenamento foi definido através de estudo prévio das características físicas do so lo, dos quais, foi construída a curva característica de umidade do solo (umidade $x$ tensão de ägua) e determinada a densidade aparente.

Ficou também demonstraram, que a utilização da eva potranspiração potencial mensal média diāria de vārios anos de observações (série) é uma medida muito satisfatōria, e que a utilização de dados anuais, individualmente de Evapotranspiração potencial não tem justificado em termos de ganho de precisão, sem contar o maior trabalho que daria o cálculo desta forma.

A seca, assim avaliada, tem um verdadeiro caráter agronómico e é um método adequado de medida do clima e so 
lo e para prever condições ōtimas de umidade do solo. os resul tados obtidos através deste método podem ser usados diretamente, através de cālculos, para achar as necessidades de suplementar irrigação, bem como o tamanho adequado de reservatório de àgua para uma dada localidade, cultura e solo.

Sob a orientação de VAN BAVEL, numerosos trabalhos de caracterização da estiagem, usando o critērio de "dia seco", foram realizados em diversos Estadosda América do Norte como: Virginia, Carolina do Norte, Carolina do Sul, Georgia e Al abama.

MATHER (1954), utilizando tambēm a aproximação climatológica de balanço de àgua do solo de THORNTHWA ITE(1946) e VAN BAVEL (1953), determinou o curso anual de āgua disponí vel no solo à diferentes níveis de probabilidade $(10,50$ e $90 \%)$ para a localidade de Seabrook, N.J. 0 autor descreve ainda que o método de computação de umidade do solo, através de dados climāticos, não é um procedimento de fäcil realização. 0 método fornece, apesar de requerer uma certa generalização geogrä fica e aproximações, razoáveis resultados.

THORNTHWAITE e MATHER (1955) propuseram um balan ço de ägua semelhante ao descrito por VAN BAVEL (1953), apenas, introduzindo o conceito de que a evapotranspiração da āgua re tida abaixo da capacidade de campo ( $C C$ ), diminui linearmente com o secamento do solo, isto é, na razão de um para um $(1: 1)$. Desta forma, a evapotranspiração real é igual a evapotranspira ção potencial (ETP) quando o solo se encontra na capacidade de 
campo (CC) e é igual a metade da ETP quando o solo perdeu a me tade de sua água disponível. Os autores elaboraram tabelas que auxiliam no cálculo da evapotranspiração real, conforme o conteúdo de umidade do solo e para diferentes capacidades de arma zenamento de água. Obtiveram com esta metodologia uma boa con cordáncia entre os valores de água no solo calculados por este método e os valores medidos.

A frequência de dias secos depende das características da precipitação, da umidade do solo, da profundidade do solo, da profundidade do enraizamento e da razão de evapotranspiração.

MORETTI FILHO (1965), apresentou um estudo bás i co para a elaboração dos projetos de irrigação, aplicando o mé todo proposto por VAN BAVEL (1953) para estimativa da seca agronómica para períodos mensais e anual na Zona Canavieira do Estado de São Paulo. Utilizou para esta caracterização, dados climatológicos e de solos de sete municípios e estimou a quantidade de àgua necessária para irrigação, a um nível de 90\% de probabilidade, para cada localidade e para três quantidades bá sicas de armazenamento de àgua no solo. Verificou, também, que a ocorréncia de seca depende marcadamente da quantidade de água disponível do solo na zona efetiva de exploração das raí zes e que, em muitos casos, sobretudo durante o verāo, que pa ra um aumento de $10 \mathrm{~mm}$ na quantidade base de água disponível, - nümero de dias secos reduzia-se de, aproximadamente, $50 \%$ a um mesmo nivel de probabilidade. 
BAIER e ROBERTON (1966) propuseram o chamado "Ba lanço hïdrico versátil" que fornece, atravēs de um modelo para computação eletrōnica, a umidade diäria do solo em função dos elementos meteorológicos conhecidos e algumas propriedades fí sicas do solo e características da cultura. Apesar deste méto do apresentar uma maior aproximação nas situações particulares de solos e cultivos, introduz uma complicação nos cálculos, não sendo conveniente para análises de carácter regional.

\section{DAMARIO e ESCALES (1971) caracterizaram o regime} de seca agroclimatológica para a região semi-árida Pampeana na Argentina, em uma área de $100.000 \mathrm{~km}^{2}$, aplicando o cālculo de balanço hidrológico preconizado por THORNTHWAITE (1948). Utili zaram dados climáticos de 20 anos, correspondendo a 10 estaçóes meteorológicas, nos quais estimaram a água disponível diária do solo. Por comparação com informações existentes sobre a ocorrência, extensão e efeitos de seca na região, estabeleceramcer tos niveis de umidade no solo que definiram quatro condições ou categorias do fenómeno. Sobre esta base, foram computados as frequencias anuais estacionais e mensais, classificadas de acordo com o ne de dias em que a umidade do solo permaneceu den tro dos limites de cada categoria.

SCARDUA (1979) apresentou um estudo da ocorrência de seca numa área do Sul do Estado do Espírito Santo. A ca racterização da seca foi efetuada através de "dias secos conse cutivos" e os "dias secos" determinados pelo método climatológico de balanço de água no solo, descrito por VAN BAVEL (1953) 
e por MORETTI FILHO (1965), para as quantidades de $15 \mathrm{~mm}, 35 \mathrm{~mm}$, $45 \mathrm{~mm}, 60 \mathrm{~mm}, 100 \mathrm{~mm}$ e $140 \mathrm{~mm}$ de ãgua disponível, com base nas curvas características de dois solos representativos e considerando diferentes profundidades. Apresentou gräficos do número mínimo de dias secos consecutivos esperados em cada mês e para cada quantidade de āgua disponível aos níveis de $5 \%, 10 \%, 20 \%, 30 \%, 40 \%$ e $50 \%$ de probabilidade. 
3. MATERIAL E METODOS

3.1. Local de Estudo

A àrea abrangida pelo estudo localiza-se na Região de Laguna, Litoral Sul do Estado de Santa Catarina, carac terizada entre as isolinhas de deficiēncia hídrica anual de 100 e $125 \mathrm{~mm}$, para um solo com capacidade de armazenamento de àgua māxima-CAD de $75 \mathrm{~mm}$, segundo Zoneamento Agroclimātico do Estado de Santa Catarina (1978). A Região em apreço constitui-se de planícies litoráneas. Na Figura l, mostramos a ārea abrangida pelo estudo com suas delimitaçōes políticas e estações meteorológicas existentes.

\subsection{Dados Disponíveis}

\subsubsection{Dados Climāticos}

As informações meteorolōgicas utilizadas para es ta caracterização, constituem-se de 26 anos (1955-1980) de dados diārios de precipitação, bem como mêdias mensais de temperatura do ar, insolação, umidade relativa, velocidade do vento 
31.

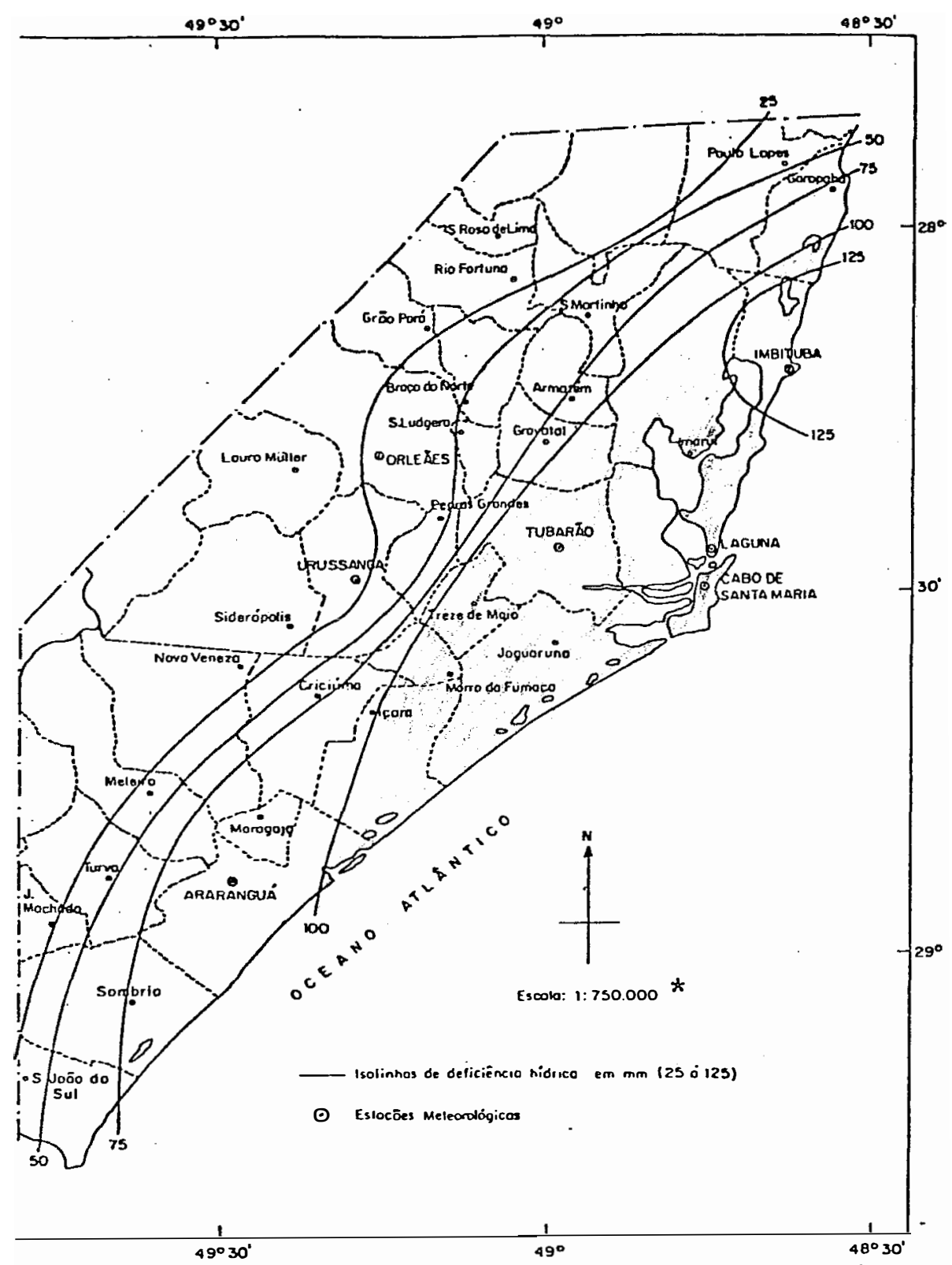

Figura 1 Mapa com a Localização da Região de Laguna, Litoral Sul, com suas delimitações polfticas e isolinhas de deficiência hídrica anual de 25 a $125 \mathrm{~mm}$.

11 Area Abrangida pelo Estudo

* Reduzido da escala de 1:750.000

Escala aproximada de $1: 1.212 .000$ 
e evaporaçāo de "piche", ref̣erentes a Estação Meteorológica de Laguna pertencente ao 8: DISME do Instituto Nacional de Meteoro logia do Ministério da Agricultura, definida pela Latitude Sul de $28^{\circ} 29^{\prime} 23^{\prime \prime}$, Longitude Oeste de $48^{\circ} 48^{\prime} 12^{\prime \prime}$ e pela Altitude de 30,9 metros. Devido nāo existirem dados meteorológicos em alguns meses ( 23 ao todo) da série de 26 anos, ou seja, 312 meses, utilizam-se dados de precipitação diāria de algumas estações me teorológicas próximas da àrea de abrangência do estudo, como: Araranguá e Urussanga.

\subsubsection{Caracterização dos Solos}

Tomou-se como base para a caracterização dos principais solos ocorrentes na região, os trabalhos de "Levantamento de Recolhimento dos solos do Est. de Sta. Catarina(1973), bem como o "Levanta mento Semi-Detalhado dos Solos das Regiões de Laguna e Sul do Estado de Santa Catarina"(1973).

Desta forma, quatro solos considerados representa tivos da regiāo, foram definidos e amostrados, sendo eles:

a) Araranguá $(A R)$ : Areias Qủartzosas Distrōficas, Ocrico, exces sivamente drenado, textura arenosa, relevo plano, suave ondu lado e ondulado, substrato sedimentos marinhos e eôlicos;

b) Morro da Fumaça (MF): Pódzölico Vermelho Amarelo Cascalhento EPI - Eutrōfico, Ocrico, bem drenado, textura argilosa, re levo ondulado e forte ondulado, substrato granito;

c) Tubarão (TU): Cambisol Eutrōfico, mólico, moderadamente dre nado, textura argilosa, relevo plano, substrato sedimentos flú viais recentes com influência do granito;

d) Jacinto Machado (JM) : Cambísol EPl - Eutrốfico, ócrico, bem 
drenado, textura argilosa, relevo plano e suave ondulado, sub trato sedimentos recentes fluviais com influéncia do basalto. A Figura 2, apresenta um mapa da área estudada com os principais solos ocorrentes, baseado na Carta de Aptidão Agrícola das Terras do Estado de Santa Catarina (1978).

3.3. Caracterização da Água Disponível no Solo

- levantamento e amostragem desses quatro princi pais solos ocorrentes na região de Laguna, teve apenas a inten ção de ter-se uma idéia da capacidade de água disponível máxima (CAD) que os mesmos podem reter. Desta maneira, estes solos foram amostrados em très profundidades bāsicas de 15,45 e 80 $\mathrm{cm}$, representando os perfis de $\underline{0}$ a $30 \mathrm{~cm}$, de 30 a $60 \mathrm{~cm}$ e de 60 a $100 \mathrm{~cm}$, respectivamente.

A amostragem teve como objetivo a determinação da densidade global ( $d_{G}$ ), atravēs de anēis volumétricos (de UHLAND) e obtenção de amostras deformadas para a caracterização das curvas características de água para cada profundida de e solo estudado (relação $\Psi m \times \theta$ ). Atravês do conhecimento da densidade global de cada solo e camada, as amostras deforma das foram compactadas em anēis de volume conhecido, visando dar ao solo uma porosidade semelhante à encontrada em condições na turais e determinou-se a umidade base peso $(\mathrm{g} / \mathrm{g})$ para cada ten são através do uso da Câmara de Richards e de Funil de Pdaca Porosa (BUchner).

Para a determinaçâo das curvas características ou 


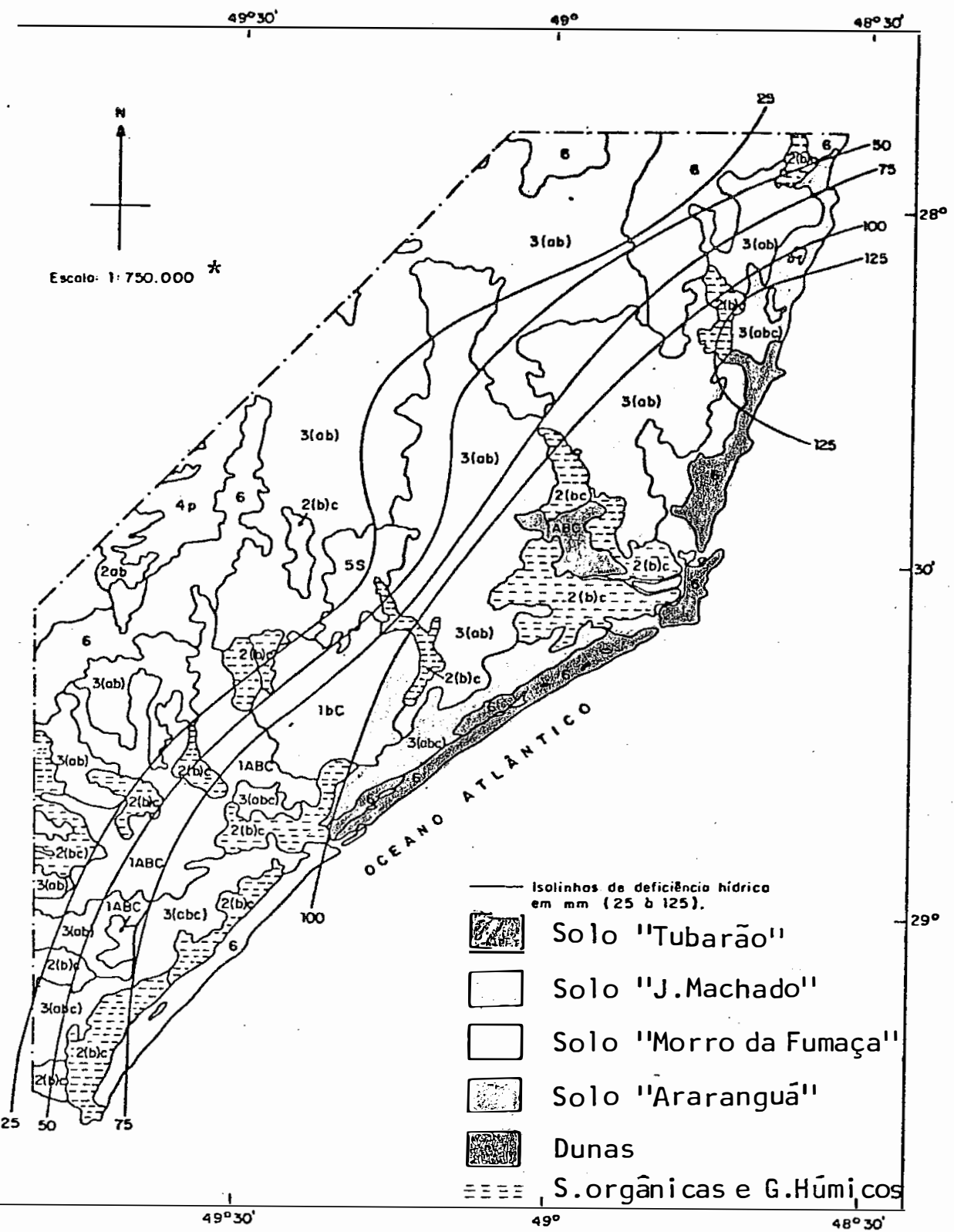

Figura 2 - Mapa da Área de Abrangéncia do Estudo com a ocorréncia e localização dos principais solos. Baseado na Carta de Aptidão Agrícola das Terras do Estado de Santa Catarina(1981)

* Reduzido da escala de 1:750.000

Escala aproximada de 1:1.212.000 
curvas de retençâa de água em cada profundidade e solo, uti lizou-se o Funil de Placa Porosa (BUchner). para baixas tensões (de 0 e 0,1 atm) e a Cámara de Richards para altas tensões (de 0,1 a 15 atm), com três repetiçōes.

Multiplicou-se a umidade por peso $(\mathrm{g} / \mathrm{g})$ pela den sidade global $\left(d_{G}\right)$, obtendo-se os valores da umidade por vol u me- $\left(\mathrm{cm}^{3} / \mathrm{cm}^{3}\right)$, para cada solo, camada e tensão, traçando-se as respectivas curvas características.

$\longrightarrow$ De posse das curvas características de cada solo e profundidade, determinou-se a capacidade de Armaze namento ou Capacidade de Água Disponível Máxima para cada con dição, atravēs do emprego da seguinte expressão:

$$
C A D=\int_{0}^{z=H} \int_{\theta_{p m}}^{\theta^{c c}} d \theta \cdot d z \cong\left(\theta_{c c}-\theta_{p m}\right) H
$$

onde, CAD è a capacidade de àgua disponível máxima que o solo pode reter em mm de altura d'água; $\theta_{c c} e \theta_{p m}$, são as umidades por volume nos limites da capacidade de campo e no ponto de mur chamento, respectivamente, em $\mathrm{cm}^{3} / \mathrm{cm}^{3}$ e $\mathrm{H}$ é a profundidade da camada de solo considerada em mm. Adotou-se as tensões de umidade do solo de $1 / 3$ de atmosfera para caracterizar a capacidade de campo para os solos argilosos, ou seja, Morro da Fumaça, Tubarão e Jacinto Machado e $1 / 10$ de atmosfera para o solo arenoso Araranguá, e de 15 atmosferas para o ponto de murchamento, conforme considerações adotadas por HILL, citado por GRADWELL (1968) e MEDINA (1975).

Como, tambêm, a ägua disponível no solo para o normal desempenhio das funçôes físiolögicas das plantas ê função 
da demanda atmoșférica e da espécie yegetal, utilizou-se da se guinte expressāo para caracterizar a Agua Disponível Efetiva,

$$
|A D E=P . C A D|
$$

Sendo, ADE, a Agua Disponível Efetiva para a planta em mm; P, a parte fracional da CAD prontamente disponível, que é função da demanda atmosfērica (ETP) e da espécie vegetal (cultura), de acordo com os critérios preconizados pela FAO (1977) e apresen tados na Tabela 1.

o fator P, por outro lado, pode ser também definido como a fração da CAD no qual a condição de Evapotranspira ção Atual ou Real (ETR) mantēm-se igual a Evapotranspiração Pọ tencial ou de Referéncia (ETP ou ETo).

Tabela 1 - Grupo de Culturas de acordo com a Perda de Agua do Solo (a) e Fração P para Grupos de Culturas e Evapotranspiração Potencial (ETP), (b).

(a)

\begin{tabular}{cl}
\hline Grupo & Cultura \\
\hline 1 & Cebola, Pimenta, Batata \\
2 & Banana, Repolho, Uva, Ervilha, Tomate \\
3 & Alface, Feijão, Cítricas, Amendoim, Abacaxi,Giras- \\
$* 4$ & Sol, Melancia, Trigo \\
& Algodão, Milho, Azeitona, Açafrão, Sorgo, Soja, Be \\
& terraba, Cana-de-Açúcar, Fumo
\end{tabular}

(b)

\begin{tabular}{clllllllll}
\hline Grupo de & \multicolumn{10}{c}{ ETP $(\mathrm{mm} / \mathrm{di}$ a) } \\
\cline { 2 - 10 } Culturas & \multicolumn{1}{c}{2} & 3 & 4 & 5 & 6 & 7 & 8 & 9 & 10 \\
\hline 1 & 0,50 & 0,425 & 0,35 & 0,30 & 0,25 & 0,225 & 0,20 & 0,20 & 0,175 \\
2 & 0,675 & 0,575 & 0,475 & 0,40 & 0,35 & 0,325 & 0,275 & 0,25 & 0,225 \\
3 & 0,80 & 0,70 & 0,60 & 0,50 & 0,45 & 0,425 & 0,375 & 0,35 & 0,30 \\
$* 4$ & 0,875 & 0,80 & 0,70 & 0,60 & 0,55 & 0,50 & 0,45 & 0,425 & 0,40 \\
\hline
\end{tabular}

* Gupo utilizado neste trabalho 
Os trabalhos. da FAO (1279), ao invēs de utilizarem ETP como elemento indicativo da demanda atmosférica, lançam mão da chamada Evapotranspiração Máxima ou Demanda Ideal (ETM), que nada mais é do que a perda d'ågua por uma cultura qualquer em condições de nenhuma restrição de âgua em cada estādio de desenvolvimento. Desta forma, para caracterizarmos a ETM necessitaríamos do coeficiente de cultura ( Kc) para ser multiplicado pelo ETP ou ETo, operação esta que dificultaria em demasia as etapas de cálculo do balanço hídrico, alèm de ser variável com a época de plantio, cultivar, estádio de desenvol vimento. Esse critêrio, adotandorse valores de ETM, prestam-se muito bem para estudos de balanço hídrico para uma cultura e é poca específica de plantio. Isto é para condição particular,não para trabalhos de àmbito regional, envolvendo aspectos gerais climatolōgicos. Dessa feita, adotamos a ETP como critẻrio de medida da demanda atmosfērica, já que esse trabalho abrange as pectos regionais e não específicos. Assim o fator $\underline{P}$ será funçăo da ETP e da cultura em desenvolvimento ativo.

As culturas ou grupo de culturas adotadas, conforme podemos ver na Tabela l, referem-se ao grupo 4, isto é, culturas mais resistentes ao "stress hídrico", muitas delas jä cultivadas na Regíăo estudada, como Milho, Sorgo, Cana-de-açúcar, Fumo. Desenvolveu-se uma equação exponencial para exprimir o fator $\underline{P}$ em função da ETP, conforme valores do grupo 4, Tabela l, com a finalidade de facilitar a contabilização do ba lanço hî́drico, jä que o mesmo foì realizado com auxílio do com 
putador, ficando assim expressa:

$$
\begin{aligned}
P= & 1,0454, \exp (-0,1015765 E T P) \\
& \left(r^{2} 0,9840\right)=
\end{aligned}
$$

Portanto, através da CAD, definida para cada solo e camada e do fator $\underline{P}$ caracterizourse ADE, a qual terá papel destacado no cál culo do balanço hidrico, como veremos adiante.

3.4. Determinação da Evapotranspiração Potencial (ETP) ou de Referência (ETo)

Devido às dificuldades inerentes na medida elou estimativa da evapotranspiração potencial (ETP) ou de referência (ETo) para períodos diários, adotourse a ETP ou ETo média diāria para cada més do calendário e para cada mês da série de 26 anos estudados (1955-1980). Isto é, para cada mês e para ca da ano da série estudada adotou-se seus correspondentes valores médios diários de ETP. Devido ao fato de estar faltando 23 meses de dados da série de 26 anos, adotou-se valores médios diārios da ETP em termos normais. (média da sērie), nesses casos. Em trabalhos de balanço hídrico climatológico,vi sando a caracterização da seca agronómica, conduzidos por VAN BAVEL (1952 e 1953), foram adotados valores de ETP média diäria mensal em termos normais, afirmando o autor que essa è uma medida bastante satísfatōria e que a utilização de dados anuais individualmente não se justificam em termos de ganho de precisão, sem contar com o trabalho excessivo que resultaria reali zandorse o cálculo desta maneira. Entretanto, para este traba- 
Iho, adotamos valores médios diārios de ETP, para cada més e a no, uma vez que empregamos o uso de Computação Eletrônica(IBM-1130 da ESALQ).

A estimativa da ETP foi obtida pela adaptação e simplificação do método de PENMAN (1948), segundo metodologia utilizada por VILLA NOVA e OMETTO (1981) com modificações no termo energia, constando do seguinte:

A) Simplificação do Termo "Energia" através de um estudo de correlação entre o Balanço de Energia Média Mensal (H), a Cons tante Solar Média Mensal (Qo), Razão de Insolação Média Mensal $\left(\frac{n}{N}\right)$ e Pressão Atual de Vapor Média Mensal (e $\left.{ }_{a}\right)$.

o desenvolvimento constou do seguinte, considerando a equação geral de PENMAN (1948):

$$
E T P=\frac{\Delta}{\Delta+\gamma} \cdot H+\frac{\gamma}{\Delta+\gamma} \cdot E a
$$

O balanço de energia $H$, foi obtido através de um estudo entre $H$, Qo, $\frac{n}{N}$ e ea na forma de uma equação do tipo:

$$
H=Q_{0}\left(a^{\prime}+b^{\prime} \frac{n}{N}+b^{\prime \prime} \sqrt{e}_{a}\right)
$$

onde os parâmetros a', b' e b" resultantes, foram determinados considerando-se a equação de estimativa de H, proposta por PENMAN (1948),

$H=Q O\left(a+b \frac{n}{N}\right)(1-R)-\sigma T a^{4}(0,47-0,075 \sqrt{e} a)\left(0,17+0,83 \frac{n}{N}\right)$

Os valores de Qo, $\sqrt{e_{a}}$, Ta, $\frac{n}{N}$, correspondem as médias mensais da região em estudo; $R$, sendo o poder refletor da superfície ve getada, considerado igual a 0,25 (MONTEITH, 1959). Os parâmetros a e $\underline{b}$ são dependentes do estado da atmosfera, latitude e 
época do ano. Para esse trabalho, adotou-se os valores médios determinados por MOTA et ali $i$ (1977), ou seja, a=0,28 e b=0,44. Onde:

a) $H$ = energia líquida disponível ou saldo de radiação em $\mathrm{mm} /$ /dia. Corresponde ao balanço de energia radiante de onda curta e longa;

b) $\Delta=$ tangente à curva de saturação de vapor. Seus valores fo ram obtidos por intermédio de cálculos, conforme desenvolvimento abaixo.

$$
\Delta=\frac{\partial e s}{\partial T}
$$

onde, es é a pressão máxima de vapor que o ar pode conter na temperatura do ar à sombra (T)

Através da equação de TETENS, e ${ }_{s}$, fica definido da seguinte forma:

$$
e_{s}=4,5825 \times 10 \frac{7,5 \cdot T}{237,5+T}
$$

onde, T, é a temperatura do ar à sombra (média mensal) em ${ }^{\circ} \mathrm{C}$ e $e_{s}$ em mmHg. Substituindo $e_{s}$, dado pela equação (8) em (7), vem :

$$
\Delta=\frac{\partial\left(4,5825 \times 10^{\frac{7,5 . T}{237,5+T}}\right)}{\partial T}\left(\mathrm{mmHg}^{\circ} \mathrm{C}\right)
$$

Derivando a equação (9), encontrou-se a seguinte expressão para $\Delta:$

$$
\Delta=\frac{18.795 \times 10^{\frac{7,5 . T}{237,5+T}}}{(237,5+\mathrm{T})^{2}} \quad\left(\mathrm{mmHg}^{\circ}{ }^{\circ} \mathrm{C}\right)
$$

os valores de $\Delta$, também podem ser encontrados em tabelas em função da temperatura do ar (média). 
41.

c) $\gamma=$ constante psicrométrica (coeficiente). Seu valor è def nido pela seguinte expressāo:

$$
\gamma=\frac{C P \cdot P}{0,622 \cdot L} \quad\left(\mathrm{mmHg}^{\circ} \mathrm{C}\right)
$$

onde, $C_{p} e^{-}$o calor específico do ar ümido, aproximadamente igual a $0,241 \mathrm{cal} / \mathrm{g}^{\circ} \mathrm{C} ; \mathrm{P}, \bar{e}$ a pressão atmosférica, tomada como sendo de $760 \mathrm{mmHg}$ (Nível do Mar) e L, è o calor latente de vaporização da āgua, aproximadamente, $590 \mathrm{cal} / \mathrm{g}$, à $20^{\circ} \mathrm{C}$.

Assim:

$$
\gamma=\frac{0,241 \mathrm{cal} / \mathrm{g}^{\circ} \mathrm{C} \times 760 \mathrm{mmHg}}{0,622 \times 590 \mathrm{cal} / \mathrm{g}} \cong 0,5 \mathrm{mmHg} /{ }^{\circ} \mathrm{C}
$$

o valor para $\gamma$ de $0,5 \mathrm{mmHg}$, refere-se à psicrómetros aspirados, ou de ventilação forçada. Em nosso estudo, dispúnhamos de psi-. crômetro comum, isto é, não aspirado e, neste caso o valor de $\gamma \dot{e}$ de, aproximadamente, $0,6 \mathrm{mmHg} /{ }^{\circ} \mathrm{C}$.

d) Qo, corresponde a radiação extra-terrestre, função da latitude e época do ano, obtida de tabelas (FAo, 1979), em mm de evaporação equivalente por dia.

e) $n$ = insolação ou horas de brilho solar, medida pelo heliọ grafo da estação meteorológica, em horas e décimos por dia.

f) $N$ = insolação teórica māxima, função da latitude e época do ano, obtida de tabelas (FAO, 1979) em horas e dēcimos por dia.

g) $\sigma T a^{4}=$ emissão teórica de um corpo negro à temperatura média do ar, Ta, em ${ }^{\circ} \mathrm{K}$; onde, o é a constante de STEFAN-BOLTZMANN e corresponde à $1,171008 \times 10^{-7} \mathrm{cal} \mathrm{cm}^{-2} \cdot \mathrm{dia}^{-1} \mathrm{O}_{\mathrm{K}^{-4}}$.

h) e ${ }_{a}$, Pressão parcial de vapor d'água do ar (mmHg), dado por: 
$\mathrm{e}=(U . R / 100) \mathrm{e}_{\mathrm{s}}$; onde, UR é a umidade relativa dada em percentagem e e $e_{s}$ a pressão máxima de vapor, em mmHg, jä defi nida.

B) Simplificação do Termo Aerodināmico, estimando-o através da Evaporação de "Piche" (Ep), eliminando o parámetro de vento, me dida pouco usual.

A simplificação do termo aerodinámico baseou-se na determinação de uma função na qual o relacionasse com a eva poração de "Piche" (Ep), medida à sombra. Na equação (4) o ter mo $\frac{\gamma}{\Delta+\gamma}$. Ea, é denominado de Termo Aerodinâmico e Ea, isoladamen te, de Poder Evaporante do ar à sombra.

De acordo com VILLA NOVA e OMETTO (1981) o termo Ea è relaci onado com a evaporação de "Piche" (Ep) à sombra, de acordo com a lei geraî de DALTON, da forma:

$$
\frac{E a}{E p}=\frac{F\left(U_{2}\right)}{F\left(U^{\prime}\right)} \cdot \frac{\left(e_{s}-e_{a}\right)}{\left(e_{p}-e_{a}\right)}
$$

onde:

$U_{2}=$ Velocidade do vento tomados à 2 metros de altura;

$U^{3}=$ Velocidade do vento que passa através do evaporímetro de "Piche", no abrigo meteorolögico;

$e_{\underline{p}}=$ Pressão de saturação da placa de "Piche", função da tempe ratura do termômetro de bulbo ümido.

$$
\begin{aligned}
& \text { Denominando-se de } \beta \text { a relação, } \\
& \beta=\frac{F\left(U_{2}\right)}{F\left(U^{1}\right)} \\
& \text { E substituindo-se }(13) \text { em }(12) \text {, teremos: }
\end{aligned}
$$




$$
\left.E_{a}=\beta \cdot \frac{\left(e_{s}-e_{a}\right)}{\left(e_{p}-e_{a}\right.}\right)^{-} \cdot E p
$$

Aplicando-se a equação psicrométrica à placa de "piche", obteve-se:

$$
e_{a}=e_{p}-\gamma(T-T w)
$$

Substituindo-se (15) em (14), obteve-se:

$$
E a=\beta . E p\left[\frac{\left(e_{s}-e_{p}\right)}{\gamma(T-T w)}+1\right]
$$

e, introduzindo-se o conceito de tangente à curva de saturação,

$$
\Delta=\frac{e s-e p}{T-T w}
$$

Obteve-se:

$$
\begin{aligned}
& E a=\beta \cdot E p\left(\frac{\Delta+\gamma}{\gamma}\right) \\
& O u \\
& \frac{\gamma}{\Delta+\gamma} \cdot E a=\beta \cdot E p
\end{aligned}
$$

A equação (18) relaciona o termo aerodinâmico com a evaporaçāo de "Piche" na forma do fator $\beta$.

Considerando a equação de estimativa de Ea proposta por PENMANN (1948),

$$
E a=0,35\left(1+0,54 U_{2}\right)\left(e_{s}-e_{a}\right)
$$

então, o fator $\beta$ fica definido através das equações (18) e (19) por:

$$
\beta=\frac{\gamma /(\Delta+\gamma)\left[0,35\left(1+054 U_{2}\right)\left(e_{s}-e_{a}\right)\right]}{E p}
$$

onde, $U_{2}$ é a velocidade média do vento tomada a 2 metros de altura, em m/s; (e $\left.s_{s}-e_{a}\right)$, corresponde ao deficit de saturação 
do ar $(\mathrm{mmHg})$.

Com o auxílio da equação (20), adotando-se os va lores médios mensais de $U_{2}$, $e_{s}$, e ${ }_{a}, \Delta$ e Ep, obteve-se valores médios mensais de $\beta$. Como não houve variação significativa dos diversos valores de $\beta$, entre os meses do calendário, adotou-se um valor médio igual para todos os meses, como será mostrado adiante.

A Estação Meteorolōgica de Laguna-sC, não possui velocidade do vento (U) medida à 2,0 metros de altura, mas sim à 10 metros, através de anemōmetro de deflexão (wild). A velocidade média diária obtida com esse aparelho é feita pela média de trēs leituras diárias. $(9: 00 ; 15: 00 ; 21: 00$ horas $)$.

Utilizou-se de uma relação logarítmica para transformar medidas de velocidade do vento tomados à lo metros de altura para 2,0 metros (condição de neutralidade atmosférica); da forma:

$$
\begin{aligned}
& \frac{u_{2}}{u_{10}}=\frac{\ln \left(z_{2} / z_{0}\right)}{\ln \left(z_{10} / z_{0}\right)} \\
& o u \\
& u_{2}=u_{10} \cdot \frac{\left(\ln z_{2} / z_{0}\right)}{\ln \frac{\left.z_{10} / Z_{0}\right)}{z_{10}}}
\end{aligned}
$$

Onde:

$z_{2}=$ altura que se deseja, isto é, 2 metros;

$z_{10}=$ altura do anemómetro que se dispõe em metros ( 10 metros);

$z_{0}=$ altura da rugosidade, ou parâmetro rugoso. Adotou-se o va lor de 0,01 metros (Paspalum notatum L.)

Aplicando-se a expressão (21), encontrou-se a seguinte relação 
para transformar medidas de vento tomadas à 10 metros de altu ra para 2,0 metros:

$$
U_{2}=U_{10} \cdot 0,77
$$

3.5. Balanço de Água no Solo e Determinação dos "Dias Secos"

A caracterização da seca agronōmica efetivou-se pelo desenvolvimento de um método de balanço de água no solo, através da junção de diversos métodos, teorias e critērios existentes, como os utilizados por VAN BAVEL e WILSON (1952), VAN BAVEL (1953), THORNTHWAITE E MATHER (1955), DENMEAD e SHAW (1962) e FAO (1979).

Este balanço hídrico modificado (BHM) leva em consideração não apenas a capacidade de água disponível māxima do solo, mas tambēm a planta (cultura) e a demanda atmosférica (ETP), definida através da Aqua Disponivel Efetiva (ADE).

A metodologia consta de uma contabilização do armazenamento da água do solo, determinando-se a sua umidade em dado tempo, através da diferença entre a adição (precipitação) e perda (ETP), conhecendo-se inicialmente a capacidade de àgua "disponível máxima-CAD, para cada solo e profundidade.

A perda de umidade pelo solo, admitiu-se como advinda da evapotranspiração potencial (ETP).

Pelo emprego do fator $P$ da equação (2), ou seja, fração da CAD, que é função da espécie vegetal (cultura) e da demanda atmosférica, definiu-se a Agua Disponível Efetiva( $A D E$ ) do solo e valores de armazenamento ocorrentesabaixo deste limi 
te caracterizaram a seca agronómica. Isto è, depois de consumi da a ADE, a evapotranspiração real (ETR) torna-se menor que a ETP ou ETo, impondo condição de "stress" hídrico para a planta.

0 conceito de seca agronómica aqui adotado, é o mesmo preconizado por VAN BAVEL (1953), isto é, a condição onde há uma insuficiente disponibilidade de ăgua na zona das raí zes, para promover um ótimo crescimento da planta.

Desta forma, pelo balanço hídrico seriado diārio modificado (BHM), toda vez que os limites de umidade do solo atingiam valores menores do que a fração da CAD, definida pelo fator $(1-P)$, caracterizava-se como um "dia seco".

"Dia Seco", corresponde ao período de 24 horas no qual o teor de umidade do solo atinge certo limite crítico, definido por (I-P)CAD ou a ADE ter sido consumida, abaixo do qual o processo de crescimento, desenvolvimento e produção final da planta(cultura) é apreciavelmente diminuido.

\subsubsection{O Balanço Hídrico Seriado Diārio Modificado(BHM)}

Este balanço hídrico, à semelhança daquele utili zado por THORNTHWAITE (1948) e THORNTHWAITE e MATHER (1955), ba seia-se em uma contabiliżção entre o que entra para o solo de àgua, na forma de precipitação, e o que sai na forma de evapo transpiração potencial. A quantidade de āgua que por ventura ex cedeu os limites da CAD, foi considerada comoexcesso de água, sendo perdida ou por drenagem profunda ou deflúvio sü perficial (Run-off). 
Considerou-se a ETP = ETR até os limites de utili zação da āgua do solo definidos pela equação (2), ou seja, a $A D E=P . C A D . \quad 0$ limite que definiu a àgua remanescente no solo, abaixo do qual ETR < ETP foi chamado de Armazenamento Crítico e definido matematicamente pela seguinte expressão:

$$
A R_{\text {Crítico }}=(1-P) C A D
$$

Assim, toda a ägua solicitada atravēs da demanda atmosférica, definida pela ETP, é prontamente atendida até atingir o armaze namento crítico, ou toda ADE ter sido consumida. Dessa forma, o secamento ou diminuição da água no solo segue um modelo reti líneo até atingir o $A R_{\text {Critico }}$

Abaixo deste limite, assume-se que a diminuição da água no perfil do solo apresenta uma queda exponencial, igual a adotada por THORNTHWA ITE e MATHER (1955).

No trabalho original de THORNTHWAITE e MATHER (1955), a relação entre demanda atmosférica, definida pela coluna negativo acumulado, ou seja, somatória de (P-ETP) negativo e o armazenamento, apresentado através de tabelas para diversas CAD, é dada pela seguinte expressão:

$$
A R M_{T}=C A D \cdot \exp \left(b N_{T}\right)
$$

onde, $A R M_{T}=$ armazenamento de água no solo dada pela expressão de THORNTHWAITE e MATHER (1955), em mm;

$N_{T}=$ negativo acumulado, ou seja, somatória da diferença negativa entre P-ETP, correspondente, em $\mathrm{mm}$;

$b=$ coeficiente angular, valor negativo, função da CAD. 
Neste modelo, vê-se que o esgotamento da água segue uma ciurva exponencial negativa; desde o valor inicial da demanda (negati vo acumulado).

De acordo com o modelo utilizado no presente trä balho, assumiu-se que o decaimento ou diminuição do armazenamento é linear até um valor de negativo acumulado, correspondente ao armazenamento crítico, ou seja, depois da ADE ter sido consumida e, abaixo do qual, o processo torna-se exponencial, como o modelo original de THORNTHWAITE e MATHER (1955). 0 va-lor do fator $P$, como já vimos, é uma quantidade dependente do valor médio diário da demanda (ETP) e do tipo de cultura, conforme critērios da FAO (1979).

A Figura 3, apresenta um gräfico representativo da relação entre os armazenamento da água no solo e o negativo acumulado, para $50 \mathrm{~mm}$ de CAD, pelo modelo de THORNTHWAITE, e MATHER (1955) e o modificado neste trabalho. 0 armazenamento de água no solo, referente a parte retilínea (ARM(1) $)^{e}$ dado pela seguinte expressão:

$$
A R M(1)=C A D-N
$$

Quando: $A R M \geqslant A R M_{\text {Critico }}=(1-P)$ CAD

ou

$N \leqslant P \cdot C A D$

Sendo: N, o valor do negativo acumulado (mm);

$C A D=$ capacidade de água disponível máxima do solo(mm); O armazenamento de água no solo, abäixo do ARM Crítico, tem for ma exponencial (curvilínea), como já dissemos, com o mesmo com 
49.

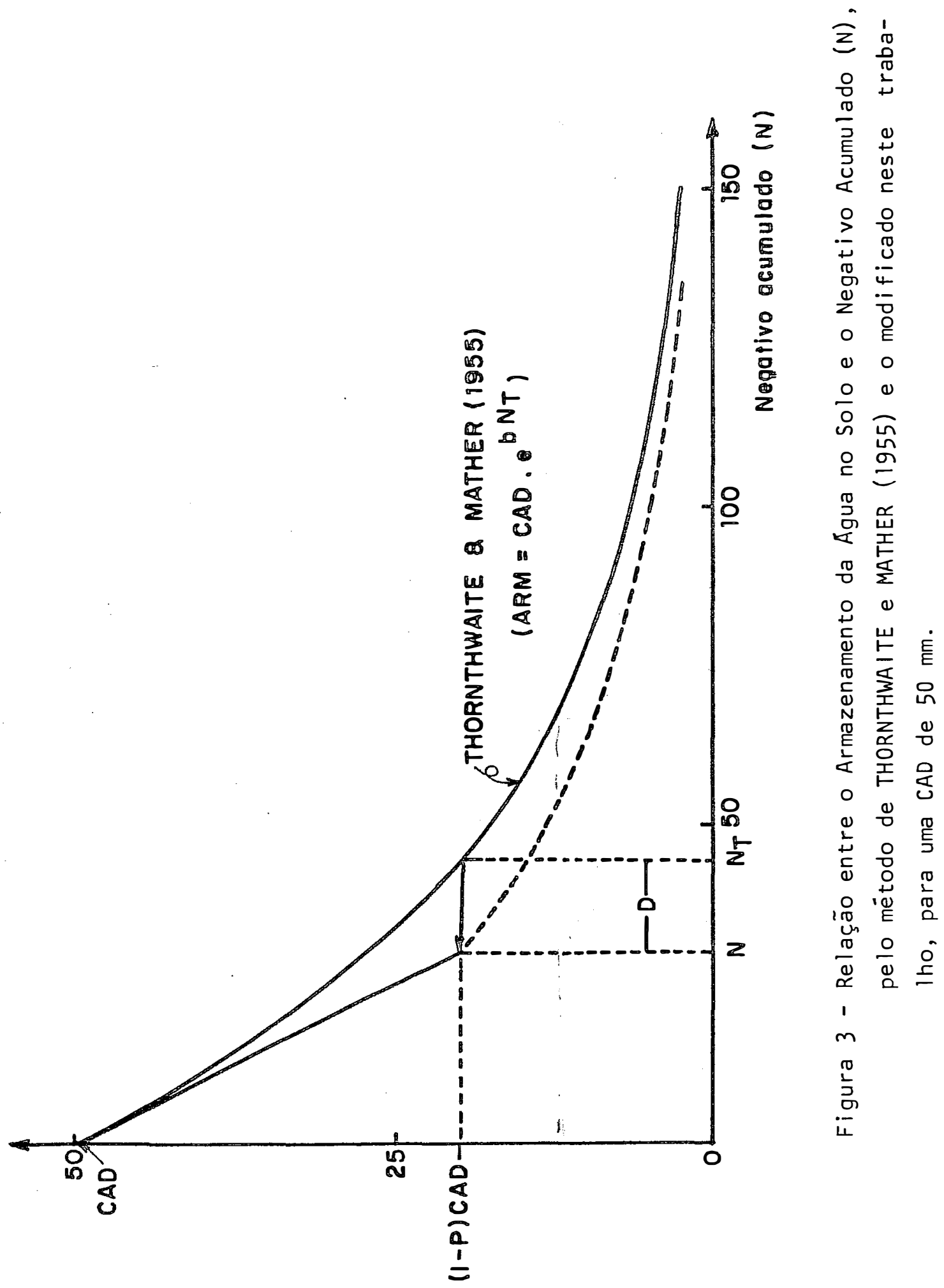

olos ou Dnb! ap ofuausuerousy 
portamento dado pelo modelo preconizado por THORNTHWAITE e MATHER (1955), ou seja:

$$
A R M_{(2)}=C A D \cdot \exp \left(b N_{T}\right)
$$

Quando:

$$
\text { ARM }<A R M \text { Critico }_{\text {Cico }}=(I-P) C A D
$$

ou

$$
N>P \cdot C A D
$$

Onde, $\mathrm{N}_{\mathrm{T}}$ corresponde ao negativo acumulado e utilizado na equa ção original exponencial.

Como podemos ver pela Figura 3 , o $\mathrm{N}_{\mathrm{T}}$ para um mes mo armazenamento, em comparação com a equação (25), tem uma so matöria acumulada maior, devido serem modelos diferentes.

$$
\text { Dessa forma, no } A R M C r i t i c o \text { o valor do armazena- }
$$
mento calculado pela expressão (25) e (26), tem a mesma magni tude, apenas diferem na somatória dos valores de $\mathrm{N}$ e $\mathrm{N}_{\mathrm{T}}$. Isso deve-se ao fato que no modelo idealizado pela equação original (26), tem decaimento ou diminuição da água no solo mais lento, is to é, acumulando um valor mais elevado de negativo acumulado $N$, quando comparado com $A R M(1)$ (retilíneo), até o ARMCrítico:

$$
\text { Assim temos: }
$$

$$
N_{T}=N+D
$$

Onde, D é uma diferença de negativo acumulado entre as expres sões $\operatorname{ARM}_{(2)}$ e $\operatorname{ARM}(1)^{\text {. }}$

No limite correspondente ao ${ }^{A R M} M_{C r i t i c o, ~} A_{(1)}=$ $=A R M_{(2)}$, ou seja:

$$
C A D-N=C A D \cdot \exp \left(b N_{T}\right)
$$

Isolando da expressão (28), a variāvel $N_{T}$ e sabendo-se que no 
${ }^{A R M}$ Critico o negativo acumulado $N$ é igual a P.CAD, temos:

$$
N_{T}=\frac{\ln [(C A D-N) / C A D]}{b}
$$

ou

$$
N_{T}=\frac{\ln [(C A D-P \cdot C A D) / C A D]}{b}=\frac{\ln (1-P)}{b}
$$

Pela expressão (27) sabemos que:

$$
\begin{aligned}
& N_{T}=N+D \\
& \mathrm{Ou} \\
& D=N_{T}-N \text { e no } A R M_{C r i t i c o}, N=P . C A D
\end{aligned}
$$

Logo, $D=N_{T}-P \cdot C A D$ e como $N_{T}$ é definido pela expressão (29), o valor de D, no ponto crítico fica assim definido:

$$
D=\frac{\ln (1-P)}{b}-P \cdot C A D
$$

Assim, $N_{T}=N+D=N+\frac{\ln (1-P)}{b}-P \cdot C A D$

Substituindo-se (31) em (26), vem:

$$
A R M_{(2)}=C A D \cdot \exp \left\{b\left[N+\frac{\ln (1-P)}{b}-P \cdot C A D J\right\}\right.
$$

Isolando o valor $\mathrm{N}$ de (32), temos:

$$
N_{\}}=\frac{\ln \left[\frac{A R M(.2)}{C A D}\right]-\ln (1-P)+b \cdot P \cdot C A D}{b}
$$

As equações (32) e (33) definem os valores correspondentes do armazenamento de àgua no solo e do negativo acumulado N, quando:

$$
\begin{aligned}
& A R M<(1-P) C A D=A R M C r i t i c o \\
& \text { ou } \\
& N>P . C A D
\end{aligned}
$$


Portanto, nesse balanço hídrico seriado diārio modificado (BHM) existem duas expressões gerais que definem o valor do armazenamento de àgua no solo, ou seja, são definidas pelas equações (25) e (26), sendo seus limites de abrangência definidos pelos valores de ETP média diária, CAD e fator $\underline{P}$. 0 valor do coeficiente angular $\underline{b}$ do modelo de THORNTHWAITE e MATHER (1955) é função do valor da CAD utilizada. Através da análise e estudo estatístico pela análise de regressão dos valores tabelados dos diversos CADs, encontrou-se uma relação entre os CADs e bs, da seguinte forma:

a $C A D=100 \mathrm{~mm}$, possui um b $=-0,0102559384$ e para valores aba ixo desta CAD, existe uma relação inversa, isto é, para a $C A D=50 \mathrm{~mm}$ o b correspondente é igual a -0,0205118768. Para a $C A D=200 \mathrm{~mm}$, possui um $b=-5,0653931 \times 10^{-3}$. Assim, para os CADs entre 100 e 200 , podem ser encontrados os corresponden tes valores dos coeficientes angulares (b), por uma simples re laçāo inversa. A Tabela 2, apresenta diversos valores correspondentes de CAD e b.

Para uma melhor fixação e entendimento da metodo logia utilizada para a caracterização do balanço hídrico seria do diário modificado (BHM), elaboramos um exemplo hipotético conforme ilustra a Tabela 3 .

Utilizou-se, nesse exemplo, uma CAD de $50 \mathrm{~mm}$ e uma $\overline{\text { ETP }}$ de $5,2 \mathrm{~mm} / \mathrm{di} a$ para um mês de janeiro. Através dessa $\overline{\text { ETP }}$ e com o auxilio da Tabela 1 (Grupo 4) ou da Equação (3), definimos o valor de $P=0,62$. A ADE foi definida pela equação 
Tabela 2 - Valores diversos de CAD e correspondentes valores de coeficientes angulares (b) da equaçāo original de THORNTHWAITE e MATHER (1955), para cālculo do armaze namento de àgua do solo.

\begin{tabular}{cccccc}
\hline $\begin{array}{c}C A D \\
(\mathrm{~mm})\end{array}$ & $b$ & $\begin{array}{c}C A D \\
(\mathrm{~mm})\end{array}$ & $b$ & $\begin{array}{c}C A D \\
(\mathrm{~mm})\end{array}$ & $b$ \\
\hline 15 & $-0,0583730$ & 60 & $-0,0170932$ & 115 & $-8,809379 \times 10^{-3}$ \\
20 & $-0,0512797$ & 65 & $-0,0157784$ & 125 & $-8,104629 \times 10^{-3}$ \\
25 & $-0,0410238$ & 70 & $-0,0146513$ & 135 & $-7,504286 \times 10^{-3}$ \\
30 & $-0,0341865$ & 75 & $-0,0136746$ & 150 & $-6,753857 \times 10^{-3}$ \\
35 & $-0,0293027$ & 80 & $-0,0128200$ & 165 & $-6,1398704 \times 10^{-3}$ \\
40 & $-0,0256398$ & 85 & $-0,0120658$ & 175 & $-5,789021 \times 10^{-3}$ \\
45 & $-0,0227910$ & 90 & $-0,0113955$ & 185 & $-5,476101 \times 10^{-3}$ \\
50 & $-0,02051188$ & 95 & $-0,0107957$ & 200 & $-5,0653931 \times 10^{-3}$ \\
55 & $-0,0186472$ & 100 & $-0,01025594$ & - & -
\end{tabular}


Tabela 3 -Exemplo Hipotētico do Balanço Hídrico Seriado Diārio Modificado (BHM) utilizado para estudo e caracterização da Seca Agronômica, atravēs do conceito de "Dias Secos". Tabela 1

$$
\begin{aligned}
& \overline{E T P}=5,2 \mathrm{~mm} / \mathrm{dia} \frac{\mathrm{T}}{\text { ou Equação } 3} \mathrm{P} \cong 0,62(\text { Grupo } 4) \\
& \text { CAD }=50 \mathrm{~mm} ; A D E=0,62 \times 50 \mathrm{~mm}=3 \mathrm{~T}, 0.0 \mathrm{~mm} ; A_{\text {Crít } \mathrm{ico}}=19,0 \mathrm{~mm}
\end{aligned}
$$

\begin{tabular}{|c|c|c|c|c|c|c|c|c|c|}
\hline Coluna & 1 & 2 & 3 & 4 & 5 & 6 & 7 & 8 & 9 \\
\hline $\begin{array}{c}\text { Mês } \\
\text { (Jane i ro) }\end{array}$ & $\begin{array}{c}\mathrm{P} \\
(\mathrm{mm})\end{array}$ & $\begin{array}{l}\text { ETP } \\
(\mathrm{mm})\end{array}$ & $\begin{array}{c}P-E T P \\
(\mathrm{~mm})\end{array}$ & $\begin{array}{l}\text { Neg.Ac. } \\
(\mathrm{mm})\end{array}$ & $\begin{array}{l}\text { Armazer } \\
\text { Valor }\end{array}$ & $\begin{array}{l}\text { Al t. } \\
\text { Alam. }\end{array}$ & ETR & DEF. & EXC. \\
\hline 1 & 15,0 & 5,2 & $+9,8$ & 0,0 & 50,0 & 0 & 5,2 & 0,0 & 9,8 \\
\hline 2 & 0,0 & 5,2 & $-5,2$ & 5,2 & 44,8 & $-5,2$ & 5,2 & 0,0 & 0,0 \\
\hline 3 & 0,0 & 5,2 & $-5,2$ & 10,4 . & 39,6 & $-5,2$ & 5,2 & 0,0 & 0,0 \\
\hline 4 & 0,0 & 5,2 & $-5,2$ & 15,6 & 34,4 & $-5,2$ & 5,2 & 0,0 & 0,0 \\
\hline 5 & 0,0 & 5,2 & $-5,2$ & 20,8 & 29,2 & $-5,2$ & 5,2 & 0,0 & 0,0 \\
\hline 6 & 0,0 & 5,2 & $-5,2$ & 26,0 & 24,0 & $-5,2$ & 5,2 & 0,0 & 0,0 \\
\hline $7 *$ & 0,0 & 5,2 & $-5,2$ & 31,2 & $18,9 *$ & $-5,1$ & 5,1 & $0,1^{*}$ & 0,0 \\
\hline $8 *$ & 0,0 & 5,2 & $-5,2$ & 36,4 & $17,0 *$ & $-1,9$ & 1,9 & $3,3^{*}$ & 0,0 \\
\hline $9 *$ & 0,0 & 5,2 & $-5,2$ & 41,6 & $15,3^{*}$ & $-1,7$ & 1,7 & $3,5^{*}$ & 0,0 \\
\hline $10 *$ & 0,0 & 5,2 & $-5,2$ & 46,8 & $13,7^{*}$ & $-1,6$ & 1,6 & $3,6^{*}$ & 0,0 \\
\hline $11 *$ & 0,0 & 5,2 & $-5,2$ & 52,0 & $12,4^{*}$ & $-1,3$ & $1:, 3$ & $3,9 *$ & 0,0 \\
\hline 12 & 18,5 & 5,2 & $+13,3$ & 24,3 & 25,7 & $+13,3$ & 5,2 & 0,0 & 0,0 \\
\hline 13 & 30,4 & 5,2 & $+25,2$ & 0,0 & 50,0 & $+24,3$ & 5,2 & 0,0 & 0,9 \\
\hline 14 & 0,0 & 5,2 & $-5,2$ & 5,2 & 44,8 & $-5,2$ & 5,2 & 0,0 & 0,0 \\
\hline 15 & 0,0 & 5,2 & $-5,2$ & 10,4 & 39,6 & $-5,2$ & 5,2 & 0,0 & 0,0 \\
\hline 16 & 0,0 & 5,2 & $-5,2$ & 15,6 & 34,4 & $-5,2$ & 5,2 & 0,0 & 0,0 \\
\hline 17 & 0,0 & 5,2 & $-5,2$ & 20,8 & 29,2 & $-5,2$ & 5,2 & 0,0 & 0,0 \\
\hline 18 & 0,0 & 5,2 & $-5,2$ & 26,0 & 24,0 & $-5,2$ & 5,2 & 0,0 & 0,0 \\
\hline $19 *$ & 0,0 & 5,2 & $-5,2$. & 31,2 & $18,9 *$ & $-5,1$ & 5,1 & $0,1 *$ & 0,0 \\
\hline $20 *$ & 0,0 & 5,2 & $-5,2$ & 36,4 & $17,0 *$ & $-1,9$ & 1,9 & $3,3 *$ & 0,0 \\
\hline $21 *$ & 6,2 & 5,2 & $+1,0$ & 33,6 & $18,0 *$ & $+1,0$ & 5,2 & $0,0 *$ & 0,0 \\
\hline : & : & $:$ & & : & : & : & : & $\vdots$ & : \\
\hline 31 & 0,0 & 5,2 & $-5,2$ & 23,6 & 26,4 & $-5,2$ & 5,2 & 0,0 & 0,0 \\
\hline
\end{tabular}

Somatöria 
(2), correspondendo ao valor de $31,0 \mathrm{~mm}$. O ARM Crítico, definido pela equação (23), como sendo igual a 19,0 mm.

Como podemos ver na Tabela 3 , o balanço hídrico seriado diário modificado (BHM) é caracterizado pelos dias do mes mais 9 colunas. A coluna 1 , serve para plotar valores de precipitação pluviométrica observados em cada dia do mês corres pondente, em mm. Na coluna 2, os valores de ETP média diária $(\overline{E T P})$ para o mês correspondente, também em mm. A coluna 3 , apresenta valores da diferença entre a coluna 1 e 2 . A coluna 4, apresenta a somatória das diferenças negativas da coluna 3 , ou seja, o negativo acumulado (N). As colunas 5 e 6 , apresentam os valores do armazenamento de água no solo e sua alteração em relação ao dia anterior. Os valores do armazenamento, co luna 5, são definidos pelas equações (25) e (32). A utilização de uma ou outra das equações depende do valor da coluna 4, negativo acumulado (N).

Quando $N$ foi menor ou igual a P.CAD, no caso $31,0 \mathrm{~mm}$, utilizou-se a equação (25); correspondendo a parte retilínea da equação do BHM. Caso contrário, isto é, N> P.CAD, aplicou-se a equação (32), correspondendo a parte curvilínea (exponencial). da equação de BHM.

Quando a coluna 3 , apresentar valor positivo, is to quer dizer que precipitou mais do que evapotranspirou no dia, caso específico, dias $1,12,13$ e 21 , então o valor do armazenamento é encontrado através da adição do armazenamento do dia anterior e do valor positivo da coluna 3. Nesse caso, o valor 
correspondente à coluna negativo acumulado $(N)$ é definido pelas equações (25), isolando o valor N, e pela equação (33). A escolha de uma ou outra expressão, dependerá do valor do armazenamento. Quando for maior ou igual ao. Armazenamentocrítico ${ }^{-A R M}{ }_{C r i t}=(1-P) C A D-a p l i c a-s e$ a equação (25), caso contrário (33). A coluna 6 , apresenta a alteração de armazenamento, ou seja, a diferença entre o armazenamento do dia anterior em relação ao do dia considerado. Os valores positivos indicam em quanto foi o aumento de água armazenada no solo e os negativos a diminuição no dia em questão. A caracterização da seca agronómica, como já nos refirimos anteriormente, é definida peila fração da CAD, através do fator $\underline{P}$, abaixo do qual a ETR torna-se menor que a ETP. Ou de outra maneira, toda vezque valores do ar mazenamento, definidos pela coluna 5 , atingiram valores abaixo do ARM Critico, caracteriza seca agronōmica, definida pelo con çeito. de "Dia Seco". Entretanto, existem situações, pelo critẹ rio aqui adotado, em que estando o teor de água no solo abaixo do ${ }^{A R M}$ Critico e ocorrendo precipitação da ordem da ETP do dia ou maior, mas insuficiente para superar o valor do ARM Crítico' teremos uma condição em que octeor de água no solo permanece a baixo do $A R M C r i ́ t i c o$ e a ETR = ETP. Acreditamos que precipitações de tal ordem não chegam a alterar consideravelmente o teor de água no solo, na zona das raízes, como o próprio armazenamento nos diz, embora pelo cálculo ETR = ETP, para o dia consí derado.

Assim sendo, nesses casos, foi considerado "Dia 
Seco"l toda vez que o teor de āgua no solo permaneceu abaixo do ${ }^{A R M}$ Critico, como podemos verificar pelo exemplo da Tabela 3 , dia 21. Portanto, os dias 7, 8, 9, 10, 11, 19, 20 e 21, preencheram esta condição, isto é, são "dias secos". Para o presente trabalho, bastava calcular-se até a coluna 5, para a determinação de "dias secos". Entretanto, houvemos por bem, introduzir as colunas $6,7,8$ e 9 como forma de demonstrar que ele mentos tão importantes como a ETR, deficiência e excesso de àgua no solo podem ser obtidos através de BHM, à semelhança com O BH preconizado por THORNTHWAITE e MATHER (1955). O valor da ETR é igual ao valor da ETP, quando a alteração (coluna 6) for nula ou positiva. Quando osvalores, da alteração do armazenamento, forem negativos, a ETR é calculada pela somatória do mó dulo da alteração (coluna 6) mais a precipitação, coluna l. A coluna 8, deficiéncia hídrica, é caracterizada pela diferença en tre as colunas 2 e 7 , isto é, entre ETP e ETR. A coluna 9 defi ne o excedente hídrico que houve, através da diferença entre a coluna 3 e 6 , isto é, valores que excederam a CAD utilizada. Por intermédio dos valores da ETR e ETP, podemos definir uma importante relação denominada de Evapotranspiração Relativa, isto é, a razão existente entre ETR/ETP, conforme é apresentado na Figura 4. Como podemos notar, a razão ETR/ETP é igual a unidade até um ponto definido pela ARMCrítico, ou se ja, (1-P)CAD. Abaixo desse valor, a evapotranspiração relativa apresenta decréscimo linear, sendo tanto mais acentuado quanto menor o ARMCrítico, definido pelo P e CAD. Na Figura 4, exem- 
58.

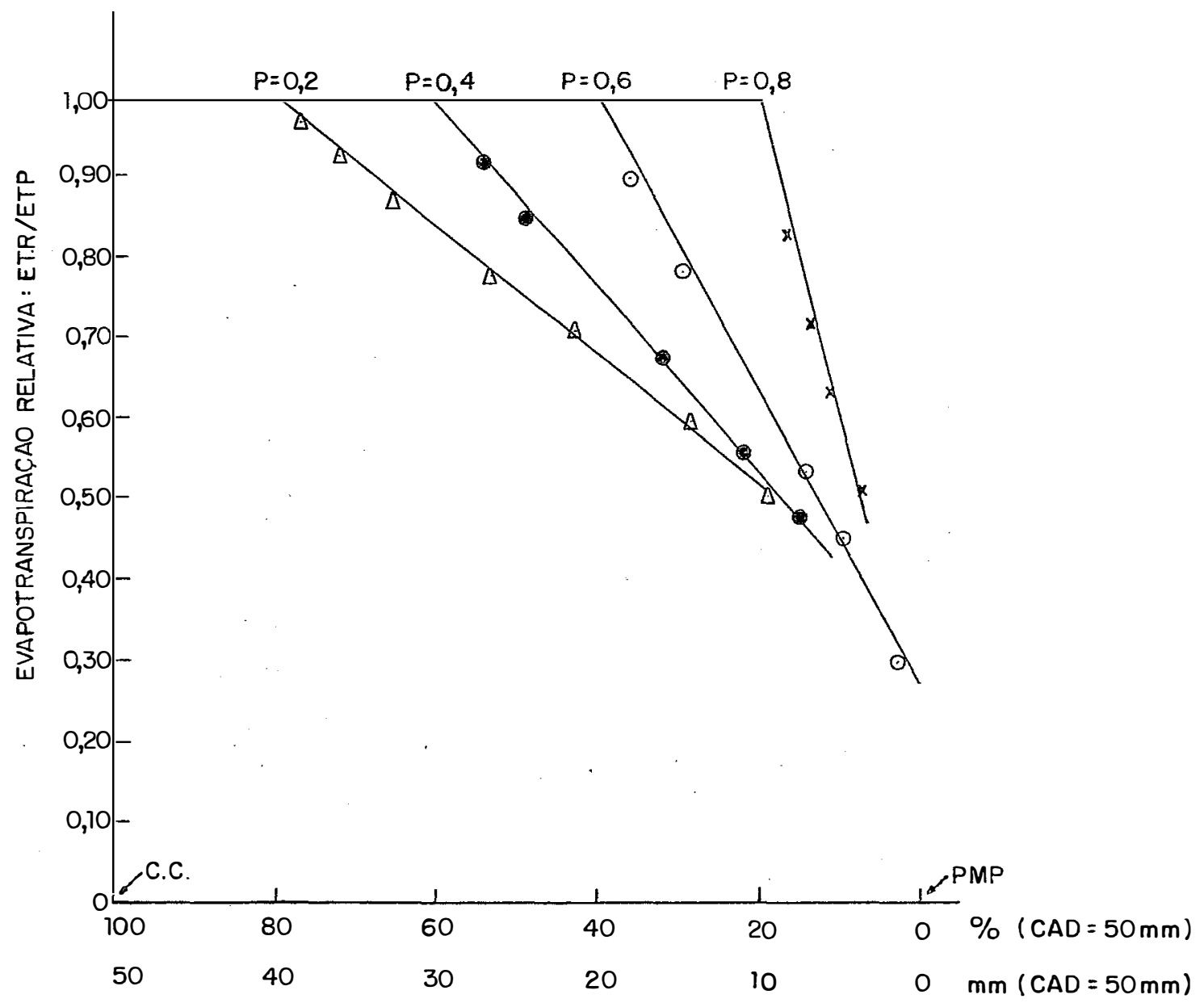

Figura 4 - Evapotranspiração Relativa (ETR/ETP), versus percentagem de Água Disponível Máxima (CAD) no solo, em função de quatro valores do Fator $\underline{p}$. 
plificou-se para um solo com uma CAD de $50 \mathrm{~mm}$ e valores do fator $P$ de 0,$2 ; 0,4 ; 0,6$ e 0,8 . Iniciou-se o balanço hídrico se riado diário, nesse estudo, considerando que a umidade do solo encontrava-se na capacidade de campo no 1 ! dia de com putação do balanço hídrico, isto é,-no dia lo de janeiro de 1955.

o balanço hídrico seriado diārio modificado, na série de 26 anos, foi realizado através da utilização de compü tador IBM-1130, pertencentes ao Departamento de Matemātica e É tatistica da ESALQ, o qual foi testado sua contabilização, em termos mensais, pelas seguintes expressões:
a) $\sum E T R+\sum$ Deficiència- $\sum E T P=0$;
b) $\sum E T R+\sum E X C+\sum A L T-\sum$ Prec. $=0$;
c) $\sum$ Prec. $-\sum E T P-\sum(P-E T P)=0$

$\Rightarrow 3.6$. Probabilidade de Ocorrência de "Dias Secos"

Pela contagem de "dias secos" obtidos através do balanço hídrico seriado diário modificado (BHM), obteve-se as frequências e frequéncias acumuladas complementares ou probabilidade empírica de ocorréncia da seca agronómica por períodos quinzenais, mensais e trimestrais. Também foram obtidas tabelas relacionando o nümero total de "dias secos" por períodos quinzenais, mensais, trimestrais e anual, nos 26 anos estudados. os "dias secos". foram computados em sequências, como forma de melhor se estudar sua severidade. Os "dias secos" consecutivos ou sequências foram agrupadas em classes, depen- 
dentes do intervalo de tempo escolhido, isto é, quinzenal, men sal e trimestrai e obtidas suas frequéncias acumuladas complementares ou probabilidades empíricas. Para o estudo quinzenal foram utilizadas 9 classes, sendo: zero, 1-2, 3-4, 5-6, 7-8, 9-10, 11-12, 13-14 e 15-16. Para o período mensal foram: zero, 1-3, 4-6, 7-9, $10-12,13-15,16-18,19-21,22-24,25-27$ e 28-31. Em termos trimestrais adotou-se 11 classes: zero, 1-10, 11-19, 20-28, 29-37, 38-46, 47-55, 56-64, 65-73, 74-83, 84-92. Portanto, para cada período qunizenal de cada mês do calendário, para cada mês e trimestre foram determinadas as frequências e as probabilidades empíricas de ocor rência de cada classe e do n.e mínimo de "dias secos consecutivos" dado pelo limite inferior de cada classe, para as diversas CADs utilizadas.

Procedeu-se, tambēm, a verificação do ajustamento lda distribuição de probabilidades empíricas da variāvel aleatōoria, Número Mínimo de Dias Secos Consecutivos, à curva normal, conforme procedimentos anteriormente adotados por SCARDUA (1979).

Como houve um bom ajustamento à curva normal, pode-se traçar em papel de probabilidade para cada período quinzenal, mensal e trimestral e cada quantidade de água disponíivel máxima (CAD) os grāficos das retas que relacionam o ne mínimo de dias secos consecutivos e as probabilidades teóricas de sua ocorrência.

Atravēs dessas retas obteve-se os dados necessários para o traçado de gráficos que relacionam os números míni mos de dias secos consecutivos esperados, aos níveis de probabilidade de $10 \%, 20 \%, 30 \%, 40 \%, 50 \% ; 60 \%$ e $80 \%$ em cada quinze na e para cada capacidade de água disponível máxima-CAD. 


\section{RESULTADOS E DISCUSSĀO}

4.1. Local de Estudo e Dados Meteorológicos

A escolha da localidade de Laguna-SC como representativa da área em estudo deveu-se ao fato da mesma encontrar-se mais centralizada em relação ao Litoral Sul, onde os efeitos de deficiências hídricas são mais evidenciados e, prin cipalmente, por possuir a série mais longa de informações meteorolōgicas. Embora a estação meteorológica de Laguna-sc não esteja bem localizada devido as proximidades com o mar, verifi cou-se, através de estudos estatísticos de análise de variância, que a mesma não difere significativamente, ao nível de 5\%, em termos de precipitação pluviométrica, com as estações meteorológicas de Imbituba, Tubarão e Araranguá, quando compara dos os diversos meses do ano em termos normais. Tambēm não diferiu estatisticamente das localidades de Orleãs e Urussanga, quando comparados em termos normais, anualmente. Difere, dessas duas últimas localidades, nos meses de verão, ou seja, janeiro, fevereiro e março. 
Dessa forma, como a região estudada é composta de planicies 1 itorâneas com altitude inferior a 200 metros, acreditamos que o local escolhido seja representativo em termos de ocorrēncias meteorológicas.

Baseado nos resultados estatísticos, acima refe ridos, é que pudemos suprir algumas deficièncias de notaçẽes meteorológicas da estação utilizada. Assim, supriu-se 23 meses de dados diários de precipitação pluviométrica com a ajuda dos dados meteorológicos das estações de Araranguá e Urussanga pạ ra que a sērie de 26 anos não se interrompesse, já que o estudo de Balanço Hídrico é seriado e diário.

4.2. Caracterização dos Solos e Água Disponível

Considerou-se como representativos da área estudada, os solos "Morro da Fumaça"(Podzólico Vermelho Amarélo Cascalhento Epi-Eutrōfico), "Araranguă" (Areias Quartzosas Dís tróficas), "Tubarão" (Cambisol Eutrōfico) e "Jacinto Machado" (Cambisol Epi-Eutrófico), segundo a"Carta de Levantamento de Reconhecimento dos Solos do Estado de Santa Catarina"(1973). 0 bservou-se que o solo "Morro da Fumaça" ocupa a maior parte da área estudada, seguido pelo "Araranguá" como podemos verificar pela Figura 2. Em menor proporção encontra-se os solos "Jacinto Machado" e "Tubarão", muito embora sejam solos de grande po. tencial agrícolas. Não foram considerados os solos orgânicos e os Gley Húmicos Distrōficos, devido possuirem lençol freático à superfície. Também foram desconsideradas as Areias Quartzosas 
não fixadas (DUNAS) por não terem potencial agrícola e serem á reas de preservação permanente. A densidade global e os níveis de umidade por volume determinados para as camadas de $0-30 \mathrm{~cm}$, 30-60 e 60-100 cm dos solos "Tubarão", "Jacinto Machado", "Mor ro da Fumaça" e "Araranguä", nas tensões, de 0,001;0,02;0,06; 0,$1 ; 0,3 ; 1,0 ; 5,0$ e 15,0 atm, estão relacionados na Tabela 4 . Por intermédio dos valores de umidade base volu me e tensão da Tabela 4, foram traçadas as curvas característi cas para cada solo e camada, representadas nas Figuras $5,6,7$ e 8 . Determinou-se a capacidade de água disponível máxima-CAD, que o solo pode reter em cada camada entre as tensões de 0,1 e 15 atm e 0,3 e 15 atm, relacionadas na Tabela 5. Para os solos argilosos "Tubarão", "Morro da Fumaça e "Ja" cinto Machado" adotou-se a água disponível máxima como sendo a quela compreendida entre as tensões de 0,3 a 15 atm e de 0,1 a 15 atm. para o solo arenoso "Araranguä". Como podemos verificar pela Tabela 5, as capacidades de água disponíveis máximas encontradas para os quatro solos e camadas foram as seguintes, em ordem crescente: $10,6 \mathrm{~mm} ; 21,3 \mathrm{~mm} ; 22,3 \mathrm{~mm} ; 37,1 \mathrm{~mm} ; 39,3 \mathrm{~mm}$; $50,7 \mathrm{~mm} ; 56,0 \mathrm{~mm} ; 90,1 \mathrm{~mm} ; 104,4 \mathrm{~mm} ; 108,8 \mathrm{~mm} ; 161,9 \mathrm{~mm} \quad \mathrm{e}$ 193,0 mm. Para representar, no balanço hídrico, essas diversas quantidades de água disponível máximas, agrupou-se em cinco classes; assim: para as CADs de 10,$6 ; 21,3$ e $22,3 \mathrm{~mm}$, adotamos a CAD de $18 \mathrm{~mm}$; para 37,1 e $39,3 \mathrm{~mm}$ adotamos o valor de $38 \mathrm{~mm}$; para 50,7 e 56,0 mm o valor de $50 \mathrm{~mm}$; para 90,1 , 104,4 e 108,8 mm o valor de $100 \mathrm{~mm}$; e para 161,9 e 193,0 mm valor de $175 \mathrm{~mm}$. 


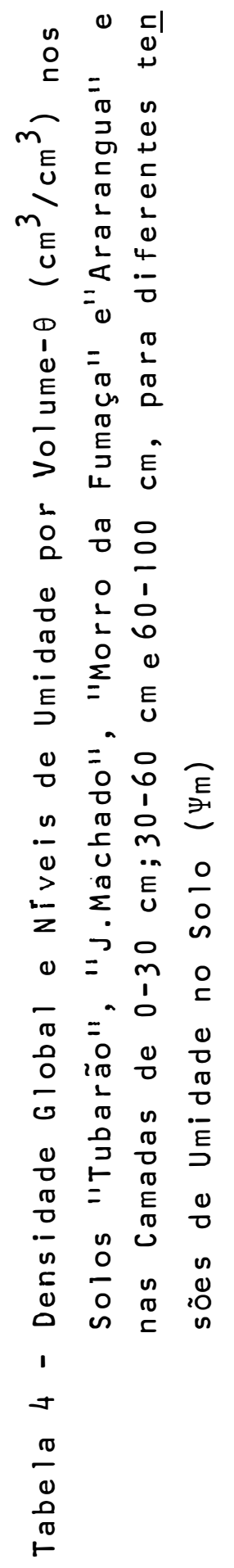

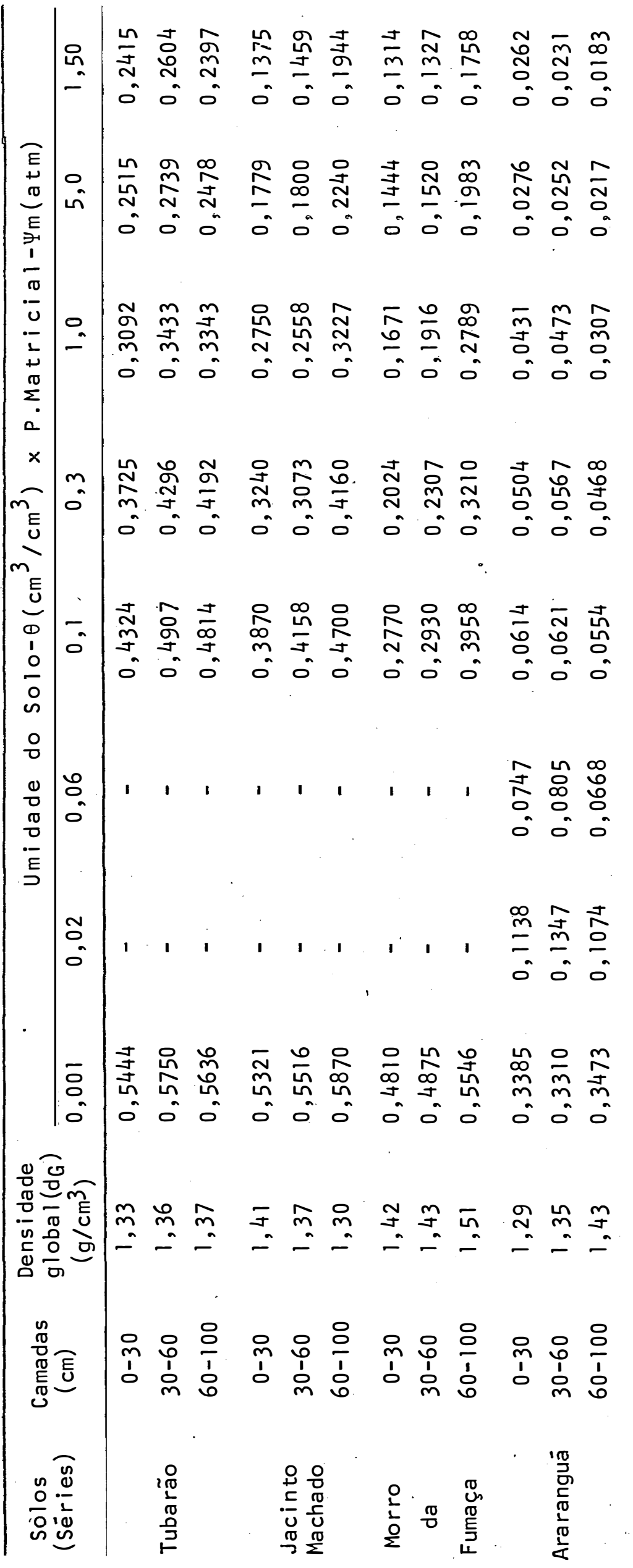


65.

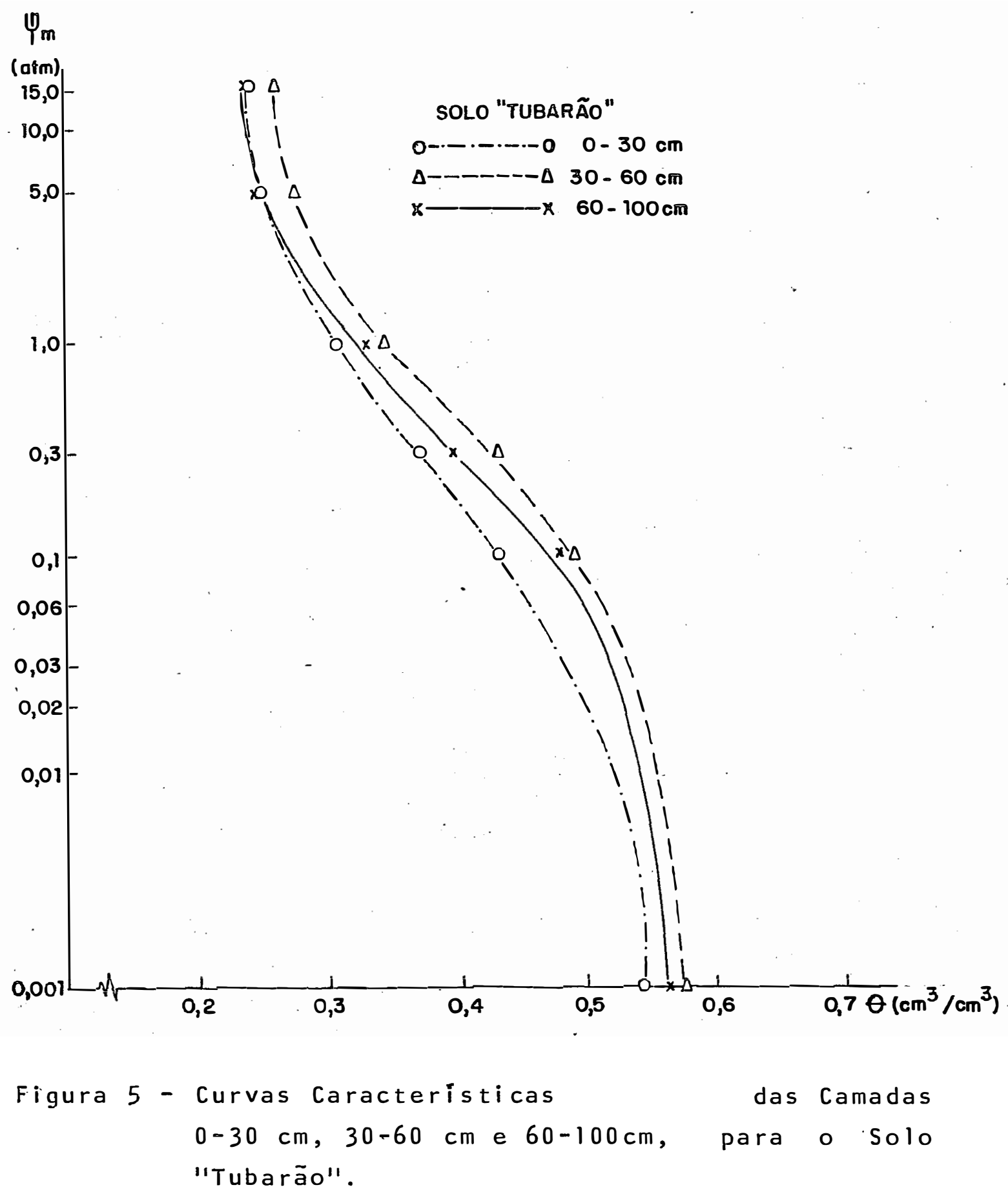


66.

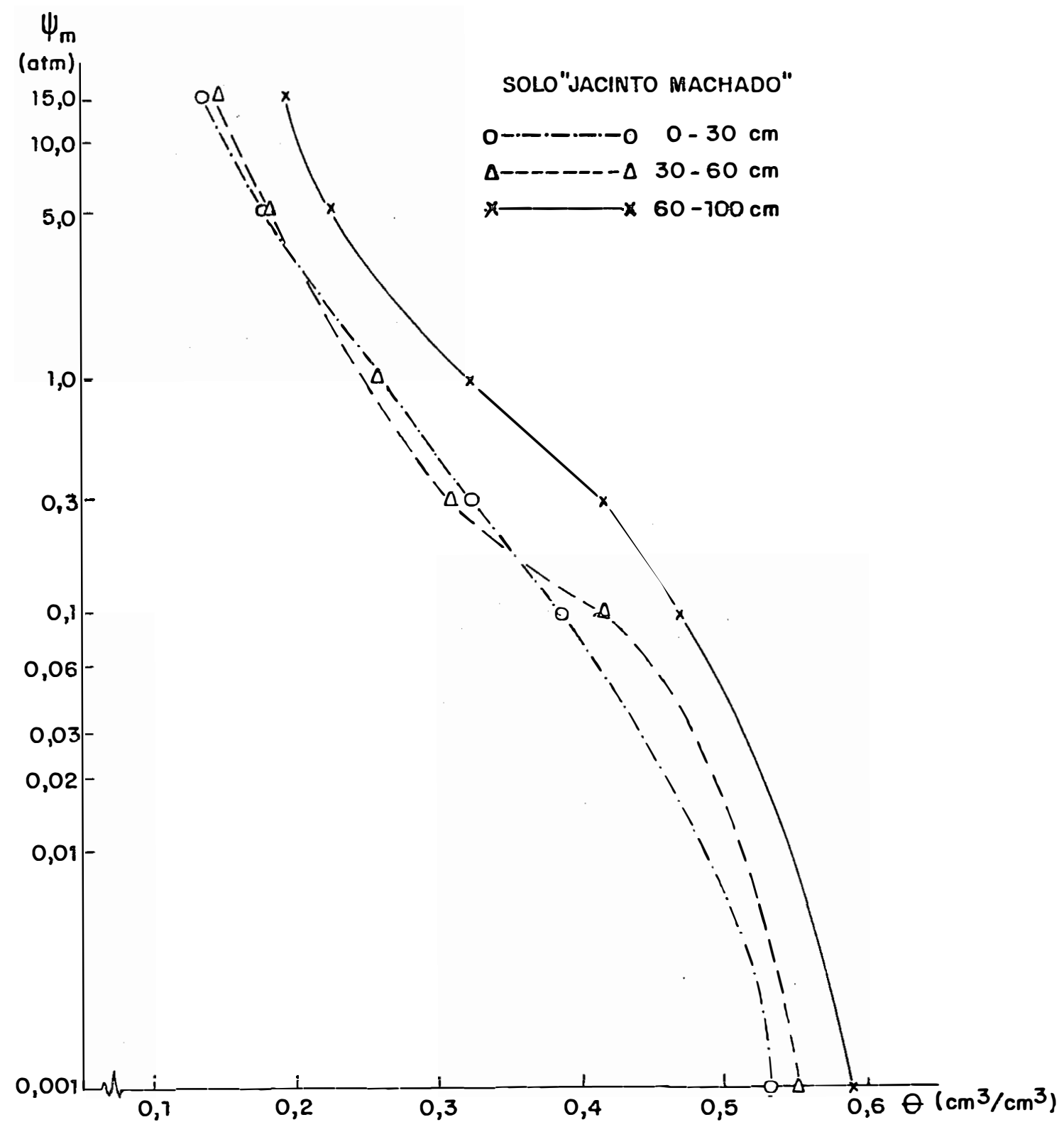

Figura 6 - Curvas Características das Camadas 0-30 cm, 30-60 cm e 60-100 cm, para o Solo "Jacinto Machado". 


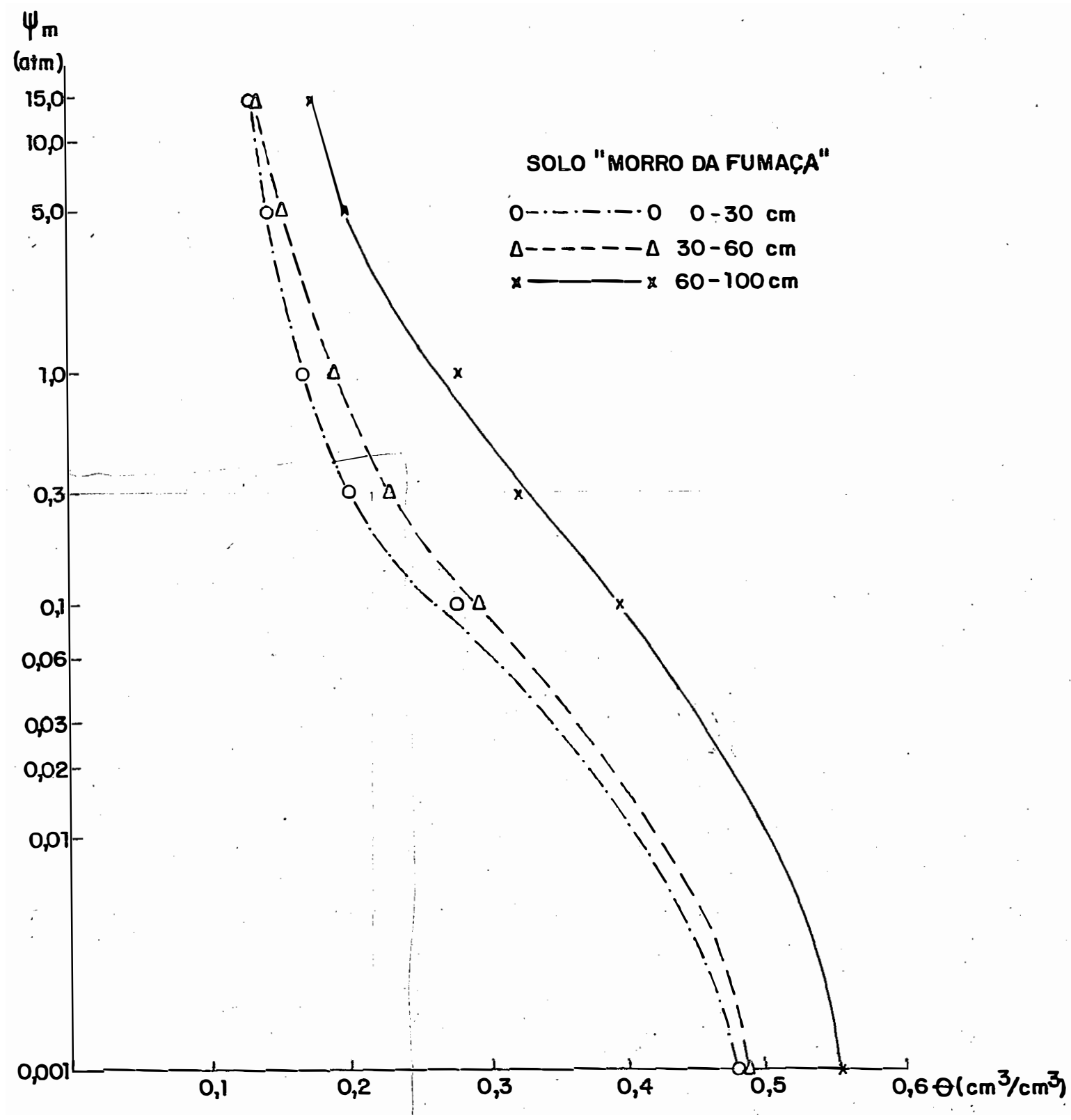

Figura 7 - Curvas Caracteristicas das Camadas 0-30.cm, 30-60 cm e. $60-100 \mathrm{~cm}$, para o Solo "Morro da Fumaça". 
68 .

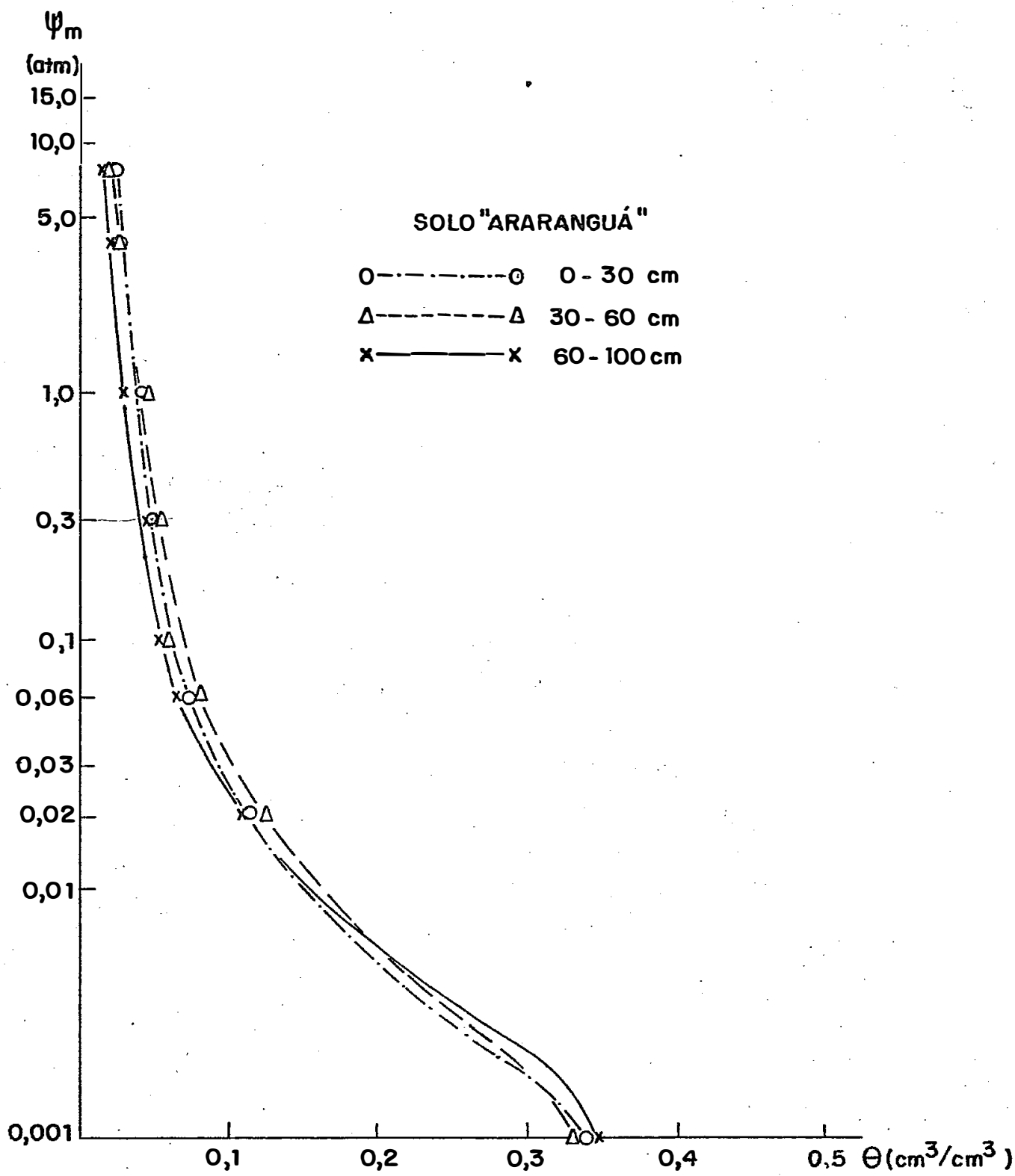

Figura 8 - Curvas Características das Camadas 0-30 cm, 30-60 cm e 60-100 cm, para .o Solo "Araranguä". 
Tabela 5 - Capacidade de Água Disponível Máxima - CAD em mm de altura d'água até as profundidades de $30 \mathrm{~cm}, 60 \mathrm{~cm}$, e $100 \mathrm{~cm}$ para os solos "Tubarão", "Jacinto Machado", "Morro da Fumaça" e "Araranguā", entre as tensões de $0,1-15$ atm e $0,3-15$ atm.

\begin{tabular}{|c|c|c|c|}
\hline \multirow{2}{*}{ Solos } & \multirow{2}{*}{$\begin{array}{l}\text { Profund. } \\
(\mathrm{cm})\end{array}$} & Capacidade de Água & \multirow{2}{*}{$\frac{\text { Disponível Māxima-CAD(mm) }}{0,3-15 \text { at̀̀m. }}$} \\
\hline & & $0,1-15$ a tm. & \\
\hline \multirow{3}{*}{ Tubarão } & $0-30$ & & 39,3 \\
\hline & $0-60$ & & 90,1 \\
\hline & $0-100$ & & 161,9 \\
\hline \multirow{3}{*}{ J.Machado } & $0-30$ & & 56,0 \\
\hline & $0-60$ & & 104,4 \\
\hline & $0=100$ & & 193,0 \\
\hline Morro & $0-30$ & & 21,3 \\
\hline $\mathrm{da}$ & $0-60$ & & 50,7 \\
\hline \multirow[t]{2}{*}{ Fumaça } & $0-100$ & & 108,8 \\
\hline & $0-30$ & 10,6 & \\
\hline \multirow[t]{2}{*}{ Araranguā } & $0-60$ & 22,3 & \\
\hline & $0-100$ & 37,1 & \\
\hline
\end{tabular}


Dessa forma, os valores representativos das capa cidades de água disponível máximas para os quatro solos estuda dos nas diversas camadas foram os seguintes: $18 \mathrm{~mm} ; 38 \mathrm{~mm} ; 50$ $\mathrm{mm} ; 100 \mathrm{~mm}$ e $175 \mathrm{~mm}$.

Procuramos não ser por demais rigorosos na utili zação dos diversos valores de CADs determinadas em laboratório, para os quatro solos e camadas, devido ao fato de que, a capacidade de àgua disponível máxima-CAD é variável com uma gama de fatores, como a textura, estrutura, teor de matéria orgân ca e tipo de argila constituinte de cada solo e camada e, por outro lado, variável também em termos espaciais. Também devido que nas determinações das diversas curvas caracteristicas utilizou-se amostras de solo deformadas, medida que, em muitos cá sos altera muito as características físicas dos solos, embora tenha-se procurado dar a mesma densidade original às amostras no momento de submetē-los à determinação da relação $\Psi_{m} \times \theta$.

A determinação das diversas CADs dos solos mais ocorrentes na ārea de estudo teve a intenção de procurar util I zar valores mais próximos da realidade, no que tange a utiliza ção dos mesmos no balanço hídrico, longe de querer se esgotar esse assunto. 
4.3. Evapotranspiração Potencial(ETP) ou de Referência(ETo) 4.3.1. Simplificação do Termo "Energia"da Equação de PENMAN (1948)

Através do estudo de correlação entre o balanço de energia média mensal (H), a constante solar média mensal (Qo), razão de insolação média mensal $\left(\frac{n}{N}\right)$ e pressão atual de vapor média mensal ( $\left.e_{a}\right)$, nos 26 anos, determinou-se doze equações ge rais que descrevem o termo "energia" (H) da equação de PENMAN (1948), para cada mês do calendário e para a localidade em estudo (Laguna-SC).

$$
\text { Sendo assim expressas: }
$$

a) Mês de Janeiro:

$$
\begin{aligned}
& H=Q_{0}\left(0,04427+0,22013 \frac{n}{N}+0,03380 \sqrt{e_{a}}\right) \\
& r^{2}=0,9984 \text { e CV }=0,18 \%
\end{aligned}
$$

b) Mês de Fevereiro:

$$
\begin{aligned}
& H=Q_{0}\left(0,04033+0,2084 \frac{n}{N}+0,03461 \sqrt{e_{a}}\right) \\
& r^{2}=0,9986 \text { e CV }=0,23 \%
\end{aligned}
$$

c) Mês de Março:

$$
\begin{aligned}
& H=Q_{0}\left(0,00262+0,19140 \frac{n}{N}+0,04269 \sqrt{e_{a}}\right) \\
& r^{2}=0,9981 \text { e } C V=0,21 \%
\end{aligned}
$$

d) Mês de Abril:

$$
\begin{aligned}
& H=Q_{0}\left(-0,01765+0,13493 \frac{\mathrm{n}}{\mathrm{N}}+0,04913 \sqrt{\mathrm{e}_{a}}\right) \\
& r^{2}=0,9959 \text { e } C V=0,35 \%
\end{aligned}
$$

e) Mês de Maio:

$$
\begin{aligned}
& H=Q_{0}\left(-0,04299+0,07193 \frac{n}{N}+0,05565 \sqrt{e_{a}}\right) \\
& r^{2}=0,9836 \text { e CV }=0,72 \%
\end{aligned}
$$


f) Mês de Junho:

$$
\begin{aligned}
& H=00\left(-0,03504+0,01839 \frac{n}{N}+0,05431 \sqrt{e_{a}}\right) \\
& r^{2}=0,9552 \text { e } C V=1,25 \%
\end{aligned}
$$

g) Mès de Julho:

$$
\begin{aligned}
& H=Q_{0}\left(-0,02200+0,03003 \frac{n}{N}+0,05194 \sqrt{e_{a}}\right) \\
& r^{2}=0,9719 \text { e } C V=0,92 \%
\end{aligned}
$$

h) Mês de Agosto:

$$
\begin{aligned}
& H=00\left(0,03941+0,08186 \frac{n}{N}+0,03673 \sqrt{e_{a}}\right) \\
& r^{2}=0,9721 \text { e } \quad C V=0,56 \%
\end{aligned}
$$

i) Mès de Setembro:

$$
\begin{aligned}
& H=Q_{0}\left(0,06758+0,14559 \frac{n}{N}+0,02937 \sqrt{e_{a}}\right) \\
& r^{2}=0,9937 \text { e } \quad C V=0,51 \%
\end{aligned}
$$

j) Mès de Outubro:

$$
\begin{aligned}
& H=Q_{0}\left(0,06600+0,18071 \frac{\mathrm{n}}{\mathrm{N}}+0,03045 \sqrt{\mathrm{e}_{a}}\right) \\
& r^{2}=0,9976 \text { e } C V=0,32 \%
\end{aligned}
$$

1) Mês de Novembro:

$$
\begin{aligned}
& H=Q_{0}\left(0,05564+0,19818 \frac{n}{N}+0,03355 \sqrt{e_{a}}\right) \\
& r^{2}=0,9987 \text { e } \quad C V=0,19 \%
\end{aligned}
$$

m) Mès de Dezembro:

$$
\begin{aligned}
& H=00\left(0,05547+0,21068 \frac{n}{N}+0,03263 \sqrt{e_{a}}\right) \\
& r^{2}=0,9987 \text { e } \quad C V=0,17 \%
\end{aligned}
$$

Onde, $H$ é expresso em mm de evaporação equivalente por dia;

$$
\text { Qo,também expresso em } \mathrm{mm} / \mathrm{dia} \text {; }
$$

e , expresso em mmHg

Como podemos observar, os coeficientes de determinação, $r^{2}$, que nos dão o grau de relacionamento entre as vá 
riāveis estudadas, foi bastante elevado. Os coeficientes de va riação, CV, que nos dão a idéia das dispersões entre as variáveis estudadas, foi menor do que $1 \%$, indicando um bom ajustamento e homogeneidade dos dados (variāveis). Também foi real i zada anālise de variância entre os parâmetros das equações (a, $b^{\prime}$ e $\left.b^{\prime \prime}\right)$, através do teste $F$ e $t$, os quais deram para todos os meses, altamente significativos, ao nível menor do que $1 \%$. Verificou-se que a variāvel independente de maior importância na equação de regressão mūltipla, foi a razão de insolação para os meses de janeiro, fevereiro, março, abril, agosto, setembro, outubro, novembro e dezembro, isto é, para os períodos de primavera e verão. Para os meses de maio, junho e julho, período outono-inverno, a maior contribuição foi devido a pressão atual de vapor $\left(e_{-a}\right)$. Isso deveu-se ao fato que, nessa região, nos meses de outono e inverno, em muitosanos, a razão de insola ção apresentou-se elevada e, no entanto, o balanço de energia (H), baixo. Isso, de certa forma pode ser explicado devido à temperatura, nesses períodos do ano, estar com valores relativamente baixos e como o balanço de energia do meio è fünção, também, da capacidade de retenção de energia no ambiente, expresso pela pressão atual de vapor $\left(e_{a}\right)$, função da temperatura, perde grande parte de sua energia para o espaço. Essa explica ção pode ser visualizada na equação geral de estimativa de (H), dada por PENMAN (1948).

As equações que definem o termo "Energia", expressas em termos mensais, poderiam ser agrupadas nos meses em 
que as mesmas fossem mais semelhantes, sem grande perda de pre cisão, como os meses de janeiro, fevereiro, novembro e dezembro. Ou de outra forma, utilizando a metodologia de VILLA NOVA e OMETTO (1981), agrupá-las em meses de primavera-verão e outono-inverno. Entretanto, como podemos notar, os meses de ou tono-inverno, principalmente, diferem bastante, no que tange ao elemento pressão atual de vapor ( $\left.{ }_{a}\right)$. E, como neste trabalho u tilizou-se de computação eletrônica, optamos pelo uso das equa ções mensais individualmente.

4.3.2. Simplificação do Termo Aerodinâmico

Para a simplificação do termo aerodinâmico $(\gamma / \Delta+\gamma \cdot E a)$, utilizou-se da evaporação de "Piche", relacionandoos através do fator $\beta$, como ficou demonstrado pela equação (20), eliminando o parâmetro de vento. Dessa forma, obteve-se valores mensais do fator $\beta$ para a série de 26 anos estudados. Nos meses da série, os quais não haviam dados; ao todo 23 meses, deixou-se de calculá-los. De posse dos diversos valores do fa tor $\beta$, para cada mês do calendārio, procedeu-se a determinação da sua média mensal $(\bar{\beta})$, desvio padrão (סP) e coeficiente de va riação (CV). A Tabela 6 apresenta os diversos valores de $\bar{\beta}$ men sal e anual, DP e CV, determinados. Devido aos valores do fator $\beta$ serem bastante semelhantes entre os meses, obteve-se um válor médio anual de 0,41 , com DP entre os meses de 0,0182 e CV de 4,45\%. Na Tabela 6 , podemos observar que o coeficiente de variação, oscila de médio a alto, em termos de operação agrí- 
75 .

Tabela 6 - Valores do fator $\beta$, para cada mês e ano, seus desvios padrões (DP), coeficientes de variação(CV\%) e namero de meses ou anos utilizados. (N).

\begin{tabular}{lcccc}
\hline \multicolumn{1}{c}{ Mês } & $\bar{\beta}$ & DP & CV $(\%)$ & $N$ \\
\hline Janeiro & 0,3873 & 0,0787 & 20,33 & 24 \\
Fevereiro & 0,4089 & 0,0936 & 22,88 & 25 \\
Março & 0,4038 & 0,0692 & 17,14 & 24 \\
Abril & 0,4070 & 0,0968 & 23,79 & 25 \\
Maio & 0,3893 & 0,0882 & 22,64 & 23 \\
Junho & 0,3945 & 0,0904 & 22,92 & 25 \\
Julho & 0,4072 & 0,0933 & 22,91 & 25 \\
Agosto & 0,4003 & 0,0938 & 23,43 & 24 \\
Setembro & 0,4100 & 0,0915 & 22,30 & 24 \\
Outubro & 0,4289 & 0,0884 & 20,62 & 23 \\
Novembro & 0,4201 & 0,0860 & 20,47 & 25 \\
Dezembro & 0,4532 & 0,0865 & 19,08 & 22 \\
Anual: & 0,4100 & 0,088 & 21,54 & 24 \\
Média & 0,0182 & & & \\
DP & $4,45 \%$ & & & \\
CV & 12 & & & \\
N & & & & \\
\hline
\end{tabular}


cola, nos vários meses (PIMENTEL GOMES, 1978). Com tais resultados, inicialmente pensou-se que o termo aerodinâmíco não se relacionava bem com a evaporação de "Piche". Posteriormente, ve rificou-se que muitos dados meteorológicos relativos ao elemen to vento foram superestimados ou subestimados. 0 elemento ven to, como sabemos, é fator fundamental na determinação do termo aerodinâmico da Equação de PENMAN (1948). Portanto, qualquer médida mal feita desse elemento causará estimativas errôneas do termo aerodinâmico. Acreditamos piamente que as medidas efetuadas de velocidade do vento foram os elementos causadores dos altos índices encontrados nos coeficientes de variação, ao invés da evaporação de "Piche", por duas razões fundamentais: a) Os valores da velocidade do vento foram obtidos na estação meteorológica de Laguna-SC, através de Anemômetro de Deflexão (Wild), pela média de três leituras diārias, das 9:00; 15:00 e 21:00 horas. Ora, este aparelho apenas nos dá uma estimativa da velocidade do vento e médias diārias a partir dessás três leituras é uma medida bastante grosseira, sem considerar que o a nemômetro encontrava-se à 10 metros de altura. Além de que, paa ra cada observador, estimativas da velocidade do vento diferen tes poderão ser obtidas.

b) Através de um teste de homogeñeidade,"Run-Test"(THOM, 1966), ou seja, de teste não paramétrico de sequências, pudemos verificar que o elemento velocidade do vento não possuia seus dados homogenéos, enquanto que os dados de evaporação "piche" o eram. 
Assim, adotamos um critério para melhorar a esti mativa do fator $\beta$. Admitiu-se uma variância em torno da média anual de $20 \%$ para $\beta$ e eliminou-se todos os meses em que observou-se valores extremos à esta consideração. Sendo o Fator $\beta$ médio anual igual a 0,41 e variấcia de $20 \%$, ou seja, $\pm 0,082$, to dos os valores de $\beta$ menores do que 0,328 e maiores do que:0,492, foram eliminados. Assim, elimininou-se possíveis medidas errô neas de velocidade do vento como também da evaporação "piche", que por ventura tivessem sido cometidas. Com esse procedimento, obteve-se novos valores médios do fator $\beta$ para cada mês e ano, conforme é relacionado na Tabela 7 .

os novos valores de $\beta$, como podemos verificar, possuem uma semelhança muito grande entre os meses do ano e, desta forma, adotamos o valor médio anual aproximado de 0,41 como valor representante do fator $\beta$ para todos os meses. 0s coe ficientes de variação ficaram entre os limites de 10 a 20 , is to é, valores médios compatíveis com trabalhos dessa natureza. Procedeu-se também estudos de correlação, através da anâlise de reğressão linear, entre o termo aerodinâmico e a evaporação "Piche", à semelhança de trabalhos conduzidos por STANHILL (1962). Entretanto, devido as falhas da obtenção da velocidade do vento, a correlação deixou muito a desejar. Assim sendo, não transcrevemos aqui seus resul tados. 
Tabela 7 - Valores do fator $\beta$ corrigidos, para cada mês e ano, seus desvios padrões (DP), coeficientes de variação (CV\%) e nūmero de meses ou anos utilizados (N).

\begin{tabular}{|c|c|c|c|c|}
\hline Mês & $\bar{B}$ & DP & CV $(\%)$ & $\mathrm{N}$ \\
\hline Jane i ro & 0,4050 & 0,045 & 12,51 & 19 \\
\hline Fevereiro & 0,4175 & 0,050 & 11,99 & 19 \\
\hline Março & 0,4174 & 0,045 & 10,81 & 20 \\
\hline Abril & 0,4082 & 0,066 & 16,27 & 16 \\
\hline Maio. & 0,4100 & 0,046 & 11,27 & 13 \\
\hline Junho & 0,4116 & 0,041 & 9,94 & 14 \\
\hline Julho & 0,4167 & 0,046 & 11,10 & 15 \\
\hline Agos to & 0,4073 & 0,054 & 13,32 & 14 \\
\hline Setembro & 0,4068 & 0,053 & 13,16 & 17 \\
\hline Outubro & 0,4054 & 0,056 & 13,75 & 16 \\
\hline Novembro & 0,4135 & 0,053 & 12,80 & 16 \\
\hline Dezembro & 0,4407 & 0,045 & 10,30 & 18 \\
\hline \multicolumn{5}{|l|}{ Anual: } \\
\hline Média & 0,413115 & & & \\
\hline$D P$ & $9,95 \times 10^{-3}$ & 0,051 & 12,27 & 16,4 \\
\hline cV & $2,41 \%$ & & & \\
\hline $\mathrm{N}$ & 12 & & & \\
\hline
\end{tabular}


4.3.3. A Equação Simplificada de PENMAN

Através da junção dos resultados obtidos na esti mativa do termo "Energia" e "Aerodinâmico" dos itens anteriores, pudemos construir a equação simplificada de PENMAN para cada mês do calendário e para o local de estudo.

Assim:

a) Mês de Janeiro:

$$
E T P=\frac{\Delta}{\Delta+\gamma} Q 0\left(0,04427+0,22013 \frac{n}{N}+0,03380 \sqrt{e_{a}}\right)+0,41 E P
$$

b) Mês de Fevereiro:

$$
E T P=\frac{\Delta}{\Delta+\gamma} Q 0\left(0,04033+0,2084 \frac{\mathrm{n}}{\mathrm{N}}+0,03461 \sqrt{\mathrm{e}_{\mathrm{a}}}\right)+0,41 \mathrm{EP}
$$

c) Mês de Março:

$$
E T P=\frac{\Delta}{\Delta+\gamma} Q 0\left(0,00262+0,19140 \frac{\mathrm{n}}{\mathrm{N}}+0,04269 \sqrt{\mathrm{e}_{a}}\right)+0,41 E p
$$

d) Mès de Abril:

$$
E T P=\frac{\Delta}{\Delta+\gamma} Q_{0}\left(-0,01765+0,13493 \frac{\mathrm{n}}{\mathrm{N}}+0,04913 \sqrt{\mathrm{e}}_{\mathrm{a}}\right)+0,41 \mathrm{EP}
$$

e) Mês de Maio:

$$
E T P=\frac{\Delta}{\Delta+\gamma} Q O\left(-0,04299+0,07193 \frac{n}{N}+0,05565 \sqrt{e_{a}}\right)+0,41 E p
$$

f) Mês de Junho:

$$
E T P=\frac{\Delta}{\Delta+\gamma} Q 0\left(-0,03504+0,01839 \frac{n}{N}+0,05431 \sqrt{e_{a}}\right)+0,41 E p
$$

g) Mês de Julho:

$$
E P T=\frac{\Delta}{\Delta+\gamma} Q O\left(-0,02200+0,03003 \frac{n}{N}+0,05194 \sqrt{e_{a}}\right)+0,41 E P
$$

h) Mês de Agosto:

$$
E T P=\frac{\Delta}{\Delta+\gamma} Q_{0}\left(0,03941+0,08181 \frac{n}{N}+0,03673 \sqrt{e_{a}}\right)+0,41 E P
$$


80 .

i) Mès de Setembro:

$$
E T P=\frac{\gamma}{\Delta+\gamma} Q 0\left(0,06758+0,14559 \frac{n}{N}+0,02937 \sqrt{e_{a}}\right)+0,41 E P
$$

j) Mês de Outubro:

$$
E T P=\frac{\Delta}{\Delta+\gamma} Q_{0}\left(0,06600+0,18071 \frac{n}{N}+0,03045 \sqrt{e_{a}}\right)+0,41 E p
$$

1) Mês de Novembro:

$$
E T P=\frac{\gamma}{\Delta+\gamma} Q_{0}\left(0,05564+0,19818 \frac{n}{N}+0,03355 \sqrt{e_{a}}\right)+0,41 E P
$$

m) Mês de Dezembro:

$$
E T P=\frac{\gamma}{\Delta+\gamma} Q_{0}\left(0,05547+0,21068 \frac{n}{N}+0,03263 \sqrt{e_{a}}\right)+0,41 E P
$$

Onde:

$\Delta=$ tangente à curva de saturação, função da temperatura média mensal $\left(\mathrm{mmHg}^{\circ} \mathrm{C}\right)$, definida pela expressão (10)

$\gamma=$ constante psicrométrica, aproximadamente, $0,6 \mathrm{mmHg} /{ }^{\circ} \mathrm{C}(\mathrm{Ps} \underline{\mathbf{i}}$ crômetro Comum);

Qo = radiação extra-terrestre em mm/dia, função do mês e latitude (tabela da FAO-1979);

$\frac{n}{N}=$ razão de insolação;

n = insolação mensal observada no Heliógrafo da estação meteo rológica, em horas e décimos;

$N$ = insolação ou brilho solar teōrico māximo, função da época do ano(mês) e latitude. (valores tabelados-FAO, 1979);

$e_{a}=$ pressão atual de vapor d'ägua média mensal em mmHg calculada pela expressão: $e_{a}=\frac{U R \% . e_{a}}{100}$ (mensal);

$e_{S}=$ pressão de saturação do vapor d'água, função da temperatü ra média mensal; 
UR\% = umidade relativa média mensal em percentagem;

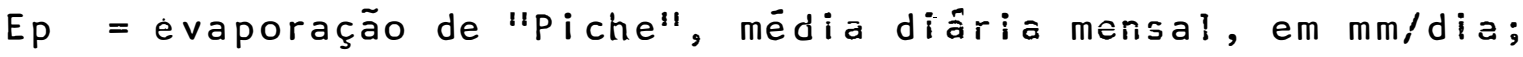

ETP = evapotranspiração potencial mêdia diāria de cada mês, em milimetros de evaporação equivalente (mm/dia).

Pelo intermédio das equações de (34) a (45), cal culou-se a ETP média diāria para cada mês do calendário e para cada ano da série de 26 anos, sendo tais valores utilizados no cômputo do balanço hídrico modificado (BHM). Apenas, como já nos referimos, em 23 meses da série, por falta de informações meteorológicas, usou-se a média normal da ETP para o mês correspondente.

Calculou-se, também, a ETP média diāria para cada mês da série pela equação original de PENMAN (1948) e compa rou-se seus valores com os do método simplificado atrav̄és de anālise de regressão entre os meses de cada ano estudado. Na Tabela 8, estão representados os diversos valores de ETP obti dos pelos dois sistemas com os parámetros a e e regressão linear, os coeficientes de determinação $\left(r^{2}\right)$ e teste $t$, para os 26 anos da sêrie. Podemos observar que os coeficien tes de determinação foram bastante elevados, bem como os testes t aplicados deram significativos ao nível de $1 \%$, com excessão de apenas um ano (1978), por insuficiência de dados, infor mando-nos do bom ajustamento entre os valores obtidos pelos dois métodos de estimativa da ETP. Nos meses em que a estimati va da ETP obtida por um método ou outro deram valores um pouco divergentes, com ênfase nos meses do outono e inverno, de- 
veu-se ao fato da obtenção errônea da velocidade do vento, fator de grande peso na estimativa do termo aerodinâmico da equação de PENMAN. 0 valor médio do coeficiente de determinação $\left(r^{2}\right)$ para a série toda foi de $99,06 \%$, com coeficiente de variação (CV) de $0,61 \%$, resultados esses bastante bons.

4.4. Contabiliżąão dos"Dias Secos Consecutivos"

Para cada capacidade de āgua disponível māxima(CAD) dos solos adotada, foram obtidas tabelas, num total de 220. Em função do grande número dessas tabelas, elas não foram relacionadas nesse trabalho, fazendo-se constar, no apèndice, somente aquelas referentes a $50 \mathrm{~mm}$ de àgua disponível, como exemplificação e para maior facilidade de compreensão do traba1ho. Assim, como podemos verificar pelas tabelas do apêndice pạ ra $50 \mathrm{~mm}$ de CAD, foram obtidas as seguintes relações:

a) Totais de dias secos por quinzena, mês, trimestre, semestre e ano, nos 26 anos, para $50 \mathrm{~mm}$ de capacidade de ägua disponível māxima no solo-CAD. Assim, por exemplo para o ano de 1955 , 1. quinzena do mês de Janeiro, ocorreram 8 dias secos, na $2^{a}$, 15 dias secos e no mês 23. 0 total de dias secos ocorridos no 19. trimestre, correspondeu a soma dos valores dos meses de janeiro, fevereiro e março, ou seja, $23+18+10=51$ dias secos, e assim por diante (Apêndice 1). Nessa tabela, pode-se observar quais os períodos de maior "stress" hídrico, atravēs da somatō ria total e médias de dias secos por períodos estudados. Dessa forma, os trimestres mais secos por ordem de ocorrência foram: 


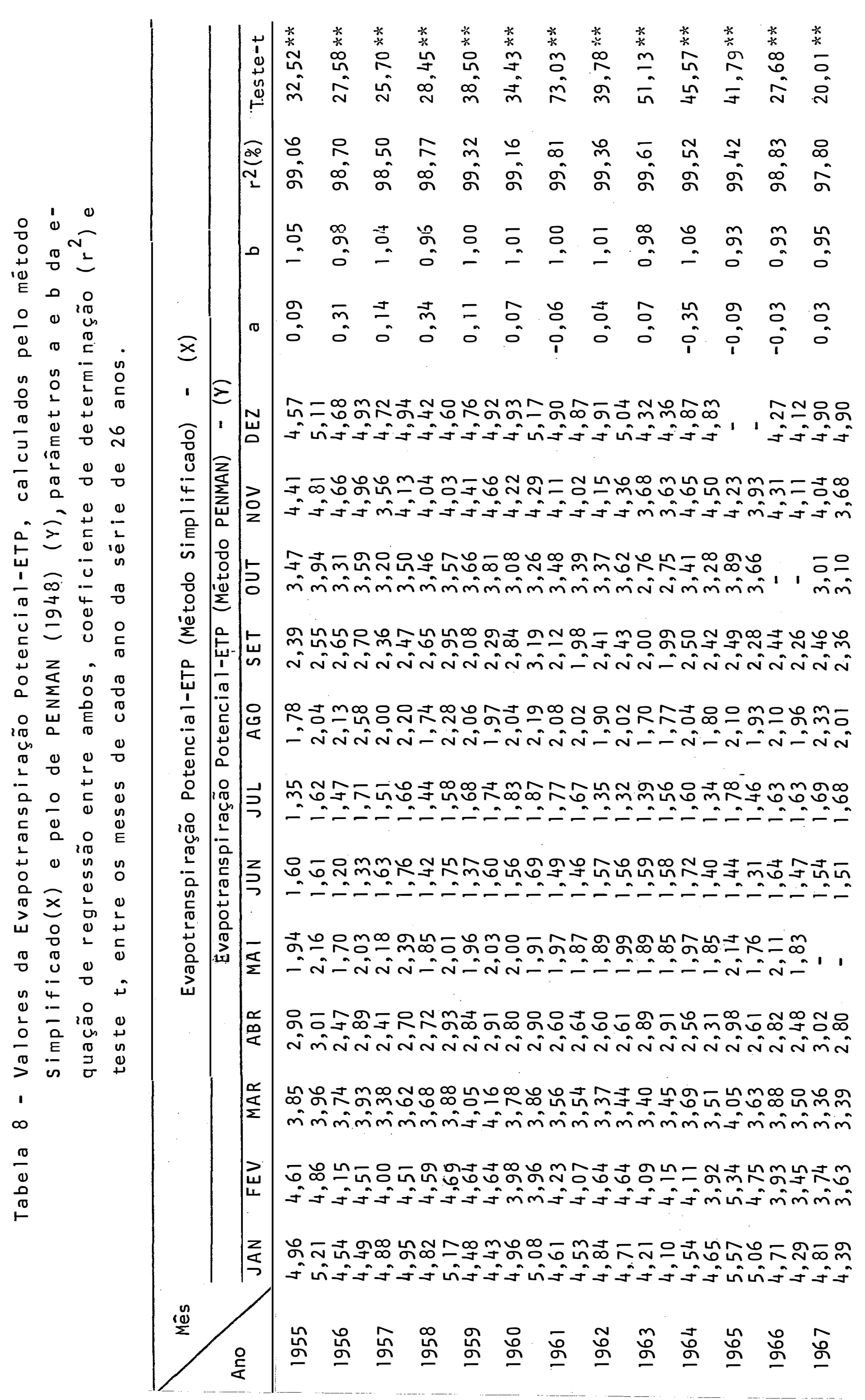




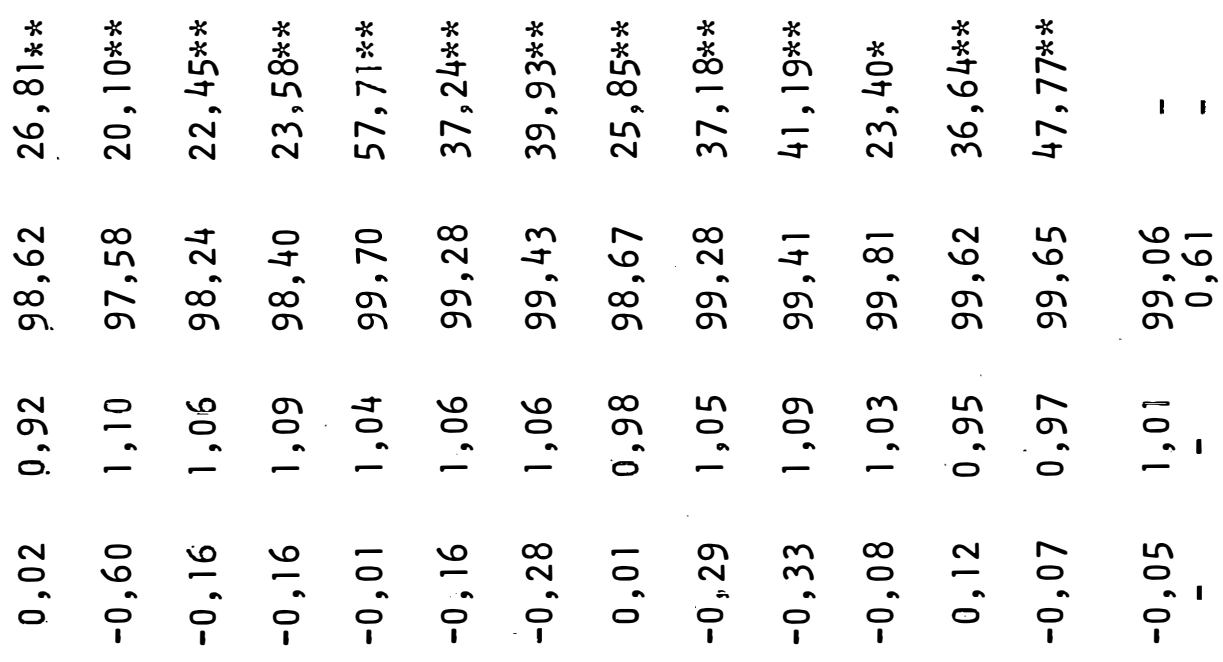

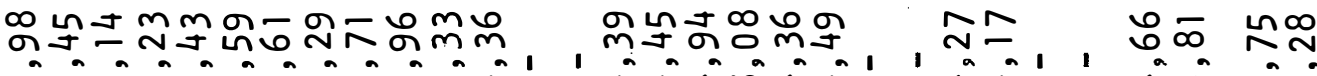

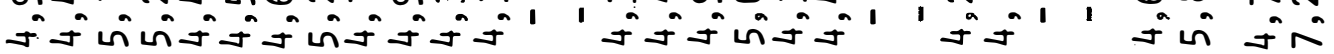

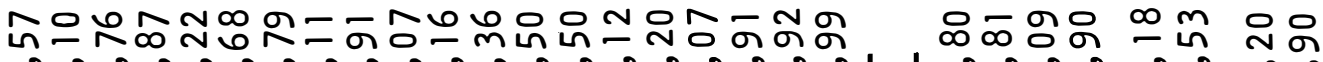

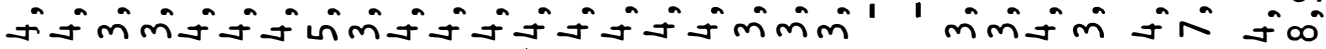

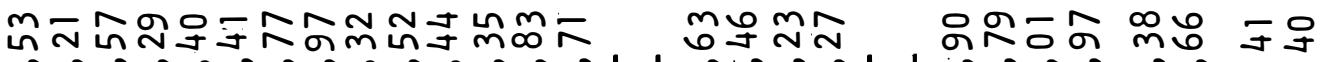

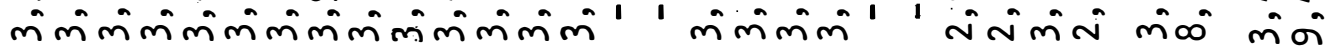

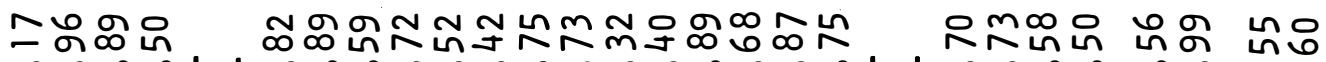

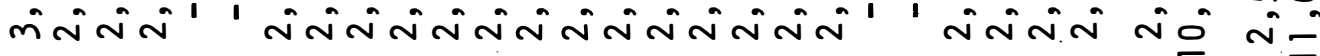

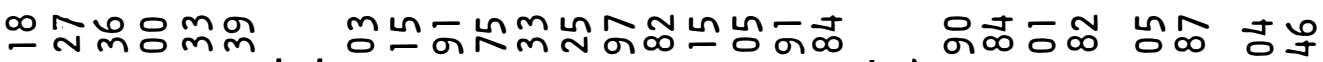

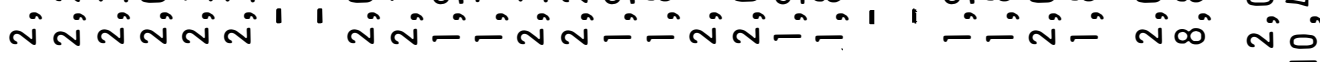

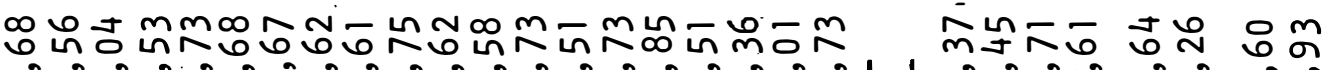

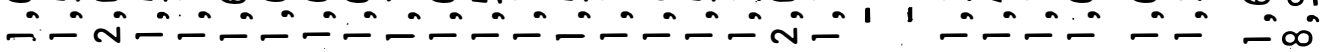

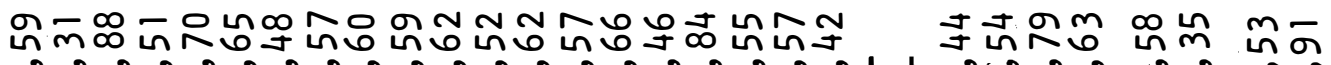

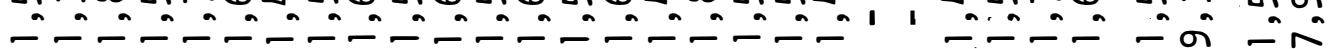

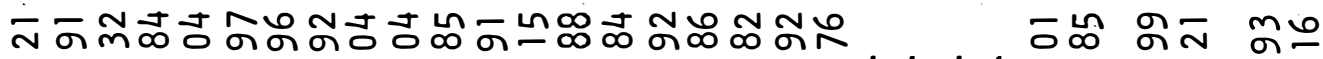

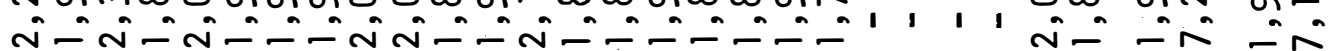

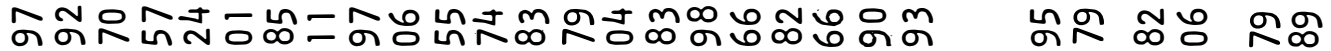

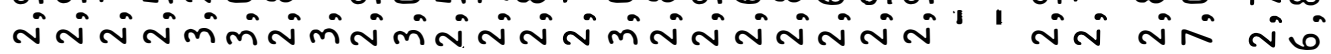

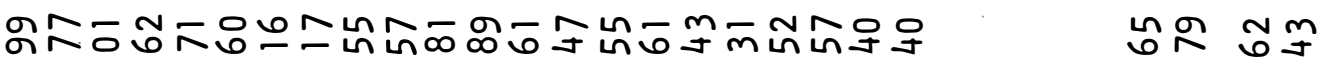

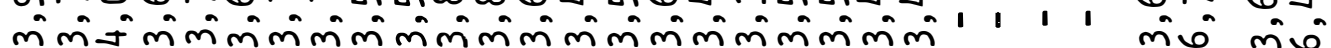

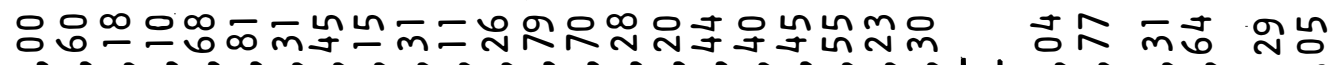

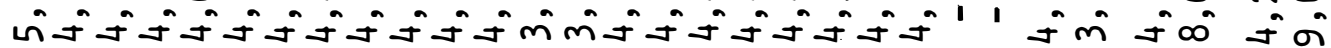

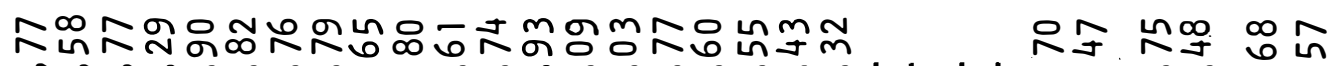

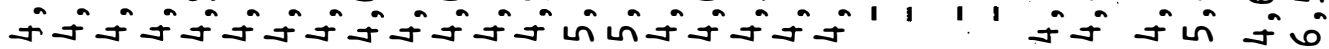


o, $4 \%, 1 \%, 2 \%$ e $3 \%$ Isto é, o $1 \%$ e $4 \%$ trimestres foram os que apresentaram maior nümero de dias secos, numa média de 41,4 e 41,3 dias respectivamente, nos 26 anos estudados. Segue-se o 2: trimestre com uma média de 18,4 e 039 com 7,7 dias secos, referentes a CAD de $50 \mathrm{~mm}$. 01 ? semestre é mais severo em ter mos de seca agronómica do que o $2 \%$

os meses mais secos correspondem aol: e 4 : trimestre do ano, bem como as suas quinzenas pertinentes. Essatabela, apêndice 1 , pode nos dar boas informações a respeito do compor tamento da marcha dos dias secos durante o ano, fornecendo sub sídios para a escolha mais adequada de épocas de plantio, necessidade de irrigação, embora apresentando apenas o total de dias secos, sem considerar se encontram-se em sequências ou não. Através da análise dessa tabela, para $50 \mathrm{~mm}$ de CAD e das demais aqui não apresentadas, pudemos concluir que os meses de maior ocorrência de dias secos totais referem-se ao 1 ? e 4\% trimestre do ano, ou seja, nos períodos de primavera-verão, embora o nümero total de dias secos para cada período diminuia à medida que a CAD aumentava.

b) Sequéncias de dias secos por quinzena de cada mês e por ano, sua duração e ordem de ocorrência para $50 \mathrm{~mm}$ de capacidade de ägua dísponível mäxima-CAD (Apêndice 2). Assim, por exemplo, a 1. quinzena do mês de janeiro do ano de 1955 apresentou'uma se quência de dias secos de 2 e 6 , isto é, ocorreram 2 períodos de dias secos consecutivos, sendo o primeiro de 2 dias secos e o segundo de 6 dias secos consecutivos. 
86.

c) Sequencias de dias secos por período mensal e por ano, sua duração e ordem de ocorrência, para $50 \mathrm{~mm}$ de CAD (Apêndice 3).A sua interpretação é semelhante ao item anterior, apenas referindo-se à período mensal.

d) Sequências de dias secos trimestrais e por ano, sua duração e ordem de ocorrência, para $50 \mathrm{~mm}$ de CAD (Apêndice 4). A inter pretação é semelhante ao item (c). Nessa tabela, podemos também verificar que o maior número de sequências e em períodos maiores encontram-se no 19 e 4 ? trimestre, destacando-se uma vez mais como os períodos mais secos do ano.

e) Dias secos consecutivos agrupados nas classes de zero, 1-2, $3-4,5-6,7-8,9-10,11-12,13-14$ e 15-16 suas frequências ab solutas, frequências relativas, frequências acumuladas complementares em percentagem e probabilidade linear, nos 26 anos,pa ra $50 \mathrm{~mm}$ de CAD (Apêndice 5). Essas tabelas, à exemplo do apenn dice 5, foram obtidas com a finalidade de se determinar o núme ro minimo de dias secos consecutivos que se espera ocorrer, a um dado nível de probabilidade, em cada quinzena do mês correspondente, e para cada quantidade de água disponível'. Ou de outra forma, qual a probabilidade de ocorrer, em cada quinzena do mês e para cada capacidade de água disponível máxima-CAD,um nümero mínimo de dias secos consecutivos, dado pelo limite in ferior de cada classe. Nas tabelas do apendice 5, podemos verificar que a somatória das frequências absolutas de todas as classes sempre foi igual a 26, correspondendo a série de 26 anos estudada. Dessa feita, uma determinada quinzena de um mês 
e ano qualquer, só foi contabilizada apenas uma sequência de dias secos, embora o periodo pudesse apresentar mais do que uma. Assim, foi computado em uma das 9 classes, conforme o número de dias secos, apenas a sua maior sequência. Mesmo que a quinzena apresentasse duas ou mais sequências máximas só foi contada uma vez. Adotando-se, como exemplificação, a $l^{a}$. quinzena do mês de janeiro, Apêndice 5, obteve-se uma frequên cia absoluta de 3 para a classe de $1-2$, significando que dos 26 janeiros, na 1 ? quinzena ocorreu pelo menos trêssequências de dias secos consecutivos nesta classe. Ou de outra forma po demos dizer que em 3 primeiras quinzenas do mês de janeiro ti veram de 1 a 2 dias secos como a ou as maiores sequências. Po demos ainda dizer que em 3 dos 26 janeiros, na la quinzena, correu pelo menos uma sequência máxima de 1 a 2 dias secos. Observa-se ainda que, nessa mesma coluná, que 3 dos 26 anos apresentaram zero dias secos. Na coluna das frequências relativas, expressas em \%, no mesmo exemplo, encontra-se que $11,54 \%$ dos janeiros, na 1 a quinzena não tiveram dias secos, outros $11,54 \%$ tiveram pelo menos uma sequência máxima com 1 a 2 dias secos; $3,85 \%$ tiveram pelo menos uma sequência máxima na classe de 3 a 4 dias secos e dessa forma para as demais classes. Em termos de probabilidade pode-se dizer que para um número grande de janeiros, na 1 a quinzena, espera-se que $11,54 \%$ deles não ocorra dia seco; em outros, $11,54 \%$ ocorra pelo menos uma sequência máxima de 1 a 2 dias secos; em outros, ain da, que $3,85 \%$ tenha pelo menos uma sequência máxima com 3 a 
4 dias secos, e assim sucessivamente para as demais classes. No mesmo exemplo, ainda, a terceira coluna apresenta as frequências acumuladas complementares, ou seja, se em $11,54 \%$ dos janeiros, na la quinzena, não ocorreu dia seco, então, em $100-$ $-11,54=88,46 \%$ dos janeiros, na 1 ? quinzena, ocorreram 1 (um) ou mais dias secos consecutivos ou no mínimo l(um) dia seco; como em outros $11,54 \%$ dos janeiros, na l. quinzena, ocorrem pelo menos uma sequência de 1 a 3 dias secos, temos que, em 88,46$-11,54=76,92 \%$ dos 26 janeiros, na 1 : quinzena, tiveram sequências maiores ou igual a 3 dias secos. Da mesma forma para as demais classes. Podemos dizer, tambēm, em termos de probabi lidade que há $11,54 \%$ de probabilidade empírica de não ocorrer dia seco, ou, há $100-11,54=88,46 \%$ de probabilidade empírica de ocorrer um ou mais dias secos consecutivos, ou de ocorrer no mínimo l (um) dia seco. Ainda, hä $88,46-11,54=76,92 \%$ de probabilidade empírica de ocorrer 3 ou mais dias secos consecutivos, ou no mínimo 3 dias secos consecutivos. Desta forma, a frequência acumulada complementar, tambēm chamada de probabi lidade empírica expressa a ..condição de ocorrer um certo número de dias secos consecutivos, não ocorrer, ou simplesmente ocorrem um nümero mínimo de dias secos consecutivos, dado pelo limite inferior de sua classe. Assim, para o exemplo citado, temos que: $88,46 \%$ de probabilidade empírica de ocorrer, pelo menos uma vez, no mínimo 1 dia seco consecutivo; $76,92 \%$ de pro babilidade empírica de ocorrer, pelo menos uma vez, no mínimo 3 dias secos consecutivos; $73,92 \%$ de probabilidade empírica de 
ocorrer, pelo menos uma vez, no minimo 5 dias secos consecutivos; e assim sucessivamente para as demais classes. Existe ain da, uma ültima coluna da mesma tabela onde aparece a probabil $\underline{\mathbf{i}}$ dade linear, a qual será devidamente esclarecida em considerações posteriores.

f) Maiores sequências de dias secos em cada mês, distribuídos nas classes zero, 1-3, 4-6,7-9, 10-12,13-15, 16-18, 19-21, 22-24, 25-27 e 28-31, suas frequências absolutas, frequências relativas, frequências acumuladas complementares em \% ou proba bi lidade empírica e probabilidade linear, nos 26 anos, para 50 $\mathrm{mm}$ de CAD (Apēndice 6). A interpretação das tabelas desse Apêndice são idênticas às do Apêndice 5, apenas que o período estudado é mensal.

g) Maiores sequências de dias secos em cada trimestre, distribuidas nas classes zero, 11-19, 20-28, 29-37, 38-46, 47-55, 56$-64,65-73,74-83$ e 84-92, suas frequências absolutas, frequên cias relativas, frequências acumuladas em \% ou probabilidade em pírica e probabilidade linear, nos 26 anos, para $50 \mathrm{~mm}$ de CAD (Apêndice 7). Sua interpretação é semelhante à do item (e), apenas mudando o período estudado.

4.5. Sequèncias de Dias Secos por Períodos Anuais, Trimestrais, Mensais e Quinzenais

Nas contagens dos períodos de dias secos consecutivos por quinzenas, meses, trimestres e anos, obviamente, o número total de dias secos encontrado é sempre o mesmo. En- 
tretanto, o nümero de sequências ou períodos de dias secos con secutivos é diferente. Tanto quanto menor o período de contagem, tanto maior serā o número de divisões em duas ou mais sequências menores. Dessa forma, na contagem por período quinze nal ou mensal, todas as sequências maiores do que o nūmero de dias do período considerado, serão divididas, no mínimo, em duas outras menores, assim como todas as sequências que começam em uma quinzena ou mês e terminam em período seguinte. Isso pode ser observado, analisando-se as tabelas do Apéndice 2, 3 e 4 . Comparando-se as contagens por mês e trimestre (Apêndice 7) podemos verificar que mais de $85 \%$ das sequências são menores do que 38 dias, considerando os trimestres mais secos. Essa conclusão pode ser generalizada para as demais CAD estuda das, aqui não transcritas. Dessa fórma, com mais ênfase ainda, comparação de contagens entre trimestres e ano, tornam-se sem sentido, além do fato que, em períodos anuais, a sua contagem nada informar sobre a ocorrência da sequência de dias secos, se no início, no meio ou no final do ano. Conclusão idêntica foi encontrada por SCARDUA (1979), admitindo ainda que é conveniente fazer-se a contagem de dias secos consecutivos de, no máximo três meses, mesmo em regiões com precipitação anual mal distribuida e escassa. Em locais onde a precipitação anual tem uma melhor distribuição, as sequências de dias secos tendem a ser menores. Consequentemente, o erro que se comete quan to as frequências e duração dos períodos de dias secos consecu tivos também tende a ser menor, em contagens por períodos me- 
nores, como um mês ou menos. Estudando a ocorrência de dias se cos consecutivos por períodos maiores como um trimestre ou mais, ganha-se em imformação quanto as ocorrências das maiores sequên cias e consequentemente de sua severidade. Entretanto, perdese muito de informações se a sequência ocorreu no inicio, no meio ou no final do trimestre.e, para a agricultura, importa- se saber a ocorrência das sequências em períodos pequenos co mo uma quinzena ou mês, como forma de se proporcionar em melhor planejamento agrícola.

Assim sendo, optamos por analisar a ocorrência de dias secos consecutivos por períodos quinzenais, mensais e trimestrais, julgando que o estudo dessa forma possa oferecer todas as informações necessārias para um melhor planejamento das operações agrícolas.

Observou-se, também, através da anālise das Tabelas do Apêndice e mais aquelas aqui não inseridas para as demais CADs, que a medida que diminuia o valor da CAD do solo, aumentava o nủnero de dias secos totais. Isso decorre do fato que, para menores capacidades de armazenamento de àgua no solo, mais rapidamente é esgotada pela demanda atmosférica, verifica ção esta jā esperada.

Entretanto, as sequências de dias secos tornaram-se em menor nümero, mas de maior período de duração, à medi da que a capacidade de água do solo aumentava. Isso também po de ser explicado pelo fato que, quanto maior a CAD, maior o va lor do seu Armazenamento Crítico $[(1-P) C A D]$ e, consequentemen- 
te, as precipitações deverão ser de maior magnitude para poder suprir todo o seu reservatório.

4.6. Probabilidade Teórica de Ocorrência de um "Nümero Míni mo de Dias Secos Consecutivos"por Período Quinzenal, Mensal e Trimestral

Em trabalhos conduzidos por MORETI (1965) com nūmero mínimo de dias secos mensais, sem considerar se sua ocorrênci a veri ficou-se em dias isolados ou nãoepor SCARDUA(1979), com número de días secos consecutivos por períodos mensais, ve rificaram que as probabilidades empíricas ou frequências acumuladas complementares em \% ajustaram-se bem à curva de dis trịuição normal. Nesse trabalho, estudamos a distribuição da variável número mínimo de dias secos consecutivos por períodos quinzenais, mensais e trimestrais, aplicando um teste. simples para ver se tambēm havia um bom ajustamento com a cürva normal, os periodos quinzenais, mensais e trimestrais, já que a sērie estudada era de apenas 26 anos. 0 teste aplicado, foi o mesmo utilizado por SCARDUA (1979). Baseia-se no fato em que, a curva normal se transforma numa reta quando traçada em papel de probabilidade. Assim quanto mais perfeito o ajustamento da di tribuição da probabilidade empírica de uma variável na curva normal, melhor se ajusta, segundo o alinhamento de uma reta, o conjunto dos pontos marcados em papel de probabilidade.

Para melhor fixação e entendimento do procedimen to, adotado, exemplificaremos, utilizando-se o Apēndice 5, e a 
Tabela referente ao mês de Janeiro, lä quinzena, para $50 \mathrm{~mm}$ de $C A D$, teremos:

a) Por intermédio da utilização do papel de probabilidade e u ma régua milimetrada, junto e paralela ao eixo das ordenadas do papel, como indica a Figura 9, foram obtidas, na escala linear da régua, os valores equivalentes aos das probabilidades de ocorrência dos números mínimos de dias secos consecutivos, dado pelo limite inferior de cada classe. Esses valores assim obti dos, denominados de probabilidade linear ( $P L)$, e mais os números mínimos de dias secos consecutivos correspondentes, formaram um novo conjunto de pares de valores. Como podemos acompanihar pelo Apêndice 5, para o mês de janeiro, 1. quinzena, e 50 mm de CAD, os valores das Frequéncias acumuladas complementares em \% ou probabilidade empírica (P) e os correspondentes valores de probabilidade linear ( $P L)$ e dos nümeros mínimos de dias secos consecutivos (D), foram:

$\begin{array}{ccc}\frac{D}{1} & \frac{P L}{P} & \frac{P}{88,46} \\ 3 & 12,88 & 76,92 \\ 5 & 11,18 & 73,07 \\ 7 & 10,74 & 57,69 \\ 9 & 9,19 & 46,15 \\ 11 & 8,12 & 38,46 \\ 13 & 7,40 & 38,46 \\ 15 & 7,40 & 23,08\end{array}$

b) Se os valores de,$P L$ e $D$ se correlacionam segundo a equação de uma reta, as probabilidades empíricas dos nūmeros mínimos de dias secos consecutivos se ajustam à curva normal e seu coe 


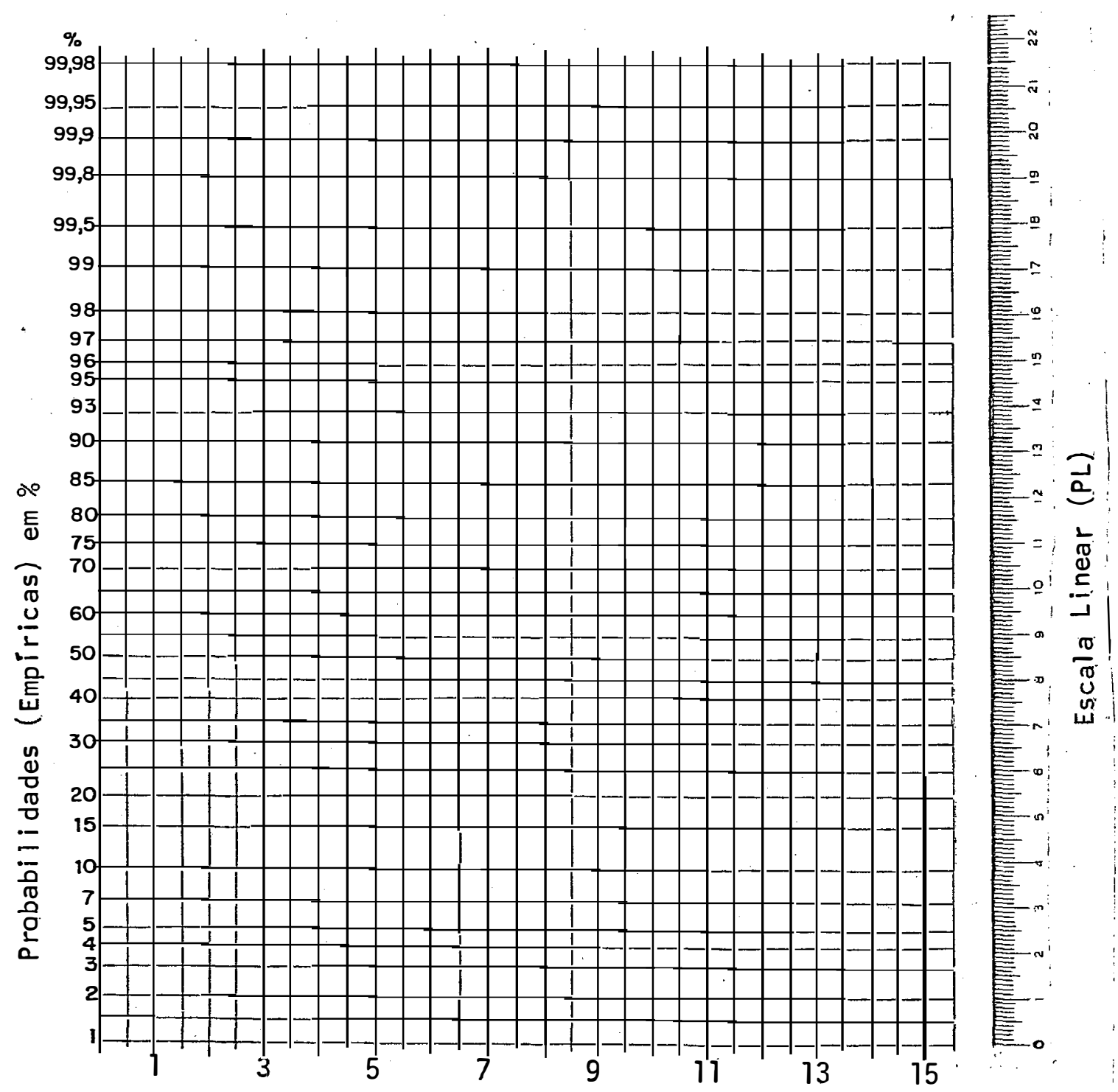

Número Mínimo de Dias Secos Consecutivos

Figura 9 - Papel de Probabilidade onde foram marcados os Números Mínimos de Dias Secos Consecutivos (abcissas) e -rsuas Probabilidades Empíricas de ocorrência (ordenada à es querda) e obtenção dos valores correspondentes às pro babilidades em escala Linear-PL(ordenada à direita). (Esse papel de Probabilidade aqui apresentado é apenas um modelo reduzido, tendo sido suprimidas suas $\mathbf{l} \underline{\mathbf{i}}$ nhas intermediārias, em relação ao original utilizado). 
ficiente de determinação $\left(r^{2}\right)$ pode ser tomado como uma medida do ajustamento das probabilidades empî́ricas dos nūmeros mínimos de dias secos consecutivos à curva normal. A equação de re gressão obtida pelo método dos mínimos quadrados e seu coeficiente de determinação, para o exemplo, foram:

$$
\begin{aligned}
& P L=12,99-0,50 \mathrm{D} \\
& r^{2}=0,98
\end{aligned}
$$

Utilizando-se a equação acima e através de dois valores para $D, D=3$ e $D=11$, obteve-se $P L=11,49$ e $P L=7,49$, res pectivamente. Aplicando o processo inverso do indicado no item a, utilizando-se da Figura 7, foram encontrados os valores das probabilidades teóricas ( $P t)$ correspondentes a esses valores de $P L$, ou seja, $P t=79,6 \%$ e $P t=39,5 \%$, respectivamente. Assim, temos para $D=3$ e $D=11$, as probabilidades teóricas ( $P t)$ de $P t=$ $=79,6 \%$ e Pt $=39,5 \%$. Através desses dois pontos de coordenadas (Pt; D) foi traçada a reta que melhor se ajusta aos pontos de probabilidade empírica marcados em papel de probabilidade, re ferentes ao mês de janeiro, primeira quinzena, para $50 \mathrm{~mm}$ de CAD, apresentado na Figura 14.

Da mesma forma, foram traçadas as retas das Figuras 10 a 19, onde o eixo das ordenadas tem-se as probabilidades teôricas de ocorrer, pelo menos uma vez, em cada quinzena e pạ ra cada CAD, os números mínimos de dias secos consecutivos indicados nas abcissas. As equações obtidas ente PL e D, foram de grande valia no traçado das retas das Figuras 10 a 19 por apenas dois pontos, evitando a necessidade de se marcar todos 
os pontos, o que é difícil de serem efetuados em gráficos redú zidos, bem como a maior precisão alcançada do traçado das retas em comparação àquelas que por ventura viessem a ser traça das a partir dos pontos marcados. Esse mesmo procedimento ado tado para a determinação das figuras de 10 a 19 foi utilizado na obtenção dos gráficos das Figuras 20 a 24 e 25 a 27 , referentes às probabilidades teóricas de ocorrer um dado número mí nimo de dias secos consecutivos, por período mensal e trimestral e para as várias CAD estudadas, respectivamente. Nas ta belas 9,10 e 11 , estão relacionados os valores dos coeficien tes de determinação $\left(r^{2}\right)$ das equações das retas referentes a cada período quinzenal, mensal e trimestrál, respectivamente e para cada CAD utilizada.

Também encontram-se relacionados os valores mëdios de $r^{2}$, Desvio Padrão da média e coeficiente de variação para cada CAD estudada e para cada período. Testou-se os coeficientes das regressões $(r)$, pelo teste-t, para todos os periodos e CADs, os quais deram todos significativos ao nível de $1 \%$.

Devido aos altos valores encontrados para o coeficiente de determinação $\left(r^{2}\right)$ achou-se desnecessārio utilizar ou tro método estatístico, mais preciso, para se testar a distrí buição normal dos dados. A partir dos grä́icos das Figuras 10 a 19, foram traçados os gráficos das figuras 28 a 32 , os quais relacionam o número mínimo de dias secos consecutivos para cada quinzena de cada mês, para cada CAD estudada, aos níveis de probabilidade teórica de $10 \%, 20 \%, 30 \%, 40 \% 50 \%, 60 \%$ e $80 \%$. Is 
Tabela 9 - Valores dos coeficientes de determinação $\left(r^{2}\right)$ das equações $\mathrm{PL}=$ $=a+b D$, onde $D$, significa o número mínimo de dias secos consecutivos observados e PL é a probabilidade empírica de ocorrência de $D$, marcada numa escala linear, probabilidade linear, paralela à escala do papel de probabilidade, para as CADs estudadas e por período quinzenal.

\begin{tabular}{|c|c|c|c|c|c|}
\hline Més/Quinz. & $18 \mathrm{~mm}$ & $38 \mathrm{~mm}$ & $50 \mathrm{~mm}$ & $100 \mathrm{~mm}$ & $175 \mathrm{~mm}$ \\
\hline $\begin{array}{l}\text { JAN }-1 \stackrel{a}{\dot{a}} \\
\text { JAN }-2 \stackrel{9}{ }\end{array}$ & $\begin{array}{l}0,94 \\
0,88\end{array}$ & $\begin{array}{l}0,98 \\
0,93\end{array}$ & $\begin{array}{l}0,98 \\
0,98\end{array}$ & $\begin{array}{l}0,97 \\
0,99\end{array}$ & $\begin{array}{l}0,99 \\
0,98\end{array}$ \\
\hline $\begin{array}{l}F E V-1 \stackrel{a}{ } \\
F E V-2 a\end{array}$ & $\begin{array}{l}0,99 \\
0,93\end{array}$ & $\begin{array}{l}0,94 \\
0,94\end{array}$ & $\begin{array}{l}0,96 \\
0,96\end{array}$ & $\begin{array}{l}0,93 \\
0,94\end{array}$ & $\begin{array}{l}0,97 \\
.0,92\end{array}$ \\
\hline $\begin{array}{l}\text { MAR }-1 \stackrel{a}{a} \\
\text { MAR }-2 a\end{array}$ & $\begin{array}{l}0,97 \\
0,98\end{array}$ & $\begin{array}{l}0,99 \\
0,95\end{array}$ & $\begin{array}{l}0,98 \\
0,98\end{array}$ & $\begin{array}{l}0,96 \\
0,95\end{array}$ & $\begin{array}{l}0,99 \\
0,98\end{array}$ \\
\hline $\begin{array}{l}A B R-1 \stackrel{a}{a} \\
A B R-2 a\end{array}$ & $\begin{array}{l}0,97 \\
0,95\end{array}$ & $\begin{array}{l}0,98 \\
0,99\end{array}$ & $\begin{array}{l}0,98 \\
0,97\end{array}$ & $\begin{array}{l}0,97 \\
0,96\end{array}$ & $\begin{array}{l}0,96 \\
0,98\end{array}$ \\
\hline $\begin{array}{l}\text { MAI }-1 \stackrel{a}{\dot{a}} \\
M A I-2 !\end{array}$ & $\begin{array}{l}0,93 \\
0,98\end{array}$ & $\begin{array}{l}0,98 \\
0,85\end{array}$ & $\begin{array}{l}0,96 \\
0,92\end{array}$ & $\begin{array}{l}0,99 \\
0,91\end{array}$ & $\overline{-}$ \\
\hline $\begin{array}{l}\text { JUN - 1ạ } \\
\text { JUN - } 2 a\end{array}$ & $\begin{array}{l}0,98 \\
0,99\end{array}$ & $\begin{array}{l}0,97 \\
0,95\end{array}$ & $\begin{array}{l}0,90 \\
0,99\end{array}$ & $\begin{array}{l}0,99 \\
0,99\end{array}$ & $\begin{array}{l}- \\
-\end{array}$ \\
\hline $\begin{array}{l}J U L=1 \\
J U L \\
J U\end{array}$ & $\begin{array}{l}0,91 \\
0,98\end{array}$ & $\begin{array}{l}0,91 \\
0,97\end{array}$ & $\begin{array}{l}0,99 \\
0,99\end{array}$ & $\begin{array}{l}0,99 \\
0,98\end{array}$ & - \\
\hline $\begin{array}{l}A G O-1 ! \\
A G O-2 a\end{array}$ & $\begin{array}{l}0,95 \\
0,97\end{array}$ & $\begin{array}{l}0,91 \\
0,93\end{array}$ & $\begin{array}{l}0,91 \\
0,95\end{array}$ & $\begin{array}{l}0,99 \\
0,98\end{array}$ & - \\
\hline $\begin{array}{l}S E T-1 \stackrel{a}{ } \\
S E T-2 a\end{array}$ & $\begin{array}{l}0,97 \\
0,99\end{array}$ & $\begin{array}{l}0,99 \\
0,93\end{array}$ & $\begin{array}{l}0,99 \\
0,79\end{array}$ & $\begin{array}{l}- \\
-\end{array}$ & $\begin{array}{l}- \\
-\end{array}$ \\
\hline $\begin{array}{l}\text { OUT }-1 a \\
\text { OUT }-2 a\end{array}$ & $\begin{array}{l}0,99 \\
0,97\end{array}$ & $\begin{array}{l}0,99 \\
0,97\end{array}$ & $\begin{array}{l}0,99 \\
0,97\end{array}$ & $\begin{array}{l}0,99 \\
0,99\end{array}$ & - \\
\hline $\begin{array}{l}\text { NOV - } 1 \stackrel{a}{\dot{a}} \\
\text { NOV - } 2 \stackrel{9}{ }\end{array}$ & $\begin{array}{l}0,98 \\
0,90\end{array}$ & $\begin{array}{l}0,99 \\
0,91\end{array}$ & $\begin{array}{l}0,98 \\
0,94\end{array}$ & $\begin{array}{l}0,94 \\
0,88\end{array}$ & $\begin{array}{l}0,99 \\
0,98\end{array}$ \\
\hline $\begin{array}{l}D E Z-1 \stackrel{a}{a} \\
D E Z-2 a\end{array}$ & $\begin{array}{l}0,93 \\
0,88\end{array}$ & $\begin{array}{l}0,93 \\
0,83\end{array}$ & $\begin{array}{l}0,88 \\
0,80\end{array}$ & $\begin{array}{l}0,99 \\
0,90\end{array}$ & $\begin{array}{l}0,98 \\
0,97\end{array}$ \\
\hline Média & 0,9466 & 0,9462 & 0,9495 . & 0,9627 & 0,9741 \\
\hline Desv.Padrão & 0,0346 & 0,0430 & 0,0555 . & 0,0332 & 0,0192 \\
\hline C.Variação (\%) & 3,6286 & 4,5461 & 5,8549 & 3,4552 & 1,9798 \\
\hline
\end{tabular}


Tabela 10 - Valores dos coeficientes de determinação $\left(r^{2}\right)$ das equações $\mathrm{PL}=$ $=a+b D$, onde $D$ significa o número mínimo de dias secos consecutivos observados e PL è a probabilidade empírica de ocorrência de $D$, marcada numa escala linear, probabilidade linear, paralela à escala do papel de probabilidade, para as CADs estudadas e por periodo mensal.

\begin{tabular}{|c|c|c|c|c|c|}
\hline Mês CAD & $18 \mathrm{~mm}$ & $38 \mathrm{~mm}$ & $50 \mathrm{~mm}$ & $100 \mathrm{~mm}$ & $175 \mathrm{~mm}$ \\
\hline $\begin{array}{l}\text { JAN } \\
\text { FEV } \\
\text { MAR } \\
\text { ABR } \\
\text { MAI } \\
\text { JUN } \\
\text { JUL } \\
\text { AGO } \\
\text { SET } \\
\text { OUT } \\
\text { NOV } \\
\text { DEZ }\end{array}$ & $\begin{array}{l}0,93 \\
0,97 \\
0,97 \\
0,98 \\
0,96 \\
0,99 \\
0,99 \\
0,98 \\
0,98 \\
0,99 \\
0,87 \\
0,93\end{array}$ & $\begin{array}{l}0,98 \\
0,99 \\
0,99 \\
0,97 \\
0,98 \\
0,99 \\
0,95 \\
0,98 \\
0,90 \\
0,98 \\
0,94 \\
0,88\end{array}$ & $\begin{array}{l}0,99 \\
0,97 \\
0,99 \\
0,99 \\
0,97 \\
0,91 \\
0,97 \\
0,96 \\
0,86 \\
0,99 \\
0,91 \\
0,94\end{array}$ & $\begin{array}{c}0,97 \\
0,99 \\
0,96 \\
0,98 \\
0,98 \\
0,99 \\
0,99 \\
0,99 \\
- \\
0,99 \\
0,99 \\
0,87\end{array}$ & $\begin{array}{c}0,96 \\
0,99 \\
0,98 \\
0,98 \\
0,99 \\
- \\
- \\
- \\
- \\
- \\
0,98 \\
0,96\end{array}$ \\
\hline $\begin{array}{l}\text { Média } \\
\text { D.Padrão } \\
\text { C.Variação(\%) }\end{array}$ & $\begin{array}{l}0,9617 \\
0,0356 \\
3,7053\end{array}$ & $\begin{array}{l}0,9608 \\
0,0367 \\
3,8293\end{array}$ & $\begin{array}{l}0,9541 \\
0,0414 \\
4,3432\end{array}$ & $\begin{array}{l}0,9727 \\
0,0355 \\
3,6518\end{array}$ & $\begin{array}{l}0,9771 \\
0,0125 \\
1,282\end{array}$ \\
\hline
\end{tabular}

Tabela 11 - Valores dos coeficientes de determinação $\left(r^{2}\right)$ das equações $P L=$ = $a+b D$, onde $D$ significa o número mínimo de dias secos consecutivos observados e PL ê a probabilidade empírica de ocorrência de $D$, marcada numa escala linear, probabilidade linear, parale la à escala do papel de probabilidade, para as CADs estudadas e por período trimestral.

\begin{tabular}{llllll}
\hline Trim/Ano CAD & $18 \mathrm{~mm}$ & $38 \mathrm{~mm}$ & $50 \mathrm{~mm}$ & $100 \mathrm{~mm}$ & $175 \mathrm{~mm}$ \\
\hline 1.: Trimestre & 0,97 & 0,96 & 0,96 & 0,94 & 0,94 \\
20: Trimestre & 0,99 & 0,98 & 0,99 & 0,99 & 0,98 \\
30. Trimestre & 0,95 & 0,93 & 0,99 & 0,99 & 0,99 \\
4: Trimestre & 0,92 & 0,90 & 0,87 & 0,91 & 0,95 \\
Média & 0,9575 & 0,9425 & 0,9525 & 0,9575 & 0,965 \\
D.Padrão & 0,0298 & 0,0350 & 0,0567 & 0,0394 & 0,0238 \\
C.Variação(\%) & 3,1186 & 3,7135 & 5,9621 & 4,1228 & 2,4668 \\
\hline
\end{tabular}


so quer dizer o seguinte, tomando como exemplo o CAD de $18 \mathrm{~mm}$ na $l^{\text {ạ }}$ quinzena do mês de janeiro, que hả $80 \%$ de probabilidade teórica de ter-se um número mínimo de dias secos consecutivos gual a 5,4 dias. Ou de outra forma que há uma probabilidade teoo rica de ocorrer um número mínimo de dias secos consecutivos igual a 5,4 dias, na 1 a quinzena de janeiro, ao nível de $80 \%$.

As figuras de 28 a 32 , foram obtidas com o intuito de ter-se uma visão geral durante as 24 quinzenas do ano e para cada CAD, de como se comporta a seca quanto aos : períodos mais ou menos severos. Atrāes de sua anālise, pode-se saber o risco de insucesso que uma cultura pode ter, plantando-se numa ou outra época, necessidades de irrigação, enfim como orientação para um melhor planejamento agrícola.

A apresentação, segundo os grä́icos das figuras 10 a 32 , foi a maneira que julgamos mais conveniente para se estú dar e apresentar os resultados obtidos quanto a caracterização da seca agronômica, segundo o critério de dias secos consecuti vos.

Para que não hajam dūvidas quanto a interpretação dos gráficos das figuras de 10 a 27 , elaboramos um exemplo relativo do mês de janeiro e $50 \mathrm{~mm}$ de capacidade de água disponí vel mâxima-CAD. Assim, atravēs do gräfico da Figura 22, podemos observar que para 15 dias secos consecutivos (eixo das abcissas) há uma probabilidade teórica de ocorrência de $50 \%$ (eixo das ordenadas). Então, tem-se para cada mês de janeiro e para $50 \mathrm{~mm}$ de CAD: 
a) $50 \%$ de probabilidade teórica de ocorrer pelo menos uma sequência igual ou maior do que 15 dias secos, ou,

b) $50 \%$ de probabilidade teórica de ocorrer pelo menos uma sequência de, no mínimo 15 dias secos, ou,

c) $50 \%$ de probabilidade teórica de ocorrer uma sequência igual ou maior que 15 dias secos, ou,

d) $50 \%$ de probabilidade teórica de ocorrer uma sequência de, no mínimo 15 dias, ou ainda,

e) $50 \%$ de probabilidade teórica (uma vez em cada 2 anos) de ocorrer no mínimo 15 dias secos consecutivos.

Evidentemente, que todas essas interpretações estão corretas, apenas que, para períodos maiores de 15 dias è irrelevante dizer-se, "pelo menos uma vez", pelo fato de : não ser possível em um mês ter mais de uma sequência de 16 dias ou mais dias secos.

Para alguns meses e para as CADs muito elevadas, não foi possível traçar a reta de probabilidade teórica versus o número mínimo de dias secos consecutivos devido ter mais de $92,31 \%$ de probabilidade de não ocorrer dia seco, e por dois pontos ou menos ficou difícil para caracterizar a reta ou mesmo ser irrelevante o período seco (Figura 18 e 19).

Como era de se esperar, a medida que aumenta a CAD do solo menor nūmero de períodos de estiagem ocorrem. Pela aná lise dos gráficos das figuras 28 a 32 , pode-se observar que os meses de outubro, novembro, dezembro, janeiro, fevereiro e mar ço, correspondendo ao 4! e $1 \%$ trimestres do ano, são os que se 
evidenciam pelo maior número de dias secos consecutivos e nas maiores sequências, em qualquer nível de CAD, mesmo para $175 \mathrm{~mm}$. As quinzenas correspondentes aos meses de abril-maio também e videnciam-se pelo nümero de dias secos consecutivos apresentados. A ocorrência das sequências de dias secos, sua marcha anual, assemelha-se muito com a da Evapotranspiração Potencial, tendo sua severidade evidenciada nos meses mais quentes do ano, diminuindo a medida que se aproxima dos meses de inverno. Nes se contexto, duas exceções devem ser ressaltadas, a primeira refere-se aos meses de abril e maio, onde o nūmero mínimo de días secos ê elevado e, segundo, a segunda quinzena de agosto e o més de setembro, possuem uma probabilidade de ocorrência de dias secos consecutivos bastante baixa, mesmo para $18 \mathrm{~mm}$ de CAD .

Podemos ressaltar, ainda, que mesmo para $175 \mathrm{~mm}$ de CAD, nos meses de outubro, novembro, dezembro, janeiro, fevereiro e março, a severidade da seca é de tal forma acentuada que para o mês de janeiro, 2 a quinzena, há $50 \%$ de probabili dade teórica de ocorrer um n: mínimo de 6,5 dias secos consecu tivos. Isso vem nos informar que a ocorrência da seca agronōmi ca, mais acentuada no 19 e 49 trimestres, não deve-se apenas a baixa capacidade de armazenamento de āgua dos solos, mas tam bēm e, principalmente, às insuficientes precipitações nessas épocas do ano, aliada a alta demanda atmosférica.

Considerando, ainda, um risco de $10 \%$ e uma sequên cia de 10 dias secos ou mais como uma condição de seca signifi 
cativa, verifica-se na região em estudo que, mesmo para $100 \mathrm{~mm}$ de CAD, há a ocorrēncia de seca em sete meses do ano, com exce ção de junho, julho, agosto, setembro e outubro. E, para um ris co de $30 \%$ e uma sequência de 10 dias secos ou mais, temos a sua ocorrência ainda em quatro meses do ano, sendo eles: janei ro, fevereiro, novembro, e dezembro (Figura 23).

Dessa forma, podemos concluir uma vez mais que, a seca na região estudada se faz sentir mais drasticamente nos meses correspondentes ao primeiro e ültimo trimestre do ano, com ênfase maior nos meses de novembro, dezembro, janeiro e fe vereiro.

Considerando o solo "Ararangua", de grande ocorrência na região e de baixa capacidade de armazenamento de água, em torno de $38 \mathrm{~mm}$ em um metro de profundidade, apresenta seca agronómica em todos os meses do ano ao nível de $10 \%$ e $20 \%$ de probabilidade (Figura 29). Aos mesmos níveis de probabilida de, verifica-se que nos meses mais quentés, isto é, 1 : e 4 : tri mestres, a menor sequência provāvel de dias secos ē de 8,7 dias, verificada na $2^{a}$. quinzena do mês de outubro, traduzindo a seve ridade com que a seca agronómica se manifesta nesses solos. 


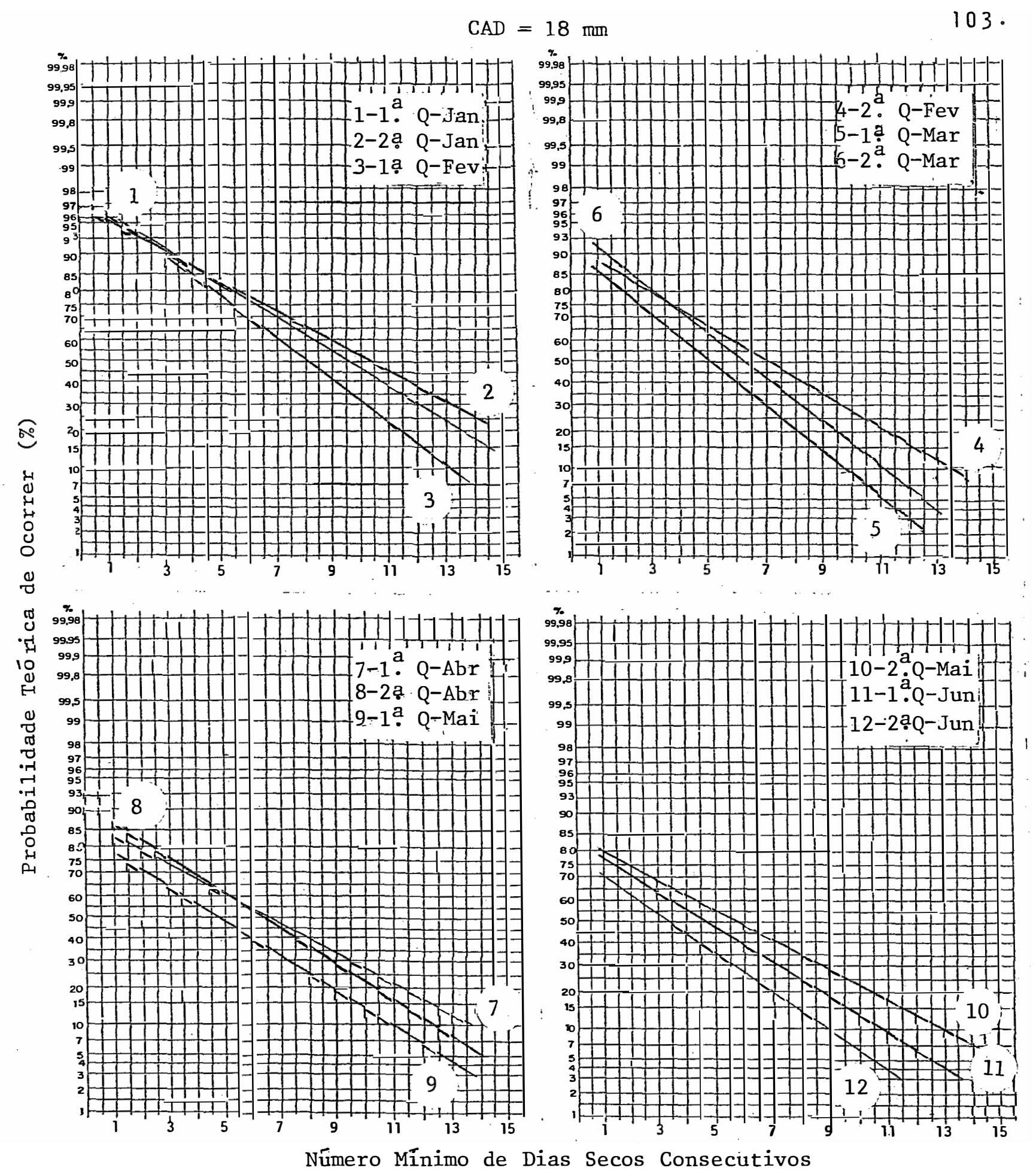

Figura 10 - Probabilidade Teórica de Ocorrer um dado Número Mínimo de Dias Secos Consecutivos, em cada quinzena de cada ìês do calendário e para $18 \mathrm{~mm}$ de Capacidade de Água Disponível Máxima - CAD. 


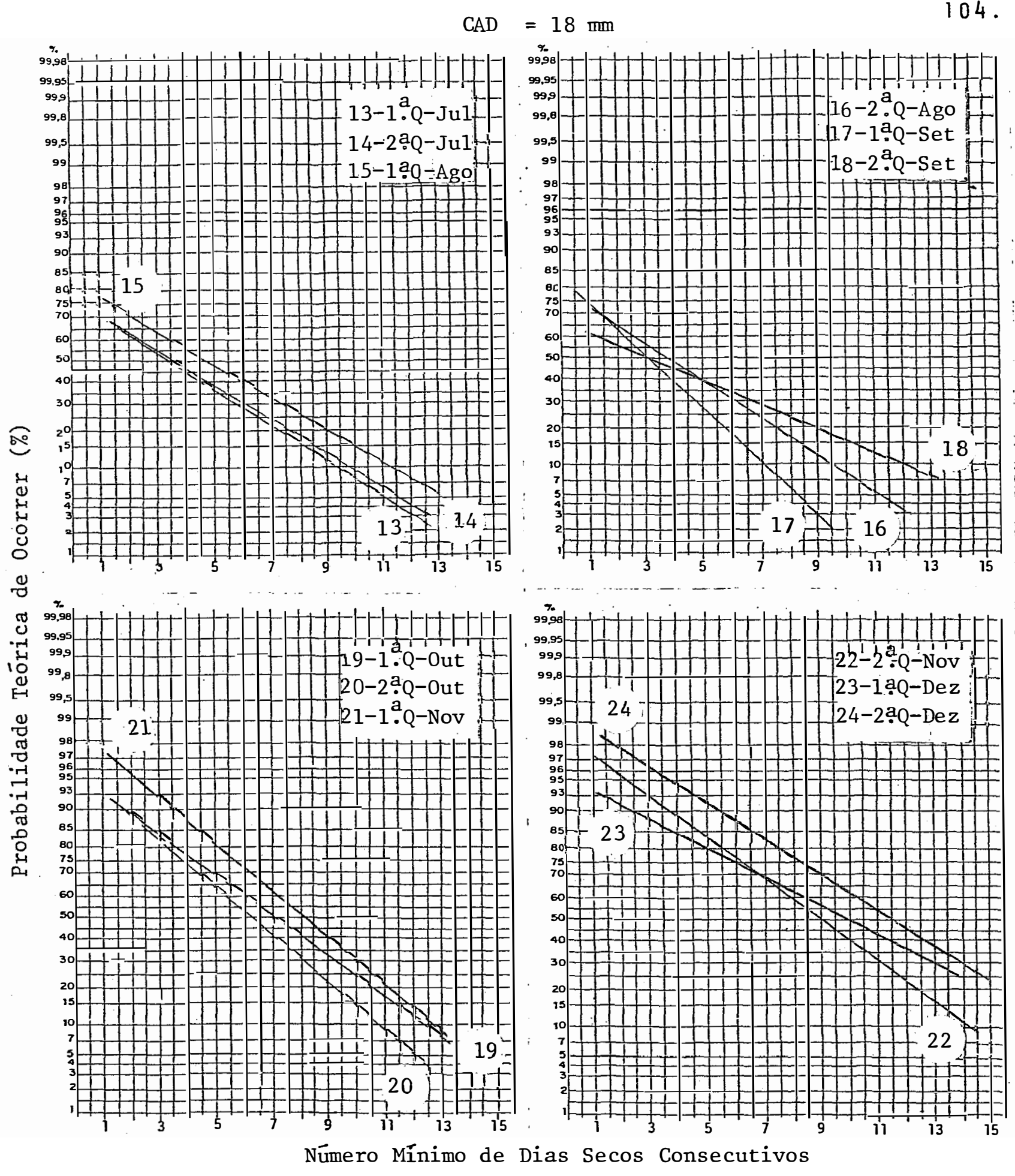

Figura 11 - Probabilidade Teórica de Ocorrer um dado Número Mínimo de Dias Secos Consecutivos, em cada Quinzena de cada mês do calendário e para 18 mm de Capacidade de Água Disponível Mäxima - CAD. 


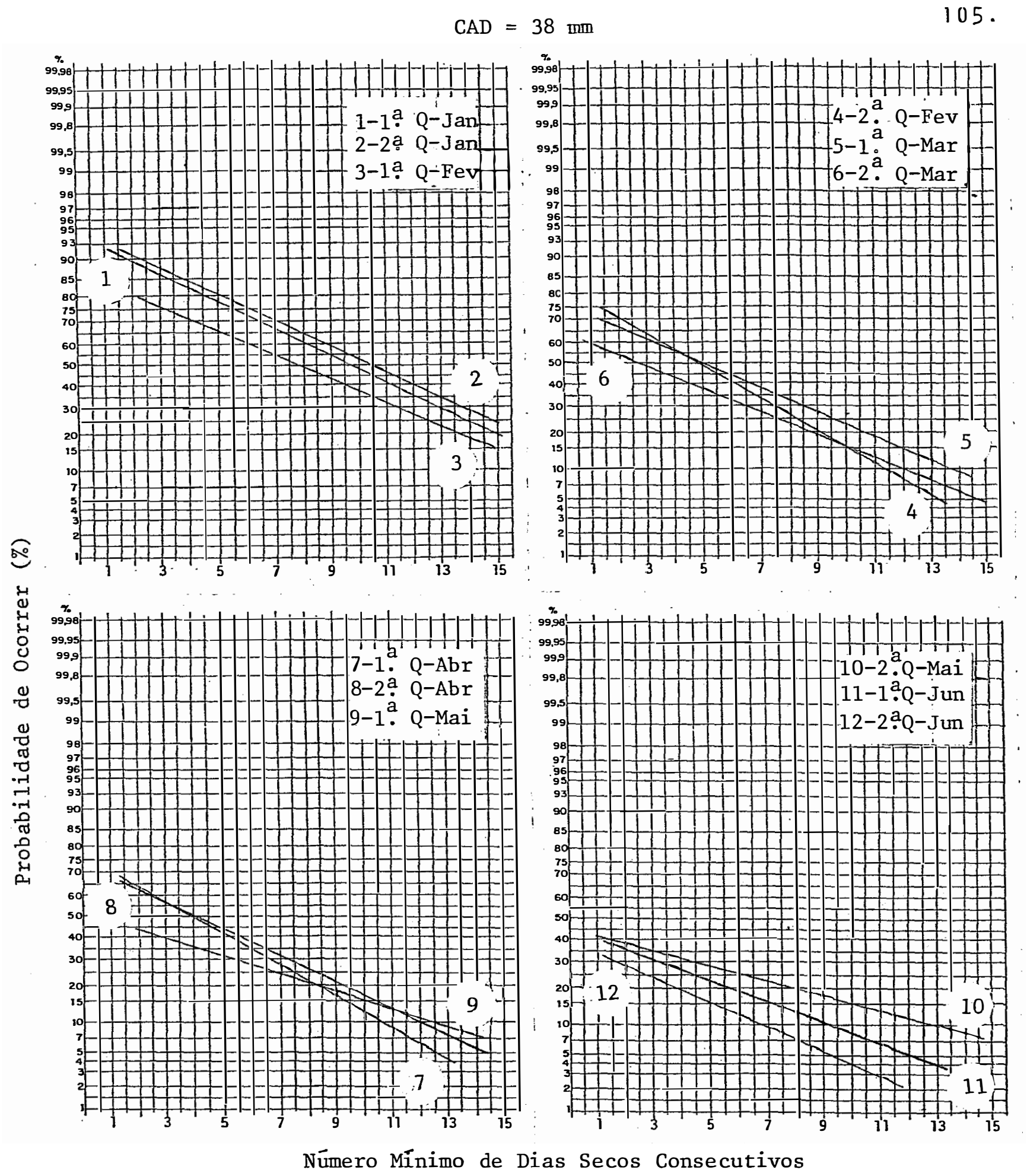

Figura 12 - Probabilidade Teórica de Ocorrer um dado Número Mínimo de Dia Secos Consecutivos, em cada Quinzena de cada mês do calendário e para $38 \mathrm{~mm}$ de Capacidade de Água Disponível Máxima - CAD. 
106.

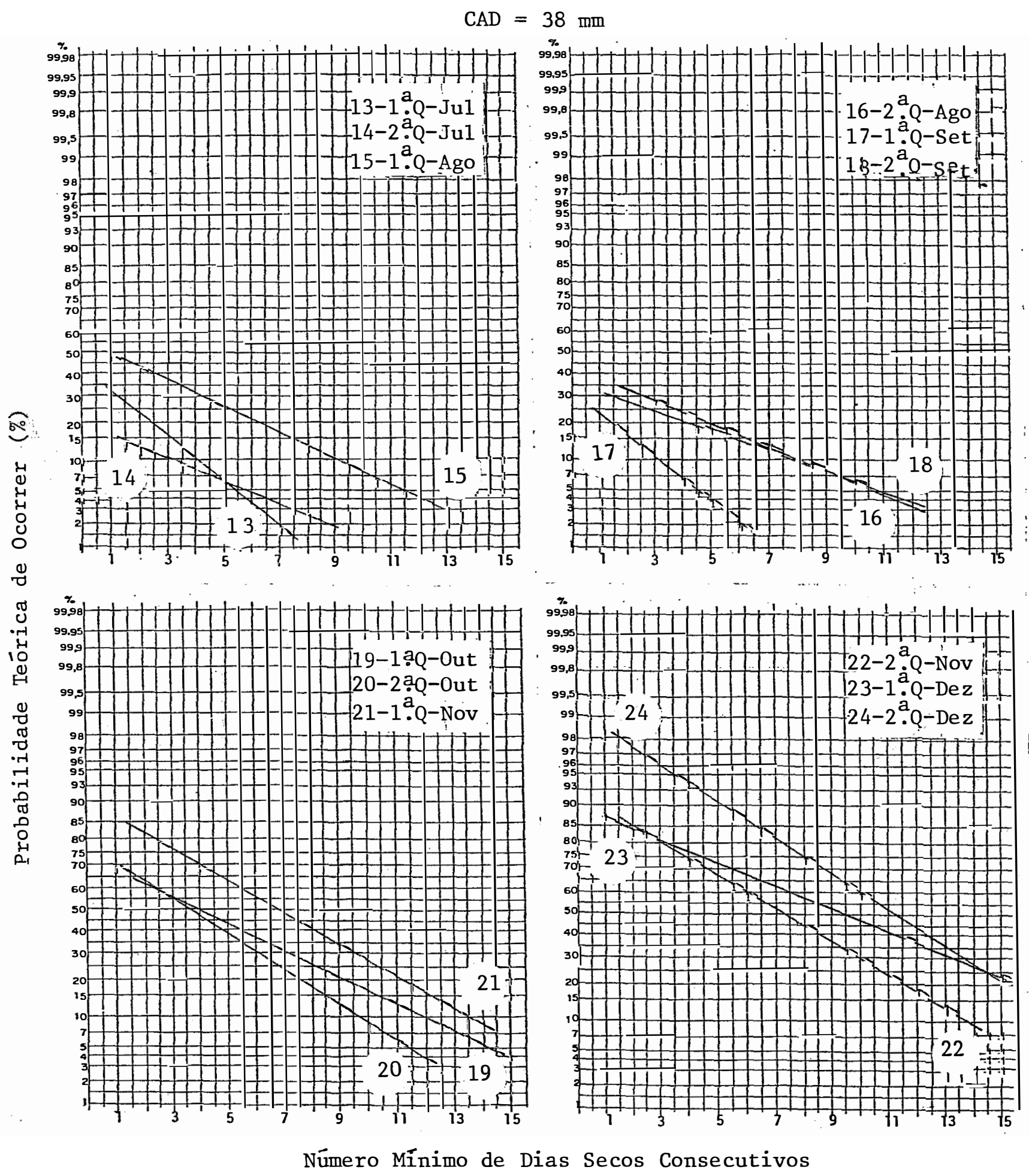

Figura 13 - Probabilidade Teórica de Ocorrer um dado Número Mínimo de Dias Secos Consecutivos, em cada Quinzena de cada mês do calendário e para $38 \mathrm{~mm}$ de Capacidade de Água Disponível Máxima-CAD. 


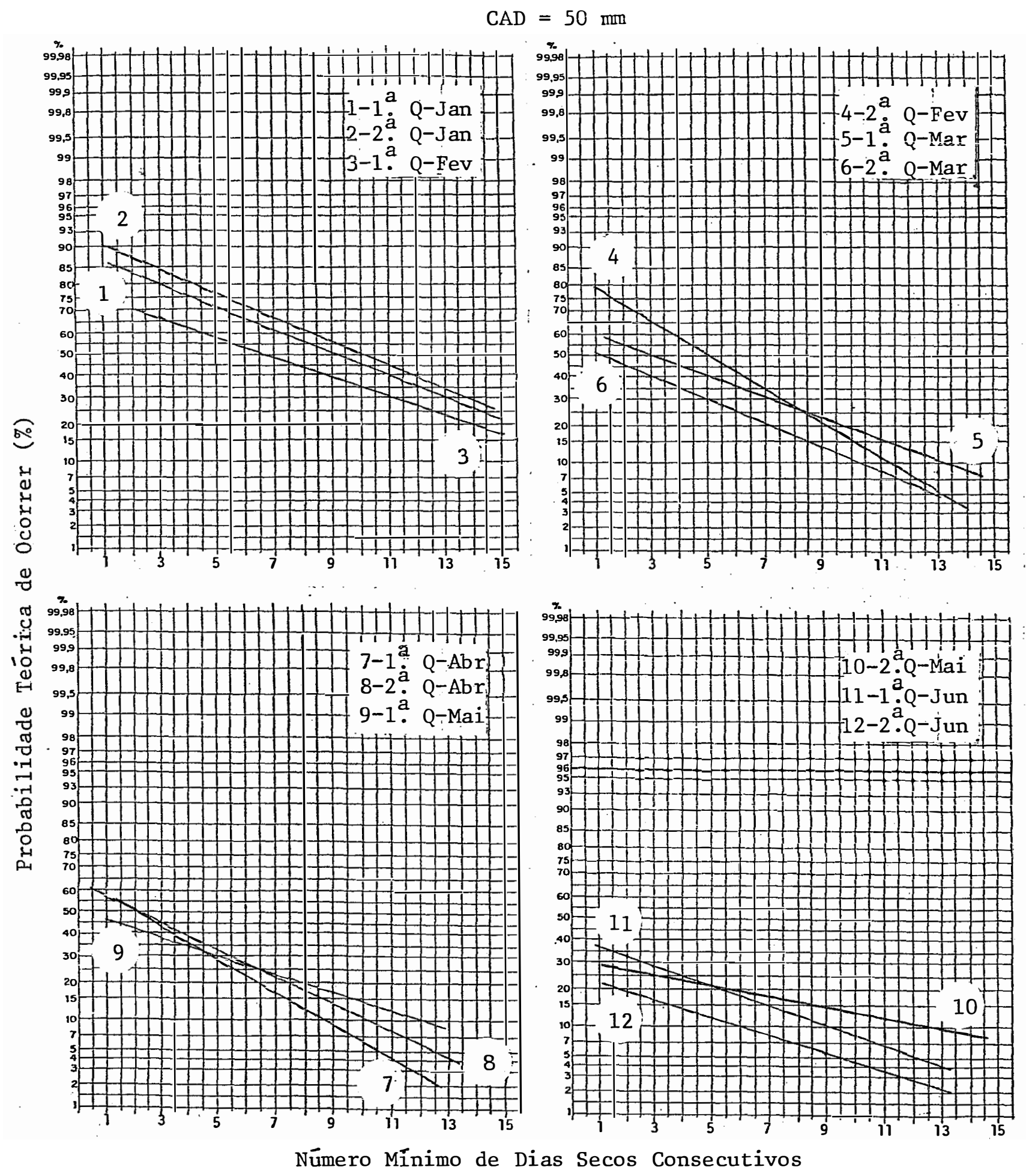

Figura 14 - Probabilidade Teórica de 0correr um dado Número Mínimo de Dias Secos Consecutivos, em cada Quinzena de cada mês do calendário e para $50 \mathrm{~mm}$ de Capacidade de Āgua Disponível Máxima-CAD. 


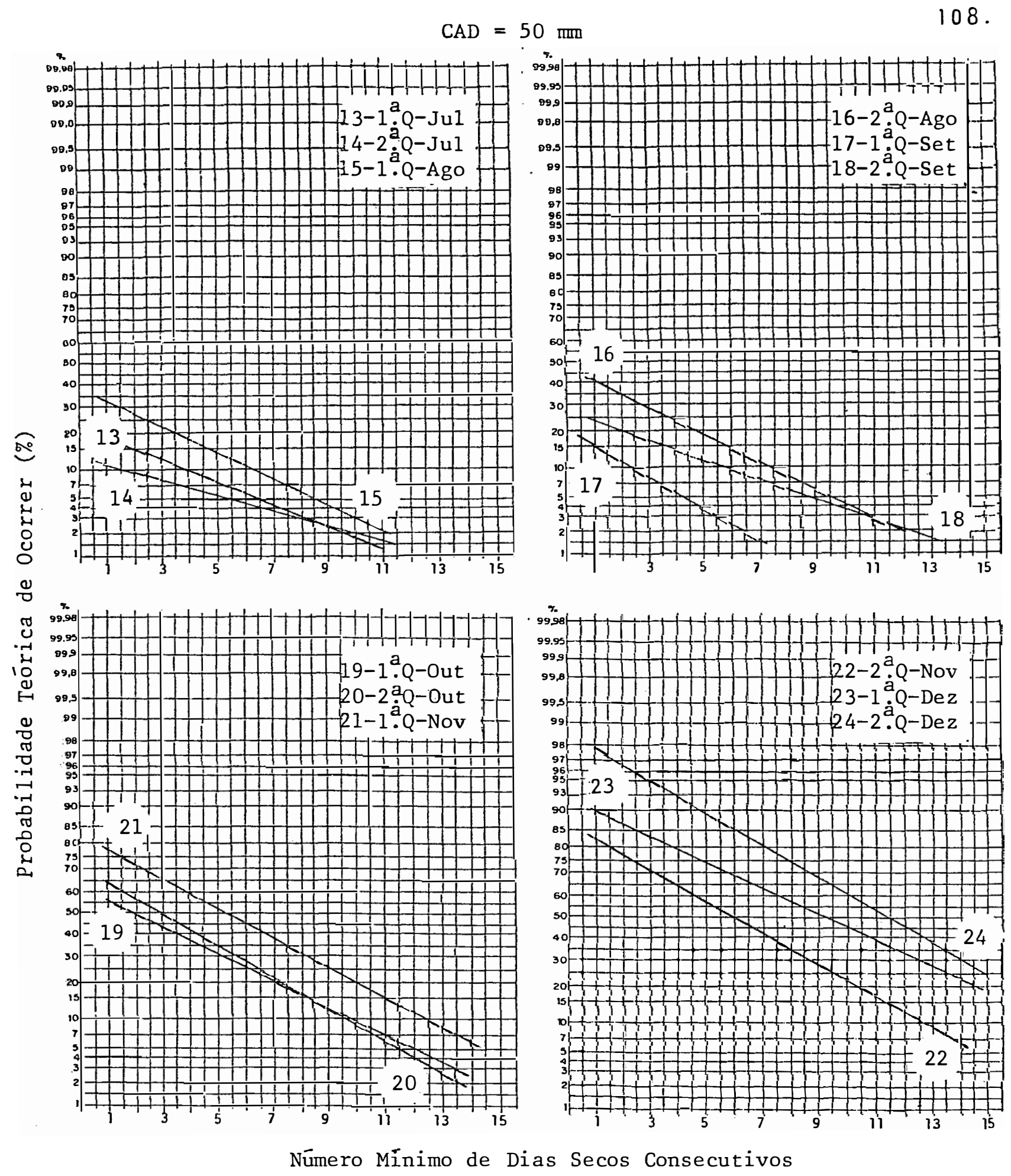

Figura 15 - Probabilidade Teórica de Ocorrer um dado Número Mínimo de Dias. Secos Consecutivos, em cada Quinzena de cada mês do calendário e para $50 \mathrm{~mm}$ de Capacidade de Água Disponível Máxima- CAD. 


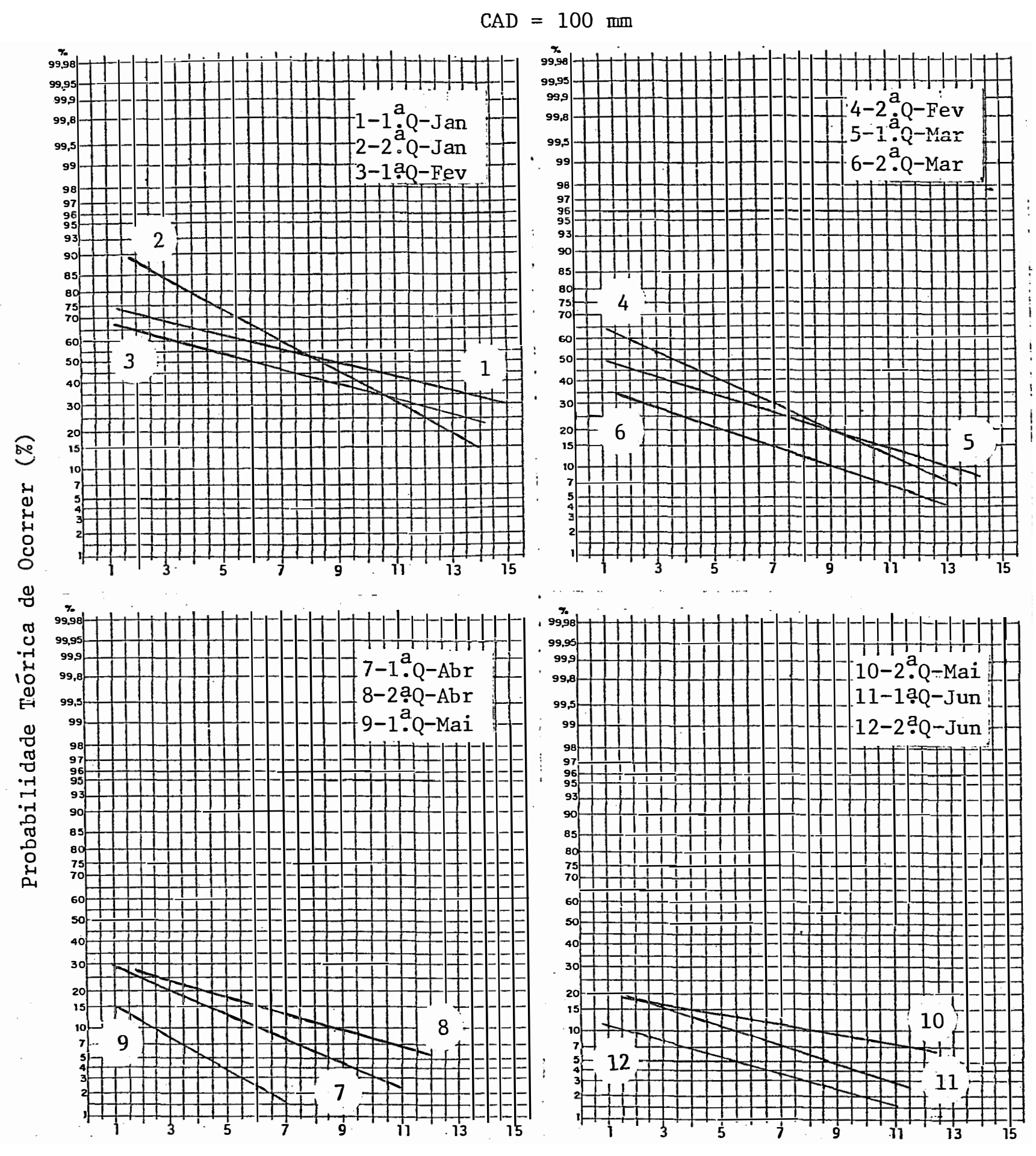

Número Mínimo de Dias Secos Consecutivos

Figura 16 - Probabilidade Teórica de Ocorrer um dado Número Mínimo de Dias Secos Consecutivos, em cada Quinzena de cada mês do calendário e para 100 mm de Capacidade de Água Disponível Máxima - CAD. 
110.

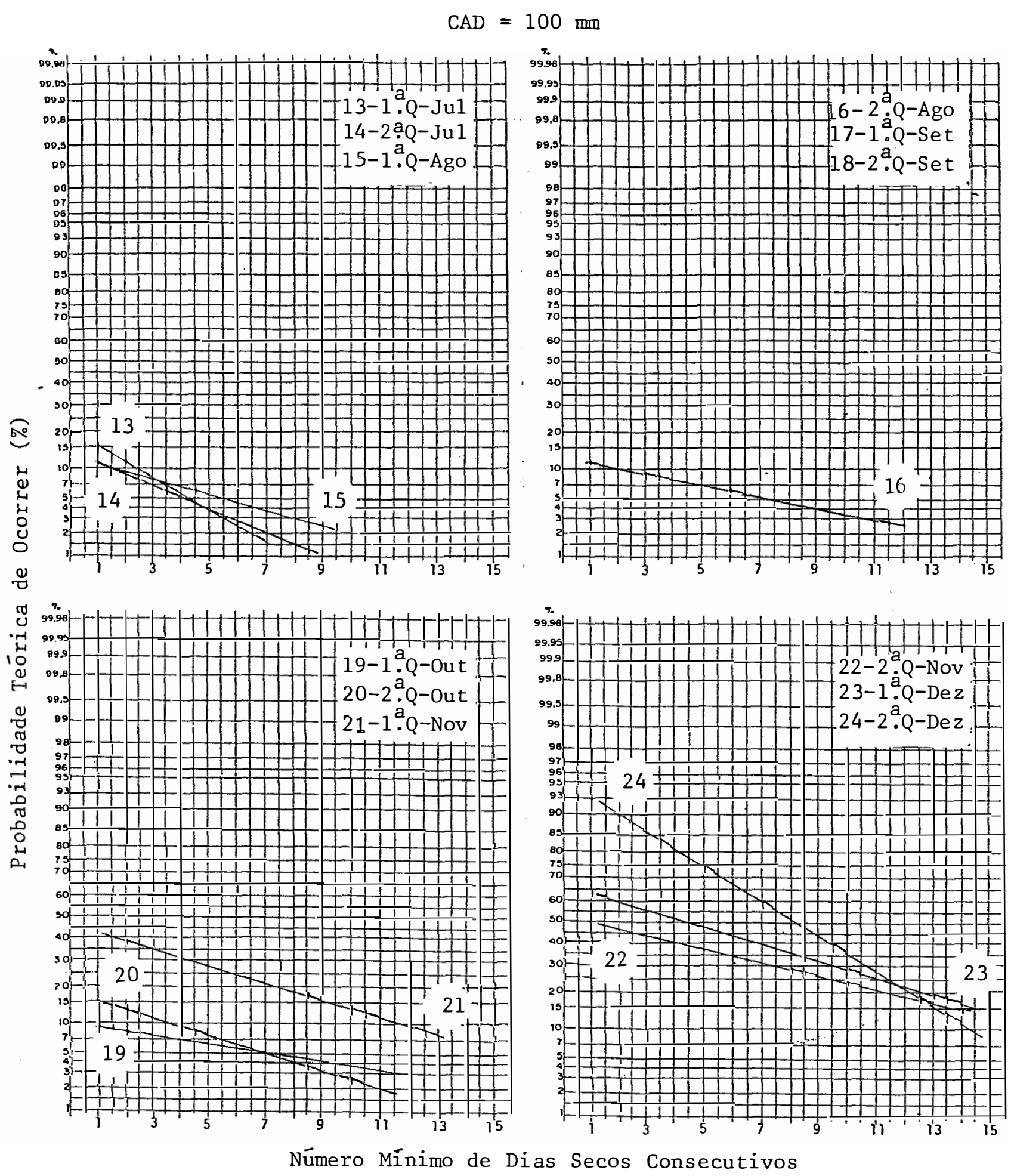

Figura 17 - Probabilidade Teórica de Ocorrer um Dado Número Mínimo de Dias: Secos Consecutivos, em cada Quinzena de cada mês do calendário e para 100 mm de Capacidade de Āgua Disponível Máxima - CAD. 
111.

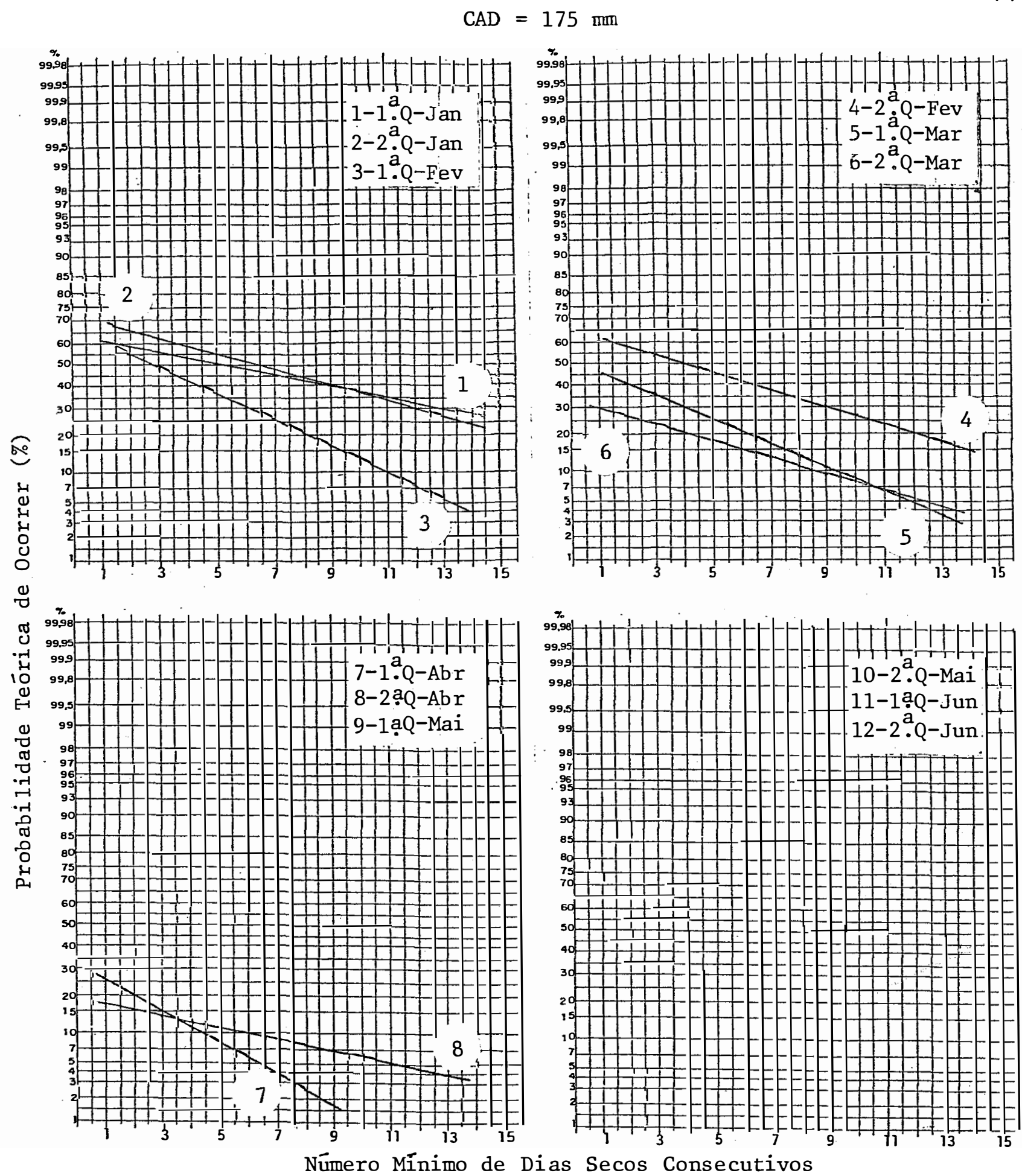

Figura 18 - Probabilidade Teórica de Ocorrer um dado Número Mínimo de Dias Secos Consecutivos, em cada quinzena de cada mês do calendário e para 175 mm de Capacidade de Água Disponível Máxima-CAD 


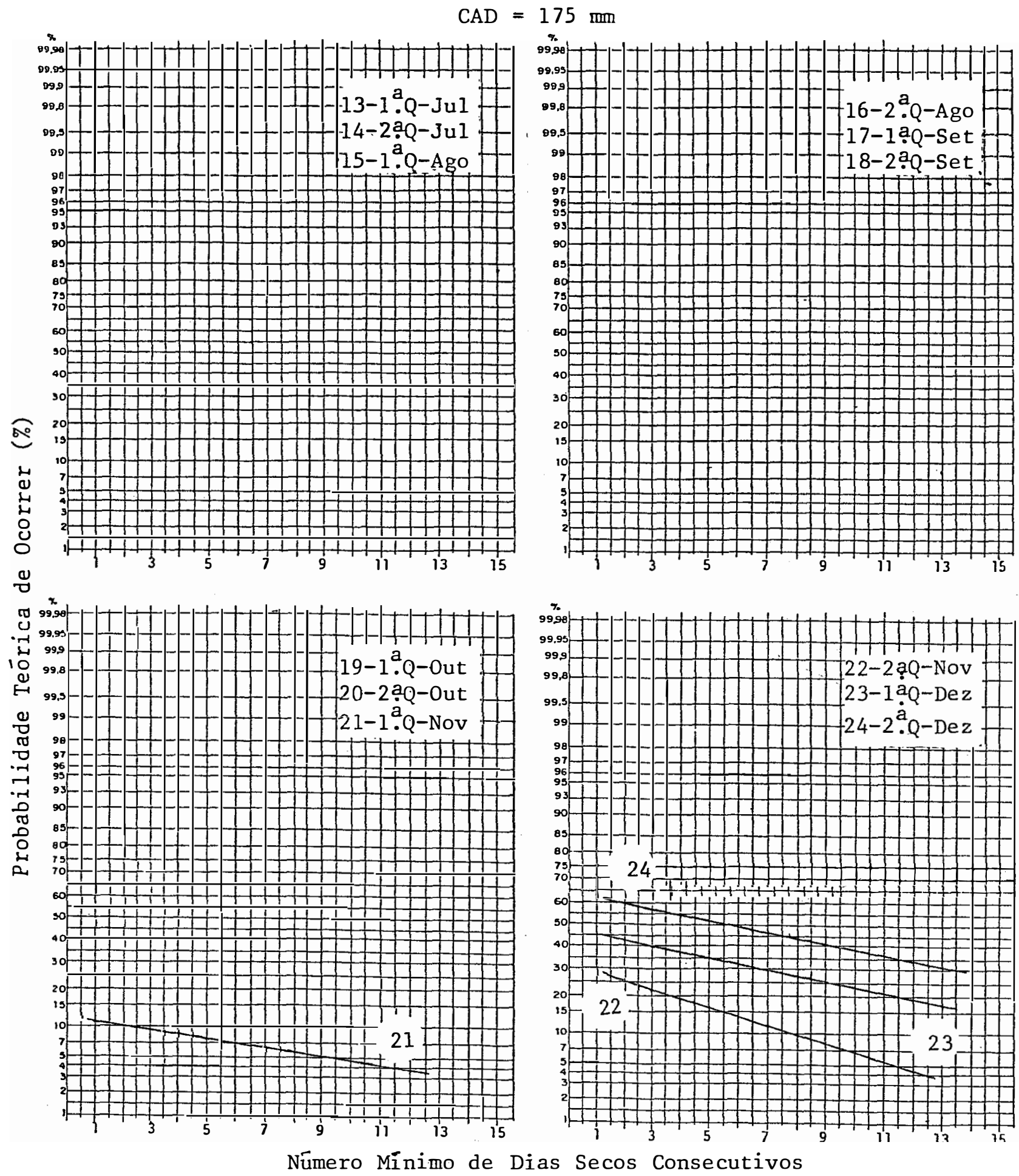

Figura 19 - Probabilidade Teórica de Ocorrer um dado Número Mínimo de Dias Secos Consecutivos, em cada Quinzena de cada mês do calendário e para 175 mm de Capacidade de Água Disponível Máxima - CAD. 

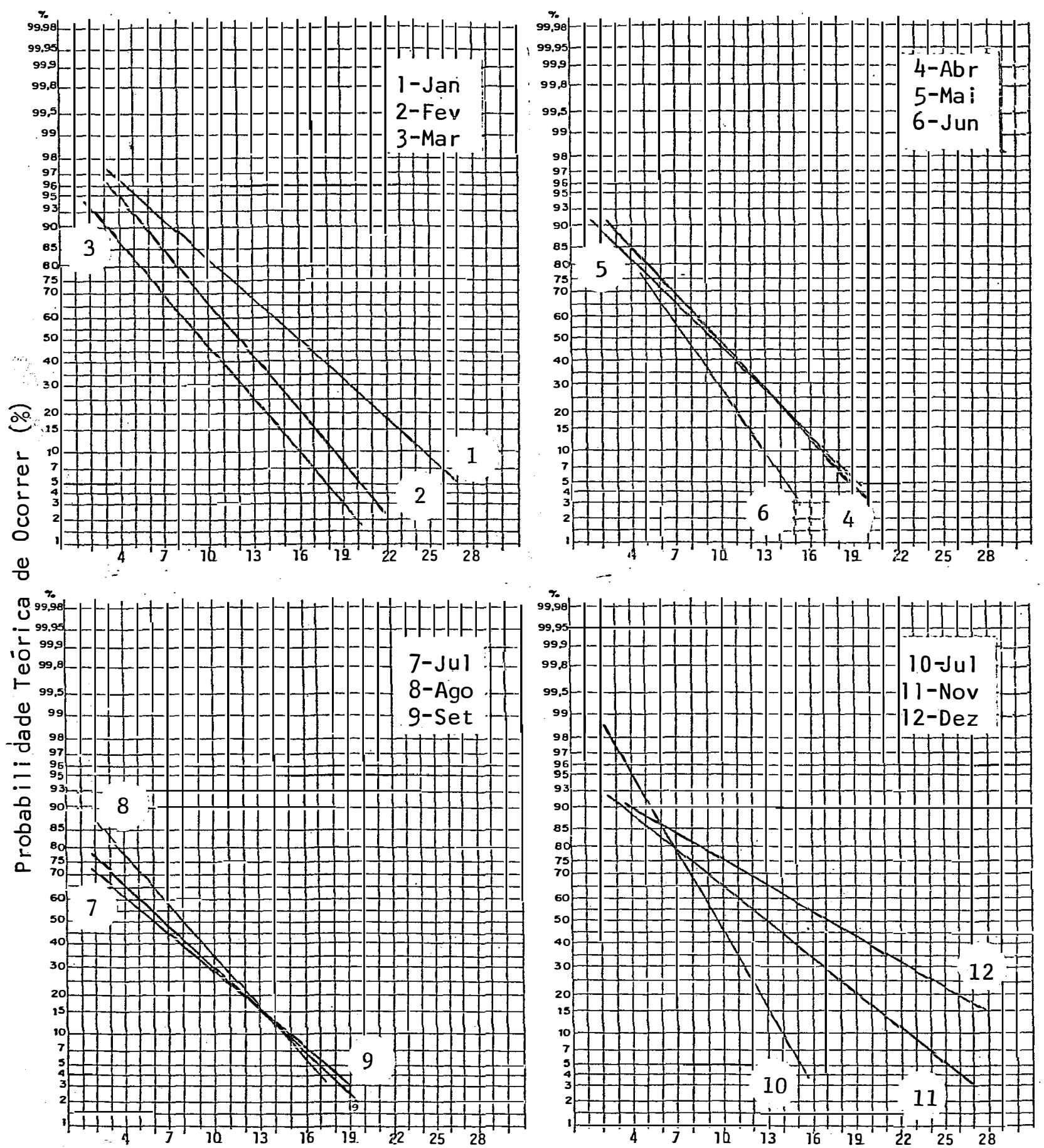

Nūmero Mínimo de Dias Secos Consecutivos

Figura 20 - Probabilidade Teórica de ocorrer um dado Nümero Mínimo de Dias Secos Consecutivos, para cada mês do calendārio e para $18 \mathrm{~mm}$ de Capacidade de Água Disponível Máxima - CAD 


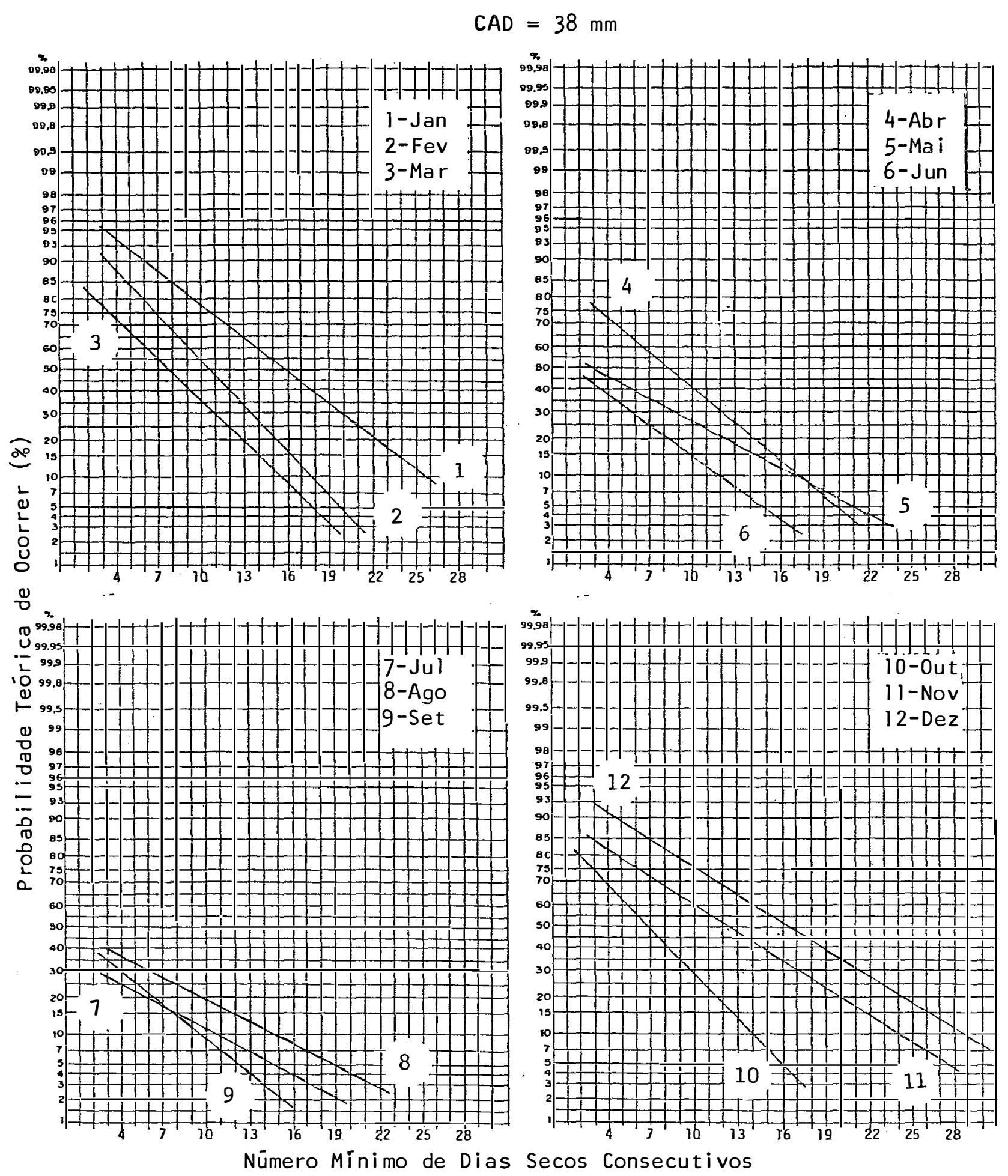

Figura 21 - Probabilidade Teórica de Ocorrer um dado Nümero Mínimo de Dias Secos Consecutivos, para cada mès do calendārio e para $38 \mathrm{~mm}$ de Capacidade de Água Disponível Máxima - CAD. 


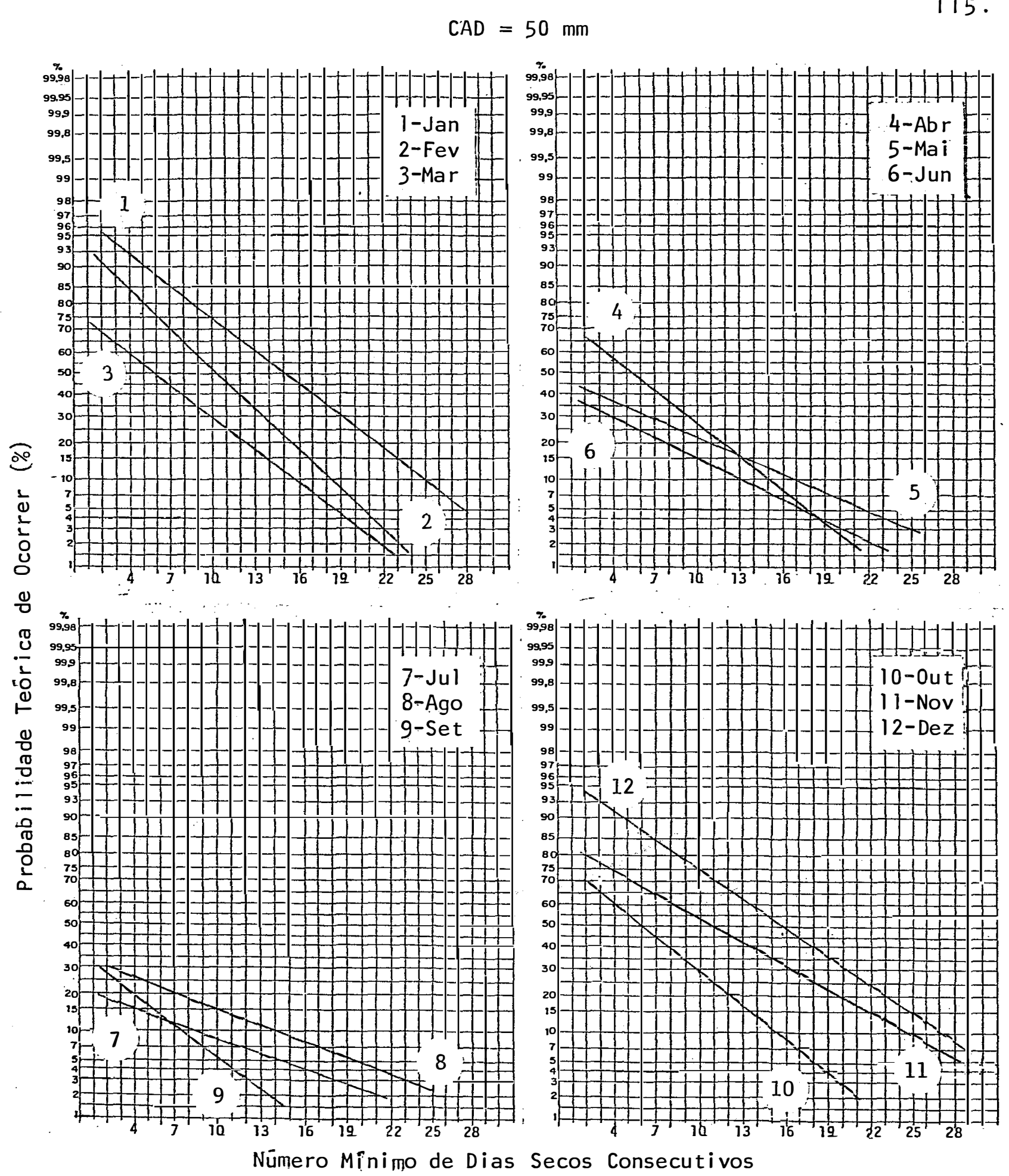

Fígura 22 - Probabilidade Teórica de Ocorrer um dado, Número Mínimo de Dias Secos Consecutivos, para cada mês do calendärio e para $50 \mathrm{~mm}$ de Capacìdade de Água Disponível Máxima - CAD 
116.

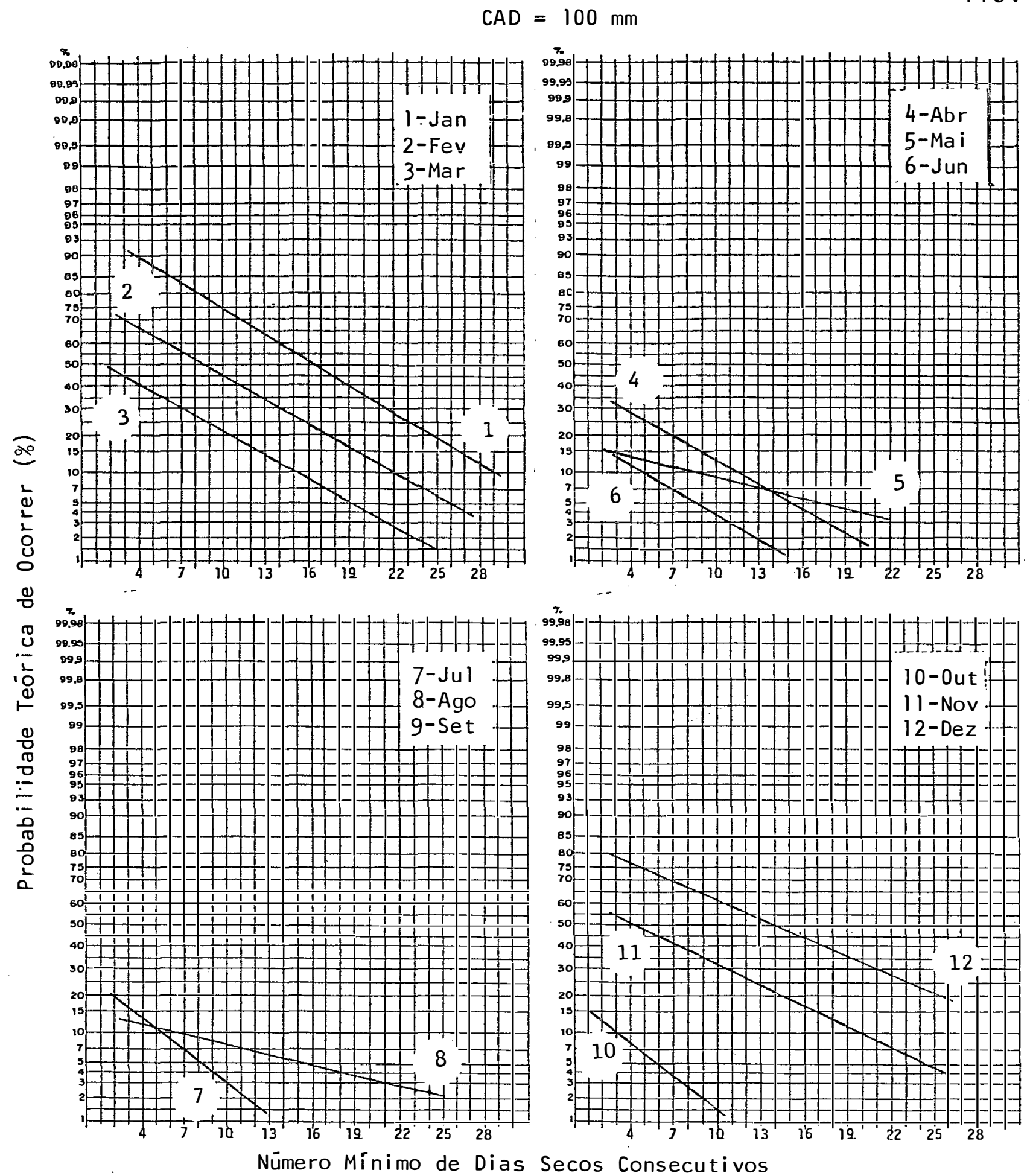

Figura 23 - Probabilidade Teórica de Ocorrer um dado Número Mínimo de Dias Secos Consecutivos, para cada mês do calendärio e para $100 \mathrm{~mm}$ de Capacidade de Água Disponível Máxima - CAD. 
117.

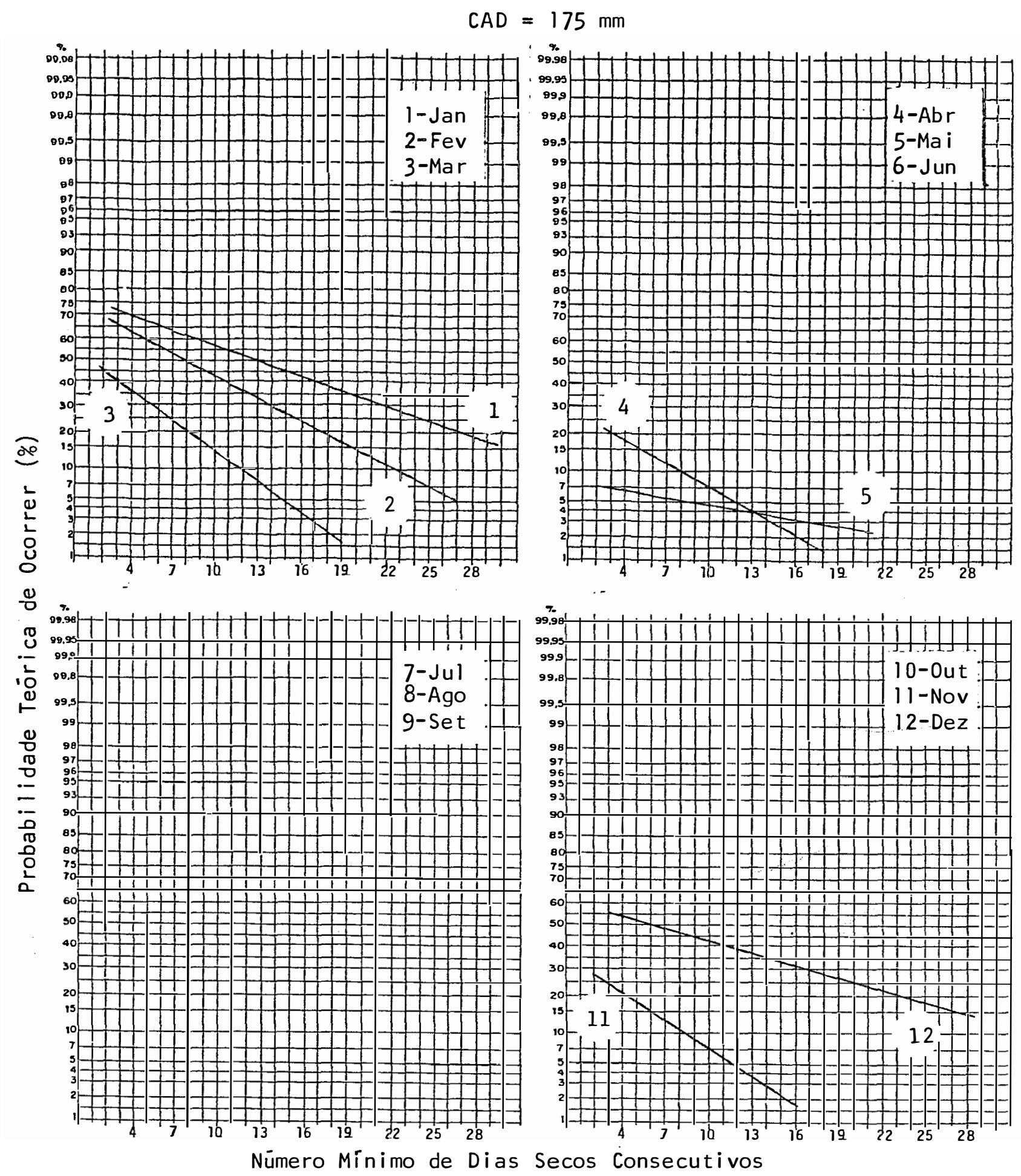

Figura 24 - Probabilidade Teórica de Ocorrer um dado Número Mínimo de Dias Secos Consecutivos, para cada mês do calendário e para $175 \mathrm{~mm}$ de Capacidade de Água Disponível Máxima - CAD 
118.

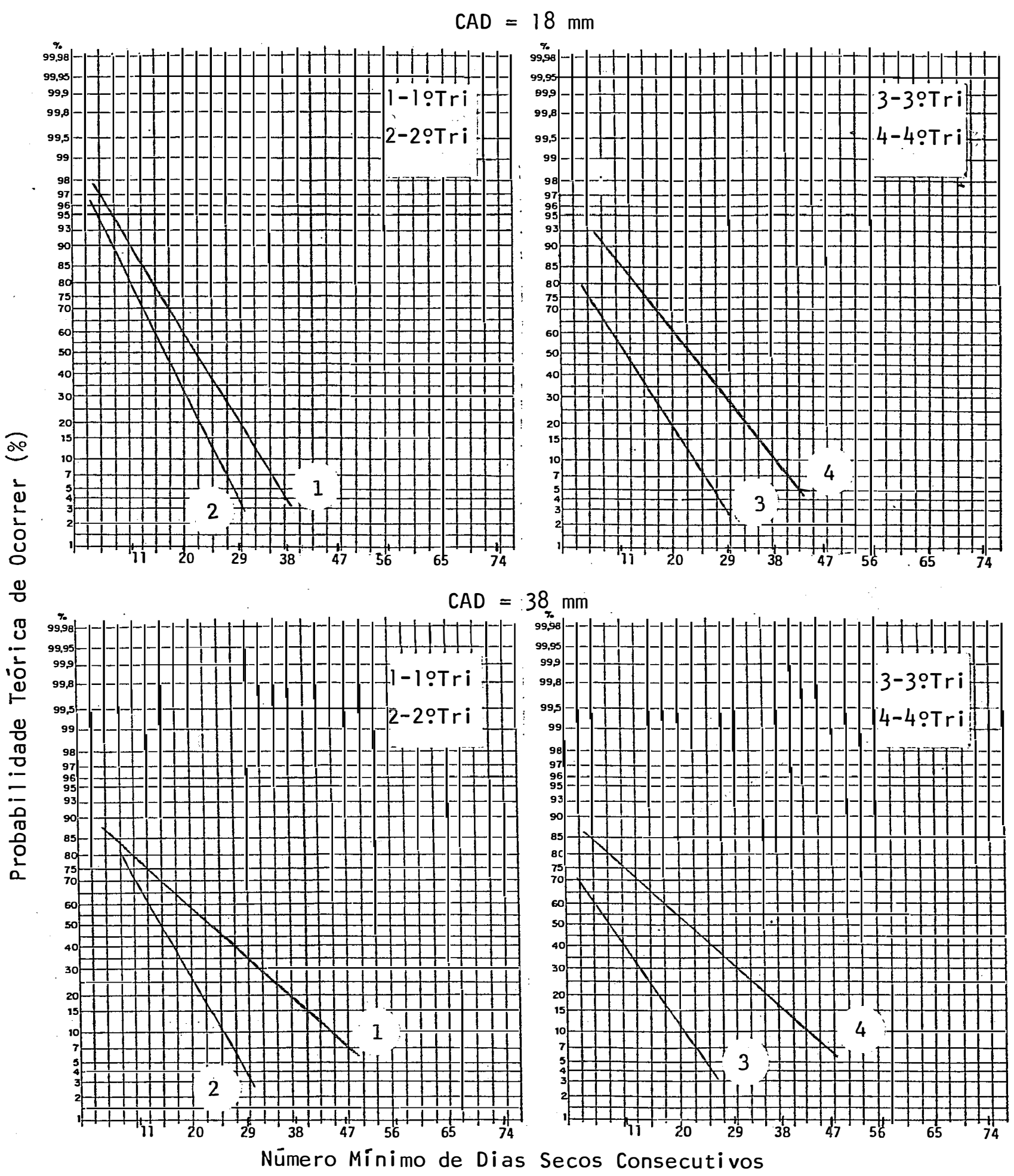

Figura 25 - Probabilidade Teórica de Ocorrer um dado Número Mínimo de Dias. Secos Consecutivos, para cada Trimestre do Ano e para $18 \mathrm{~mm}$ e $38 \mathrm{~mm}$ de Capacidade de Água Disponível Māxima - CAD. 


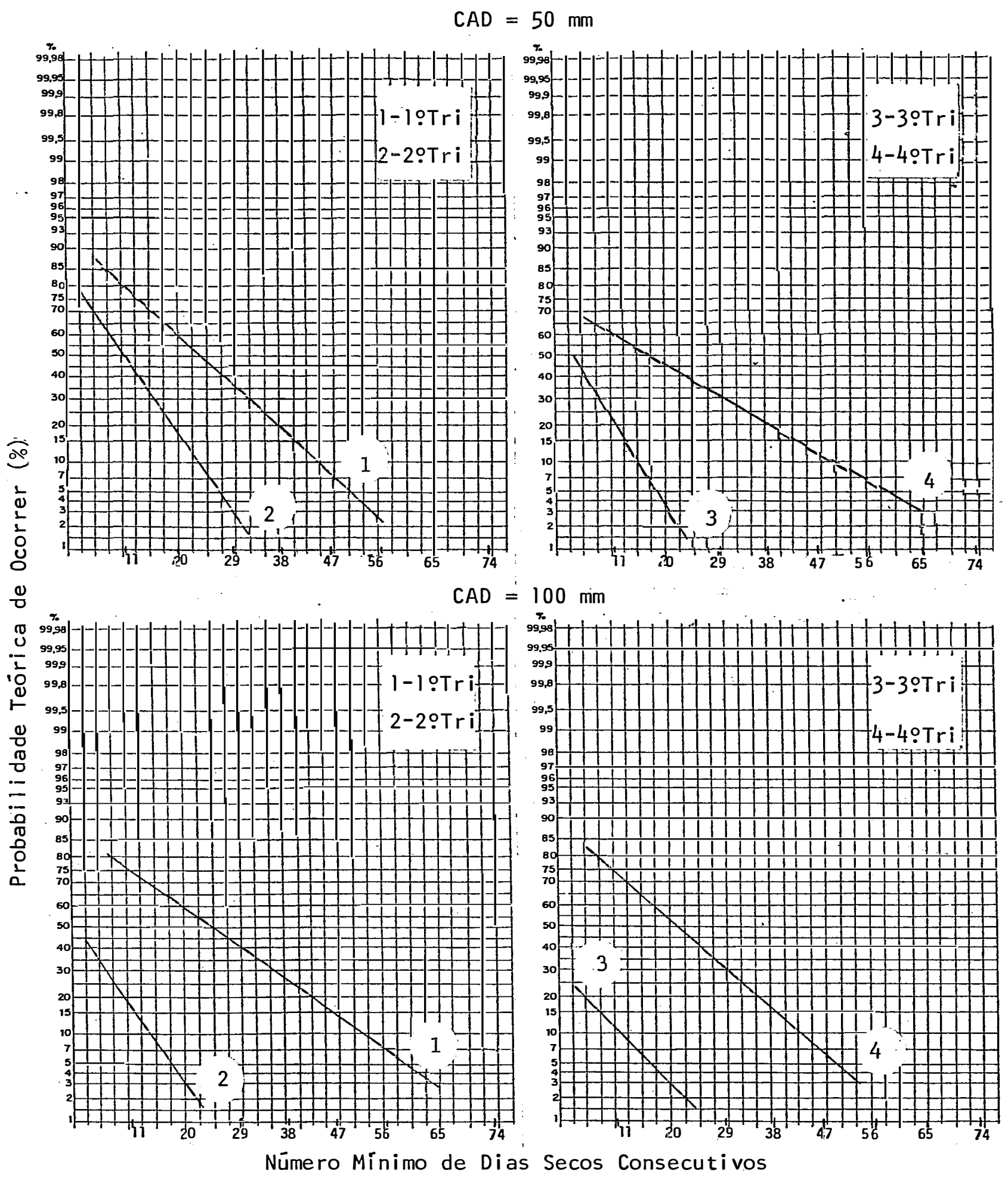

Figura 26 - Probabilidade Teórica de Ocorrer um dado Número Mínimo de Dias Secos Consecutivos, para cada Trimestre do Ano e para $50 \mathrm{~mm}$ e $100 \mathrm{~mm}$ de Capacidade de Água Disponível Máxima - CAD. 


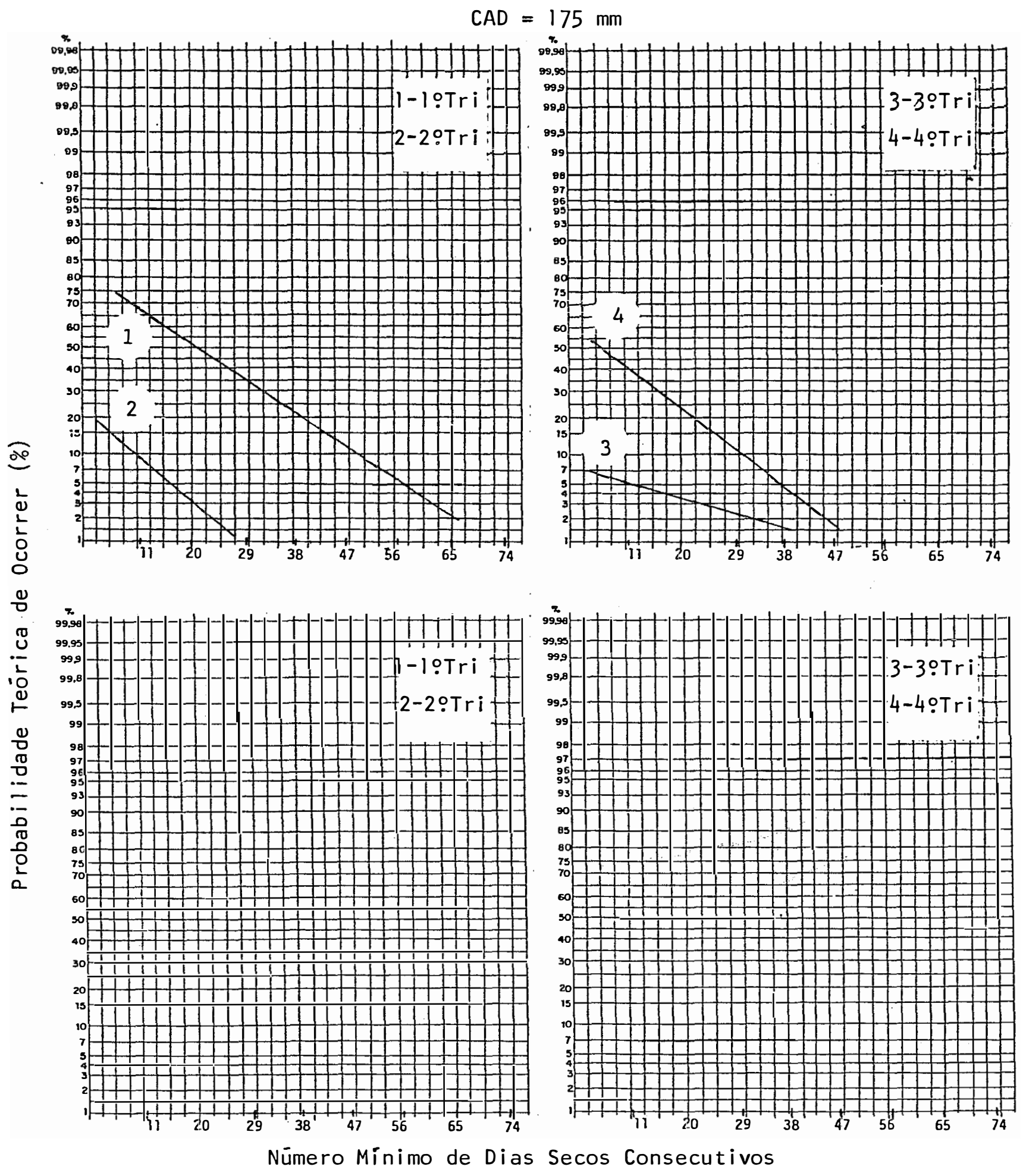

Figura 27 - Probabilidade Teórica de Ocorrer um dado Número Mínimo de Dias Secos Consecutivos, para cada Trimestre do Ano e para $175 \mathrm{~mm}$ de Capacidade de Água Disponível Māxima - CAD. 


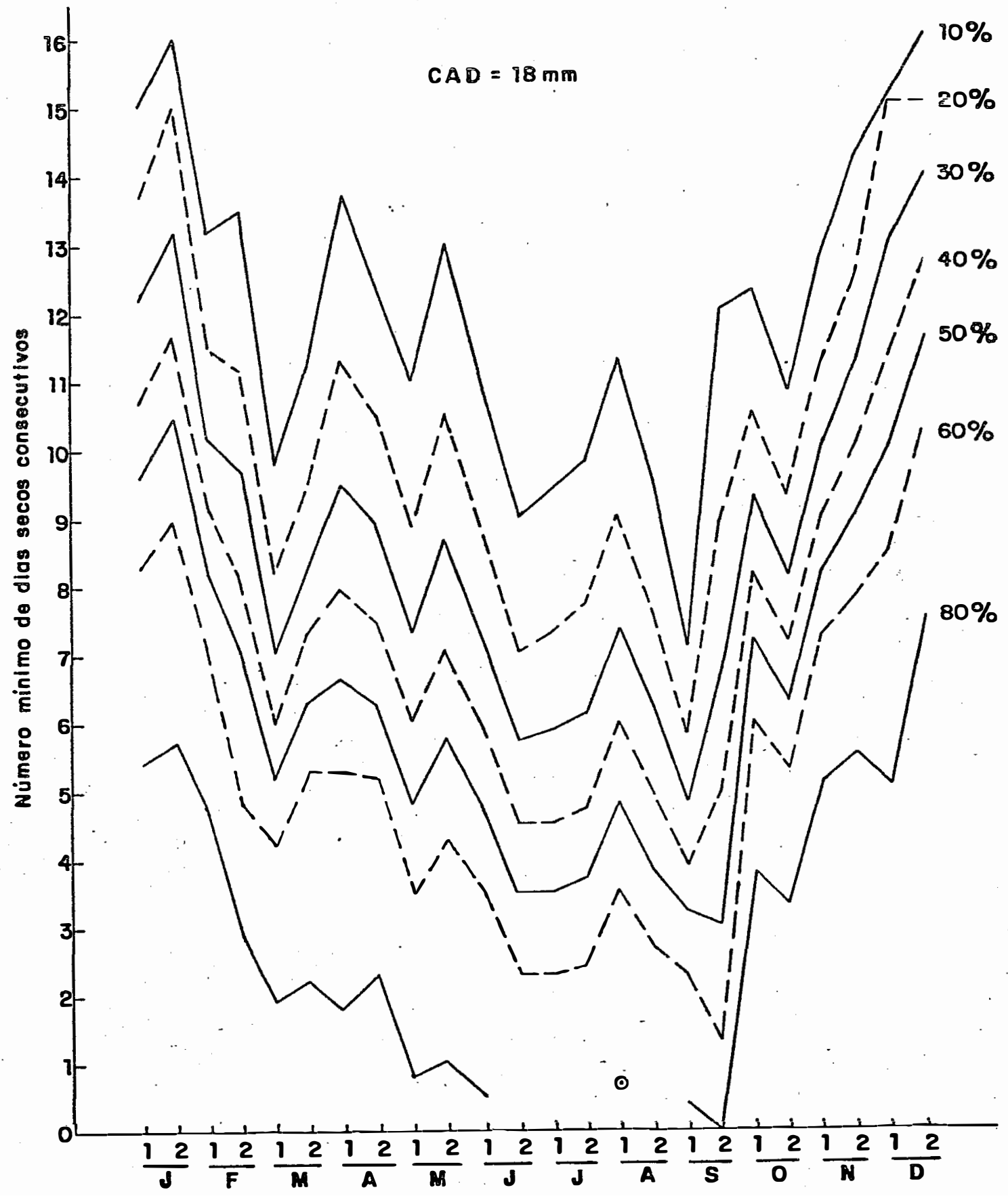

Figura 28 - Nümero Mínimo de Dias Secos Consecutivos esperados, em cada quinzena de cada mês do calendário, aos níveis de $10 \%, 20 \%$, 30\%, 40\%, 50\%, 60\% e $80 \%$ de Probabilidade Teörica, para $18 \mathrm{~mm}$ de CAD. 


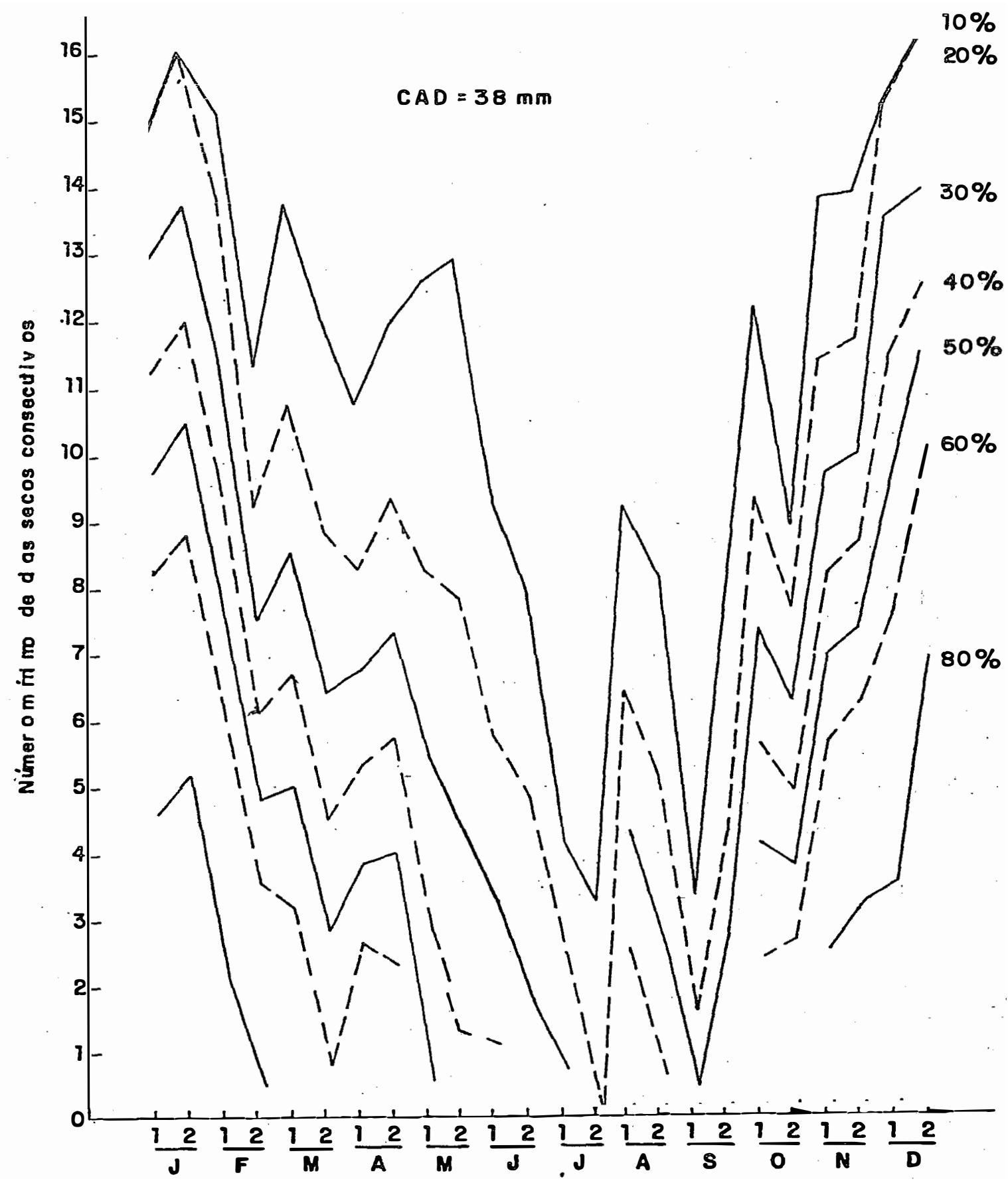

Figura 29 - Número Mínimo de Dias Secos Consecutivos esperados, em cada quinzena de cada mês do calendārio, aos níveis de $10 \%, 20 \%$, 30\%, 40\%, 50\%, 60\% e $80 \%$ de Probabilidade Teōrica, para $38 \mathrm{~mm}$ de CAD. 


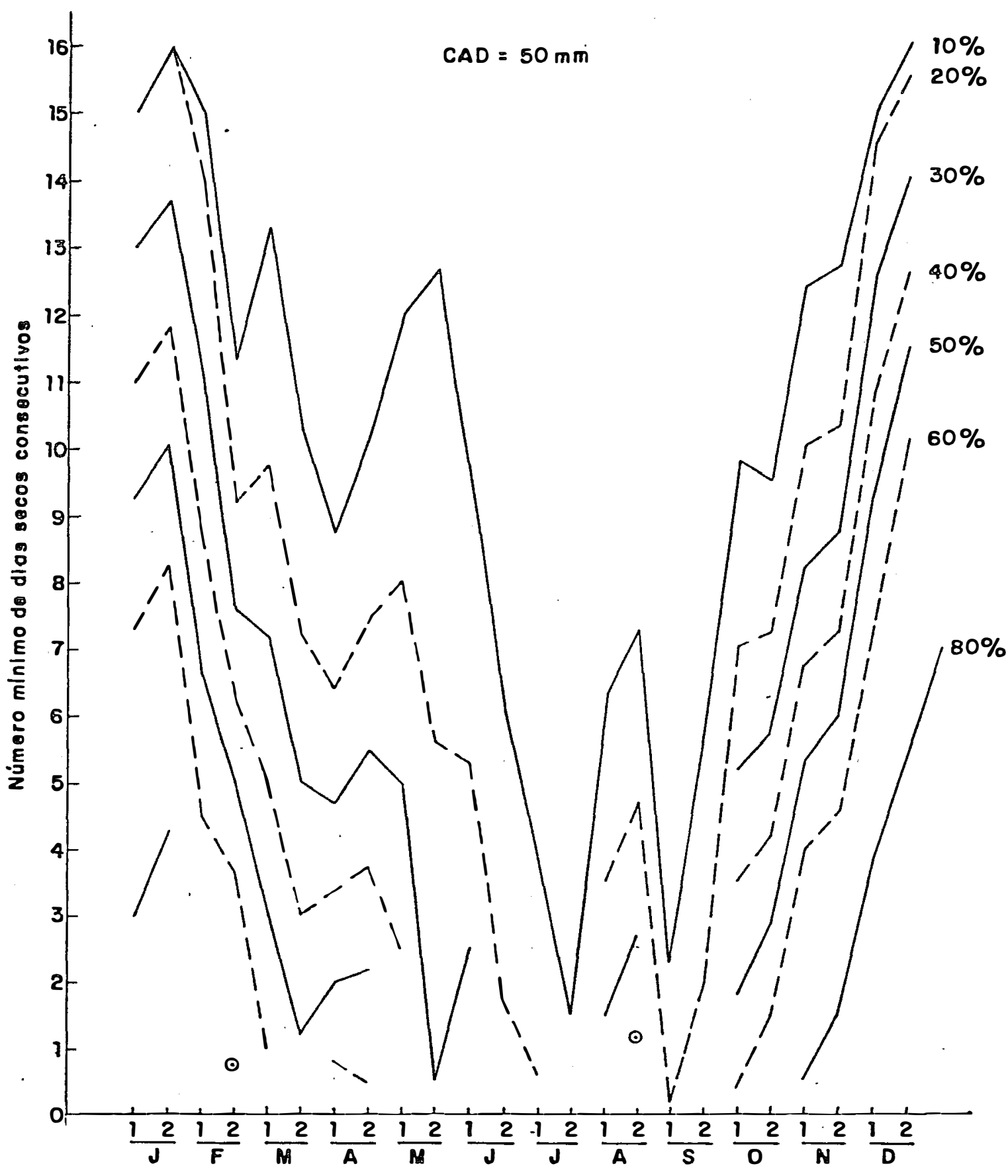

Figura 30 - Nūmero Mínimo de Dias Secos Consecutivos esperados, em cada quinzena de cada més do calendário, aos níveis de $10 \%, 20 \%, 30 \%, 40 \%, 50 \%, 60 \%$ e $80 \%$ de Probabilidade Teörica, para $50 \mathrm{~mm}$ de CAD. 


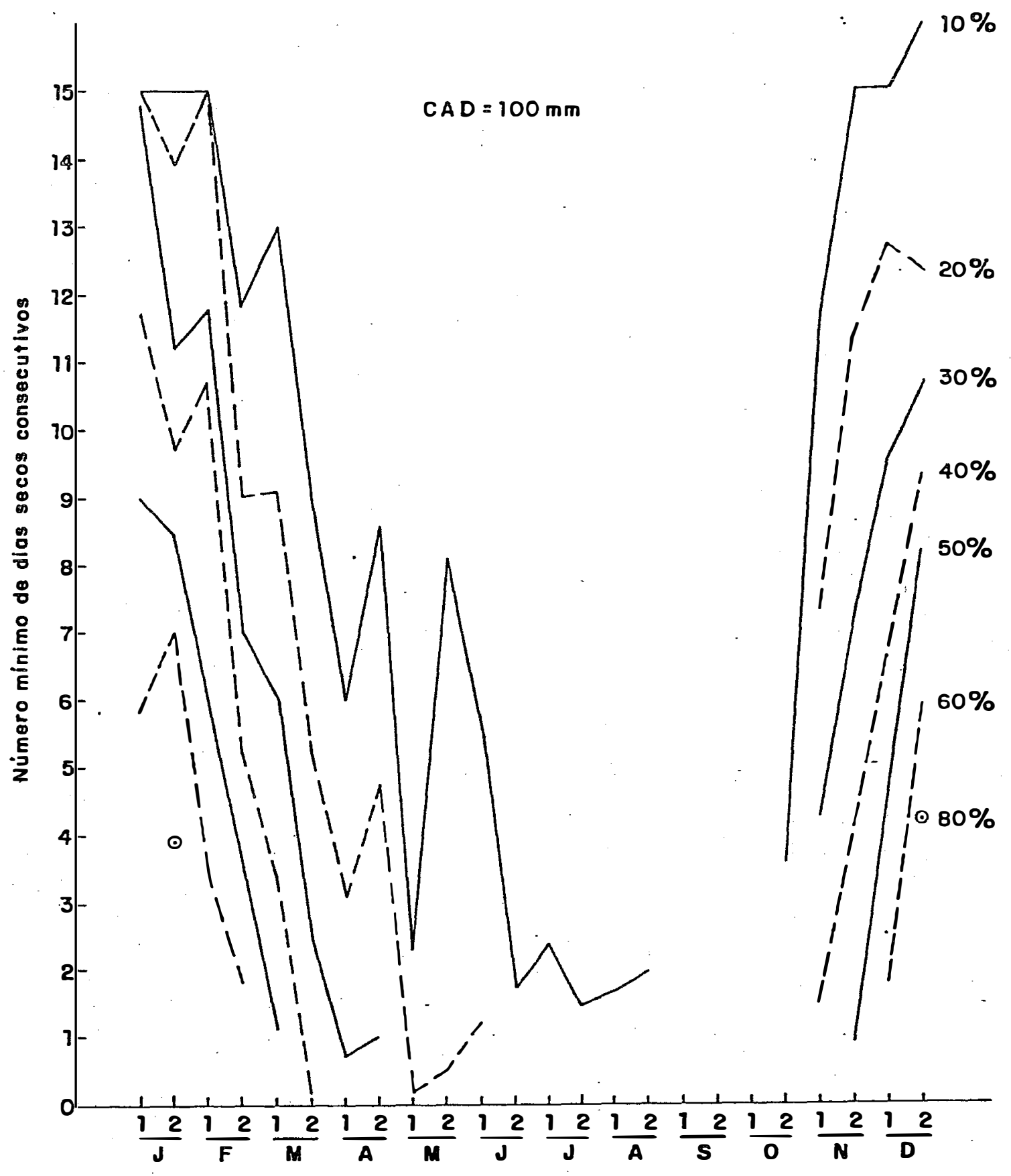

Figura 31 - Número Mínimo de Dias Secos Consecutivos esperados, em cada quinzena de cada mês do calendārio, aos níveis de $10 \%, 20 \%, 30 \%$, 40\%, 50\%, 60\% e $80 \%$ de Probabilidade Teōrica, para $100 \mathrm{~mm}$ de CAD. 


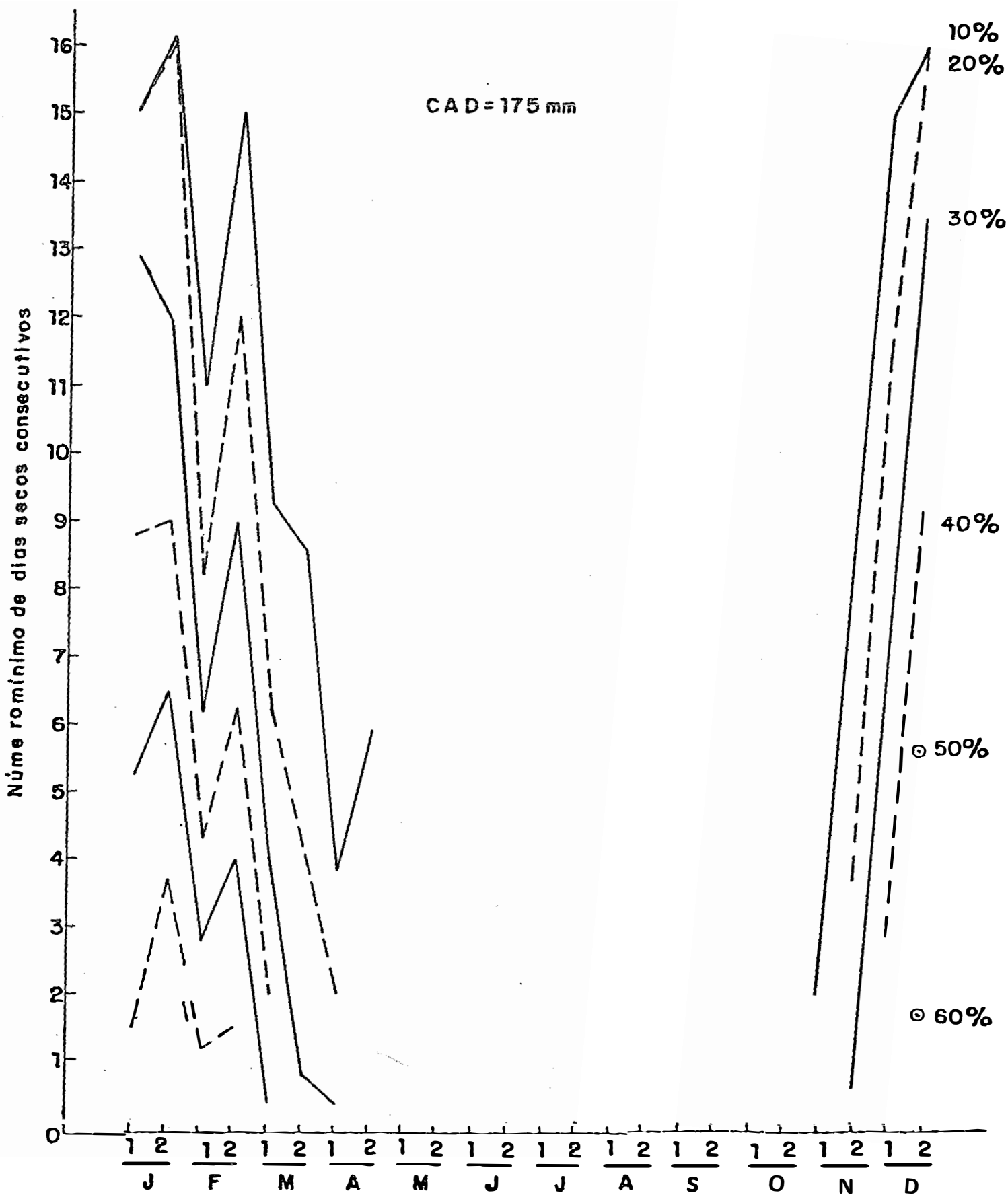

Figura 32 - Número Mínimo de Dias Secos Consecutivos esperados, em cada quinzena de cada mês do calendārio, aos níveis de 10\%, 20\%, 30\%, 40\%, 50\%, e 60\% de Probabilidade Teōrica, para $175 \mathrm{~mm}$ de CAD. 
126.

5. CONCLUSÕES

os resultados obtidos permitem as seguintes conclusões:

1) A equação de PENMAN simplificada, com a utili zação da evaporação de "Piche", em comparação com a equação original de PENMAN (1948), forneceu muito boas estimativas da $\underline{e}$ vapotranspiração potencial-ETP média diāria mensal, com um coe ficiente de determinação $\left(r^{2}\right)$ médio, para a sērie de 26 anos estudada, de $99,06 \%$ e coeficiente de variação de $0,61 \%$.

2) As estimativas do termo aerodinâmico, baseadas na evaporação de "Piche", mostraram-se muito mais seguras em relação àquelas estimadas pela equação de PENMAN (1948), bạ seadas em estimativas de velocidade média do vento pouco confiáveis. Dessa forma, as estimativas do termo aerodinâmico da equação de PENMAN, a partir de dados da evaporação de "Piche" é medida confiável e útil, principalmente em locais ca rentes de medidas adequadas da velocidade do vento ou mesmo i nexistentes. 
3) 0 nümero de contagens de dias secos totais efetuados por períodos quinzenais, mensais, trimestrais e anuais foi sempre o mesmo. Entretanto o número de sequências aumentou à medida que diminuiu o período de contagem. Comparando-se as contagens por mês e trimestre, verificou-se que mais de $85 \%$ das sequências eram menores do que 38 dias, considerando os trimes tres mais secos e, desta forma, contagens entre trimestres e a no, tornaram-se ineficientes, alèm do fato que, em períodos anuais, sua contagem nada pode informar sobre a ocorrência de suas sequéncias de dias secos, se no início,no meio ou tínal do ano.

Assim, podemos sugerir que em locais com precip $\underline{i}$ tações mais bem distribuidas, embora insuficientes, o estudo de sequências de dias secos deverá ser efetuado no máximo em contagem de três meses. As contagens de sequências por përíodos menores do que um mês, dão boas informações quanto sua maior o corréncia dentro do mês, orientando o planejamento das ativida des agrícolas, embora perdendo em informação quanto as ocorrēn cias de sequências maiores do que o período estudado e, consequentemente, sua severidade.

4). Para a Região. estudada, os meses com maiores ocorrências de dias secos totais, bem como em sequências maiores evidenciaram-se no primeiro e quarto trimestres do ano, ou seja, nos períodos de primavera-verão, embora o número total de dias secos para cada período diminuia a medida que o CAD aumentava. Os meses de outubro, novembro, dezembro, janei- 
ro, fevereiro e março, foram os que se evidenciaram pelo maior número de dias secos consecutivos e em maiores sequências, em qualquer nível de CAD estudado, mesmo para $175 \mathrm{~mm}$. As sequências correspondentes aosmeses de abril e máio também apresentạ ram-se com número elevado de dias secos consecutivos. Os meses correspondentes ao $3{ }^{\circ}$ trimestre do ano foram os que se mostra ram menos sucetíveis à ocorrência de seca agronômica. A ocorrência das sequências de dias secos, sua marcha anual, assemelhou-se, macroscopicamente, com a da evapotranspiração potencial, sendo a sua severidade ressaltada nos meses mais quentes do ano, primavera-verão, diminuindo a medida que aproximou-se dos meses de inverno.

5) As distribuições de probabilidades do número mínimo de dias secos consecutivos por períodos quinzenais, men sais e trimestrais, ajustaram-se à curva normal.

6) Mesmo para $175 \mathrm{~mm}$ de Capacidade de Agua Dispô nível Máxima no Solo-CAD, nos meses de outubro, novembro, dezembro, janeiro, fevereiro e março a severidade da seca è de tal forma acentuada que, para o mês de janeiro, na 2: quinzena, hā 50\% de probabilidade teōrica de ocorrer um nümero mínimo de 6,5 dias secos consecutivos. Confirmando que a ocorrência da seca agronômica nessa região, mais acentuada no 4 ? e 1. trimestres, não somente se deve à baixa capacidade de arma zenamento de água dos solos, mas sim às insuficientes precipitações nessa ēpoca do ano, aliada a alta demanda atmosfērica. 
7). Considerando, ainda, $100 \mathrm{~mm}$ de CAD, hà ocor rência de seca em sete meses do ano, com exceção dos meses de junho, julho, agosto, setembro e outubro, levando-se em conta um risco de $10 \%$ e uma sequencia de 10 dias secos ou mais como condição de uma seca significante. E, ainda, para um risco de $30 \%$ e uma sequência de 10 dias secos ou mais, há a sua ocorrên cia em quatro meses do ano, is to è, novembro, dezembro, janeiro e fevereiro.

8) Levando-se em consideração o solo Araranguá, de grande presença na área estudada por sua extensão e de baixa capacidade de armazenamento de água no solo, em torno de $38 \mathrm{~mm}$ para um(1) metro de profundidade, apresenta seca agronômica em todos os meses do ano ao nível de $10 \%$ e $20 \%$ de probabi lidade. Nos períodos mais quentes do ano, isto é, 19 e 4 ? trimestre, nos mesmos níveis de probabilidade, a menor sequência de dias secos ocorrida foi de 8,7 dias na $2^{\text {a }}$ quinzêna do mês de outubro, traduzindo, dessa forma, a severidade com que a se ca agronômica se manifesta nesses solos e região.

De uma maneira geral, a seca agronômica ë bastan te severa na região de Laguna, mesmo considerando-se os solos com maior CAD, nos meses correspondentes a primavera-verão. 
6. LITERATURA CITADA

AL-KHAFAF, S., P.J. WIERENGA e B.C. WILLIAMS, 1978. Evaporative Flux from Irrigated Cotton as Related Leaf area index, soil water and evaporative demand. Agronomy Journal, Was hington, $70(6): 912-17$.

AMIR, I., J.B. ARNOL.e W.K. BILANSKI, 1977. A procedure for determining problabilities of dry and wet days. Canadian Agricultural Engeneering, 0ttawa, 19:2-5.

BAIER, W. e G.W. ROBERTSON, 1966. A New Versatile Soil Moisture Budget. Canadian Journal of Plant Science, 46:299-315.

BAHRANI, B. e T. STERLING,-1961. Influence of Soil Moisture Potencial and Evaporative demand on the actual evapotranspiração from an alfafa field. A. J. Washington, 53:233-36.

BARGER, G.L. e H.C.S. THOM, 1949a. A Method for Characterizing Drought Intensity in Towa. Agronomy Journal, Washington,41: $13-19$ 
BARGER, G.L. e H.C.S. THOM, 1949b. Evalvation of Drought Hazard. Agronomy Journal, Washington, 41(11): 519-26.

BARROS FERRAZ, E.S., 1972, Estudo da Evapotranspiração Real atravēs da Medida de Umidade do Solo por Moderação de .. Neutrons. Piracicaba, SP-CENA-Boletim. Cientifico-BC.005. $40 \mathrm{p}$. BERLATO, M.A. e L.C.B. MOLION, 1981. Evaporação e Evapotranspiração. Porto Alegre, RS. IPAGRO/SA.BT, 7:96 P.

BRUNINI, 0., 1975. Relações Solo-Ãgua-Planta em Cultura de Arroz em Condições de Sequeira. Piracicaba. ESALQ. 328 P. (Tese de Doutoramento).

CAMARGO, A.P., 1966. Contribuição para Determinação da Evapotranspiração Potencial do Estado de São Paulo. Boletim do Instituto Agronômico, Campinas, n? $161,53 \mathrm{p}$.

CHANG, Jen-Hu, 1961. Microclimate of Sugar Cane. Hawaiin Planter's Record. $56: 195-223$.

CHANG, Jen-Hu, 1968. Climate and Agriculture - An Ecological Survey: Chicago. Aldine Publishing Company, $304 \mathrm{p}$.

CHAPAS, L.C.e A.R. REES, 1964. Evaporation and Evapotranspira ration in Southern Nigeria. Quarterly Journal, Royal Meteo: rological Society, $90: 313-19$.

DAKER, A., 1973. Irrigação e Drenagem. In A Ãgua na Agricultura. Rio de Janeiro. Freitas Bastos, 4. ed., vol. 3,P.325$328 ; 336-339$

DAMARI0, E.A. e A.ESCALES, 1971. Agroclimatologia de la Sequia en la Region Semi-arida Sudoccidental Pampeana. Argen tina. Rev. Fac. de Agron., La Plata, 47(2): 225-274. 
DECKER, W.L., 1957. The Likelihood of Extendend Dry Periods in Northeast Missouri. Bulletin American Meteorological Society, Vol. $38(10): 615-617$.

DENMEAD, O.P. e R.H.SHAW, 1962. Availability of Soil Water to as Affected by Soil Moisture and Meteorological Conditions. Agronomy Journal, Washington, 54(5): 385-90.

EAgLEMAN, J.R. e W.L. DECKER, 1965. The Role of Soil Moisture in Evapotranspiration. Agronomy Journal, Washington, 57:626-29.

EMPRESA CATARINENSE DE PESQUISA AgROPECUARIA. Zoneamento Agroclimático do Estado de Santa Catarina. Porto Alegre, Palotti, 1978. $150 \mathrm{p}$.

FA0, 1975. Crop Water Requirements. Rome. Irrigation and Dranage Paper n: 24, $179 \mathrm{P}$ :

FA0, 1979. Yield Response to Water. Rome. Irrigation and Dranage Paper n:33, $193 \mathrm{p}$.

FRITSCHEN, L.T. E R.H. SHAW, 1961. Evapotranspiration for Corn as Related to Pan Evaporation. Agronomy Journal, Washington, $53: 149-50$.

GAVANDE, S.A. E S.A.TAYLOR, 1967. Influence of Soil, Water Potential and Atmosferic Evaporative Demand on Transpiration and the Energy Status of Water in Plants. Agronomy Journal, Washington, 59 (1): 4-7.

GRADWELL, M.W., 1968. The Moisture-Holding Properties of Waitiatu Soils and Methods of their Determination. New Zealand Journal of Agric. Research. Wellington, 11:631-654. 
HARGREAVES, G.H., 1974. Precipitation Dependabilily and Potencial for Agriculturai Production in Northeast Brasil. Logan, UTAH STATE UNIVERSITY, $15 \mathrm{P}$.

JENSEN, M.E., J.L. WRIGHT e J.B. PRATT, 1971. Estimating Soil Moisture Depletion from Climate, Crop and Soil data. TRANSACTION OF THE ASAE, Michigan, 14:954-959.

JENSEN, M.E., 1973. Consumptive Use of Water and Irrigation Water and Irrigation Water Requirements. Am.Soc.Civil Eng., New York. P.215.

KOWAL, J.M. e A.H. KASSAM, 1973. Water Use, Energy Balance and Growth of Maize at Samaru. Northern Negeria. Agricultural Meteorology, $12(3): 391-406$.

KRAMER, P.J., 1963. Water Stress and Plant Growth. Agronomy Journal, $55: 31-35$.

LAWRENCE, E.N., 1957a. Estimation of the Frequency of Runs of Dry Days (part.1), Meteorological Magazine, London,86 (1023): $257-69$.

LAWRENCE, E.N., 1957b. Estimation of the Frequency of Rurs of Dry Days (Part.II), Meteorological Magazine, London, 86 : $301-304$.

LEMON, E.R., A.H. GLASSER e L.E. SATTERWHITE, 1957. Some Aspects of the Relationship of Soil, Plant and Meteorological Factores to Evapotranspiration. Soil Science Soc.Am.Proc., Madison, $21: 464-68$. 
LETEY, J. e G.B. BLANK, 1961. Influence of Environment of the Vegetative Growth of Plants Watered at Various Soil Moisture Suctions. Agronomy Jornal, Washington, 53: 151-53.

LEVITT, J., 1960. Some Problems in Drought Resistence. Bull. Res.Couns. of Israel, 80: 173-180.

MALLIK, A.K. e T.S. GOVINDASWAMY, 1963. The Drought Problems of India in Relation to Agriculture. Poona, USA. ANNALS of Aria Zone, Vol. 1, n: 2: 106-113.

MATZENAUER, R., 1980. Evapotranspiração do Milho (Zea mays L.) e suas Relações com Fórmulas e Parâmetros Meteorológicos. Porto Alegre, RS - UFRGS: 128 p. (Tese de Mestrado).

MATHER, J.R., 1954. The Determination of Soil Moisture from Climate Data. Bulletin of the American Meteorological Society, Easton, Pa, 35: 63-68.

MEDHI, J., 1976. A Markov Chain Model for the Occurrences of Dry and Wet Days. Indian Journal of Meteorology, Hidrology and Geophysics, New. Delhi, $27(4): 431-5$.

MEDINA, H.P., 1975. Água no Solo. In: MORIZ, A.C., Coord. Elementos de Pedologia. $2^{\text {. }}$ ed., Rio de Janeiro, Livros Técnicos e Cientificos Editora S.A., p. 45-57.

MILLAR, A.A. e W.R. GARDNER, 1972. Effect of the Soil and Plant Water Potentials on the Dry Matter Production of Snap Beans. Agronomy Journal, Washington, 64(5): 559-62.

MONTEITH, J.L., 1959. The Reflection of Short-Wave Radiation 
by Vegetation. Quartely Journal Royal Meteorological Society, $85: 386-92$.

MORETTI FILHO, J., 1965. Caracterização da Seca Agronômica na Zona Canavieira do Estado de São Paulo como Base para os És tudos de Irrigação. Piracicaba. ESALQ/USP, 93p. (Tese de Li vre-Docência.

MOTA, F.S. da, 1975. Meteorologia Agrícola. São Paulo.Livraria Nobel, 376 p.

MOTA, F.S. da e M.I.C. BEIRSDORF, 1976. Medidas e Estimativas da Evapotranspiração Potencial em Pelotas, Rio Grande do Sul. Ciência e Cultura. São Paulo, 28(6): 666-672.

MOTA, F.S. da, M.I.C. BEIRSDORF e M.J.C. ACOSTA, 1977. Estimates of Solar Radiation in Brasil. Agricultural Meteorology, Amsterdam, 18(1): 241-254.

NANKEN, L.N., C.J. GERARD e R.G. BROWN, 1968. Evapotranspiration of Cotton and Estimation Methods. Agronomy Journal, Washington, $60: 4-7$.

OMETTO, J.C., 1974. Uma Equação para a Estimativa de Evapotrans piração Potencial. Sua Aplicação no Cãlculo das Necessidades Hídricas e do Rendimento Agro-industrial da Cana-de-açú car na Região de Piracicaba (SP), (Tese de Docência-ESALQYUSP).

ORTOLANI, A.A., A.P. CAMARGO e N.A. VILLA NOVA, 1966. Correla ção entre valores decendiais da Evapotranspiração Potencial Calculados Segundo Método de PEnMAn e de THoRnthwalte de Dạ 
dos de Evapotranspirômetros, na Região de Ribeirão Preto. Bragantia, Campinas, LXV-LXVili (ñota n? 150).

PELTON, W.L., K.M. KING e G.B. TANNER, 1960. An Evaluation of THORNTHWAITE and Mean Temperature Methods for determining Potencial Evapotranspiration. Agronomy Journal, Washington, $52: 387-95$.

PENMAN, H.L., 1948. Natural Evaporation from open Water, Bare Soil, and Grass. Proceedings, Royal Society, Series A, 193: $120-45$.

PENMAN, H.L., 1949a. Meteorology and Agriculture. Quart.J.Roy. Met.Soc., 75: 298-324.

PENMAN, H.L., 1949b. The Dependence of Transpiration on Weather and Soil Conditions. J.of Soil Sci., 1: 74-89.

PENMAN, H.L., 1952. The Physical Bases of Irrigation Control. In: Report of the Thirteenth International Horticultural Con gress, London.

PETERS, D.B., 1965. Water Availability. In: BLACK,C.A. Methods. of Soil Analysis. Madison. Part.1, Cap. 19, p. 279.285.

PIERCE, L.T., 1958. Estimating Seasonal and Short Term Flutations in Evapotranspiration. Bulletin of the American Meteorological Society, Easton, Pa., 39: 73-8.

PIERCE, L.T., 1960. A Practical Method of Determining Evapotranspiration from Temperatura and Rainfall. Transactions of the ASAE, 3(1): 77-81. 
PIMENTEL GOMES, F., 1978. Curso de Estatística Experimental, USP, ESALQ, Livraria Novel, 8. ed., Piracicaba, Brasii.

PRUITT, W.0. e M.C. JENSEN, 1955. Determining when to Irrigate. Agricultural Engeneering, ST. Joseph, 36(4): 389-93.

PRUITT, W.0., 1960. Correlation of Climatological Data with Water Requirement of Crops. Departament of Irrigation, University of California, Davis.

REICHARDT, K., 1975. Processos de Transferência no Sistema Solo-Planta-Atmosfera. Piracicaba, USP/CNEN e Fundação CARGILL 3. ed., $286 \mathrm{p}$.

RICHARDS, L.A., 1955. Retention and Transmission of Water in Soils. Yearbook.

RITCHIE, J.T. e E. BURNETT, 1971. Dryland Evaporative Flux in a Subhumid Climate. II-Plant Influences. Agronomy Journal, Wastington, 63: 56-62.

ROSE, C.W., 1966. Agricultural Physics. New York.Perganon Press. 270. $\mathrm{P}$.

SANTA CATARINA. SECRETARIA DA AGRICULTURA, 1973. Levantamento. de Reconhecimento dos Solos do Estado de Santa Catarina. San ta Maria, Imprensa Universitária. 2 Volumes.

SANTA CATARINA. SECRETARIA DA AGRICULTURA, 1973. Levantamento Semi-detalhado dos Solos das Regiões de Laguna e Sul do Estado de Santa Catarina. Santa Maria, Imprensa Universitåria. SCARduA, R., 1970. Evapotranspiração Real da Cultura de Milho 
como Base aos Projetos de Irrigação. Piracicaba, ESALQ/USP. $160 \mathrm{P}$. (Tese de Doutoramento).

SCÅRDUA, J.A., 1979. Ocorréncia de Dias Secos Consecutivos na Regĩão de Cachoeira de Itapemirin, Estado do Espírito Santo. Piracicaba, ESALQ/USP, $78 \mathrm{p}$. (Tese de Mestrado).

STANHILL, G., 1962. The Use of the "Piche" Evaporimiter in the Calculation of Evaporation. Quart. J.R.Met.Soc. 88:80-82.

TANNER, C.R. e W.L. PELTON, 1960. Potencial Evapotranspiration Estimates by the Energy Balance Method of PENMAN. J.Geophys. Res. $65(10): 3391-3413$.

TANNER, C.B., 1967. Measurement of Evapotranspiration. Agronomy Journal, $11: 534-74$.

THOM, H.C.S., 1966. Some Methods of Climatological Analises. World Meteorological Organization, Geneva, Switzerland, Technical Note, $81,53 \mathrm{p}$.

THORNTHWAITE, C.W., 1946. The Moisture-Factor in Climate. Trans. Am. Geophys. Union, 27:41-48.

THORNTHWAITE, C.W., 1948. An Approach Toward a Rational Classification of Climate. Geographical Review, 38: 35-94.

THORNTHWAITE, C.W. e J.R. MATHER, 1955. The Water Balance.Centerton, New Jersey. Drexel Institute of Techonology, Publications in Climatology, Vol. VIII. $104 \mathrm{P}$.

THORNTHWAITE, C.W. e J.R. MATHER, 1957. Instructions and Tables for Computing Potential Evapotranspiration and the Wa- 
ter Balance. Centerton, New Jersey, Drexel Institute of Technology. Publications in Climatology, Vo!.x, n:3. $311 \mathrm{p}$. VAN BAVEL, C.H.M. e T.V.WILSON, 1952. Evapotranspiration Estimates as Criteria for Determining Time of Irrigation. Agricultural Engineering, 33: 417-420.

VAN BAVEL, C.H.M., 1953. A Drought Criterion and It Application in Evaluating Drought Incidence and Hazard. Agronomy Journal. Washington. 45: 167.172.

VEIHMEYER, F.J. e T.H. HENDRICKSON, 1955. Does Transpiration Decrease as the Soil Moisture Decrease? Trans. Am. Geophys. Union, $36: 425-48$.

VILLA NOVA, N.A., 1973. Estudos sobre o Balanço de Energia em Cultura de Arroz. Piracicaba. ESALQ/USP. 98 p. (Tése de Livre-Docente).

VILLA NOVA, N.A., V. BARBIERI e R. SCARDUA, 1980. Evaporação e Evapotranspiração: Principais Mëtodos de Estimativa Climato lōgica segundo as Recomendações da FAO (1979). Piracicaba. Departamento de Física e Meteorologia. ESALQ/USP. 22 p.

VILlA NOVA, N.A. e J.C. OMETTO, 1981. Adaptação e Simplificação do Mētodo de PENMAN às Condições Climāticas do Estado de São Paulo. IV Simpósio Brasileiro de Hidrologia e Recursos Hidricos. 15-19 de novembro. Fortaleza/CE, Brasil. 
A P E N D I C E S 


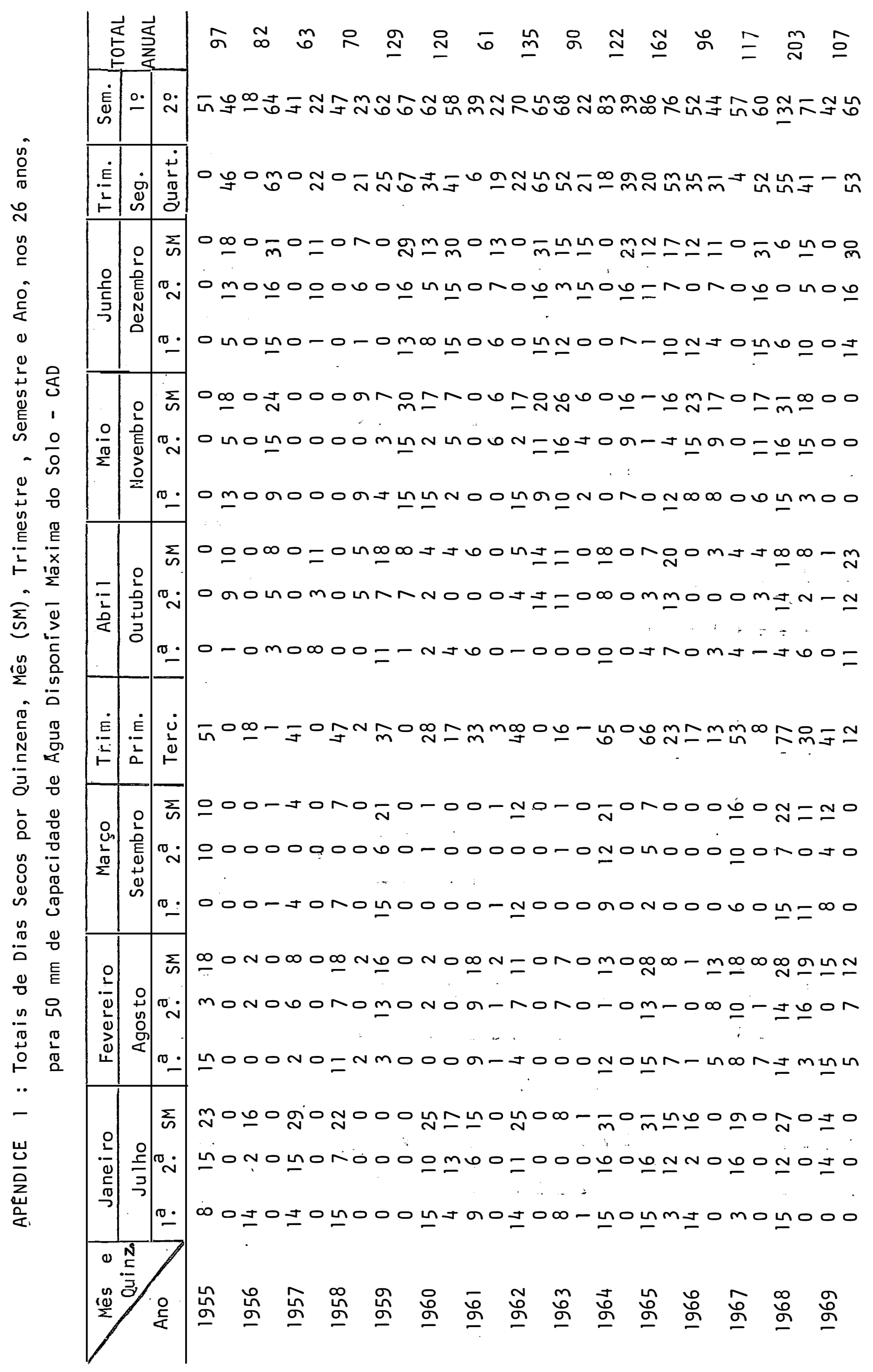

141. 


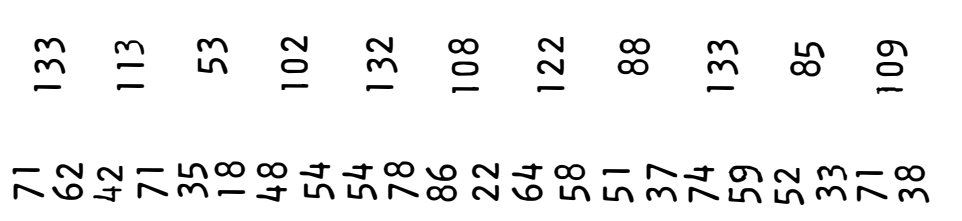

ㅇำ

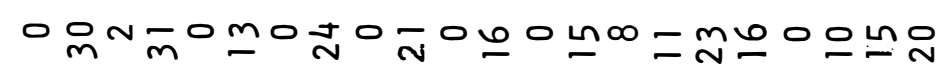

o ก

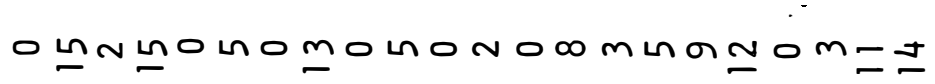

ำ

onominomogom

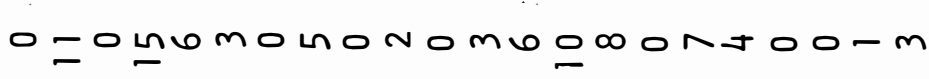

어음

E 0000 on

d Too 00 I

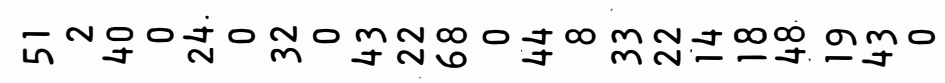

Nomoog a

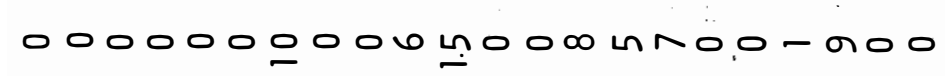

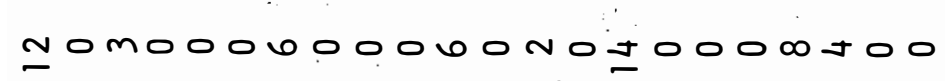

ลN Noำ INEO-

nomo a

mono

No no ino

- 000 o 0 a

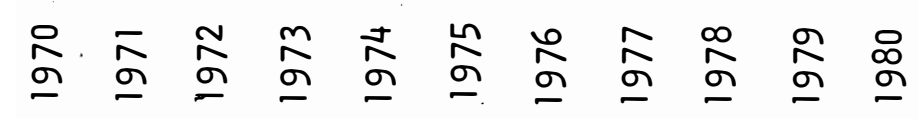

142 . 


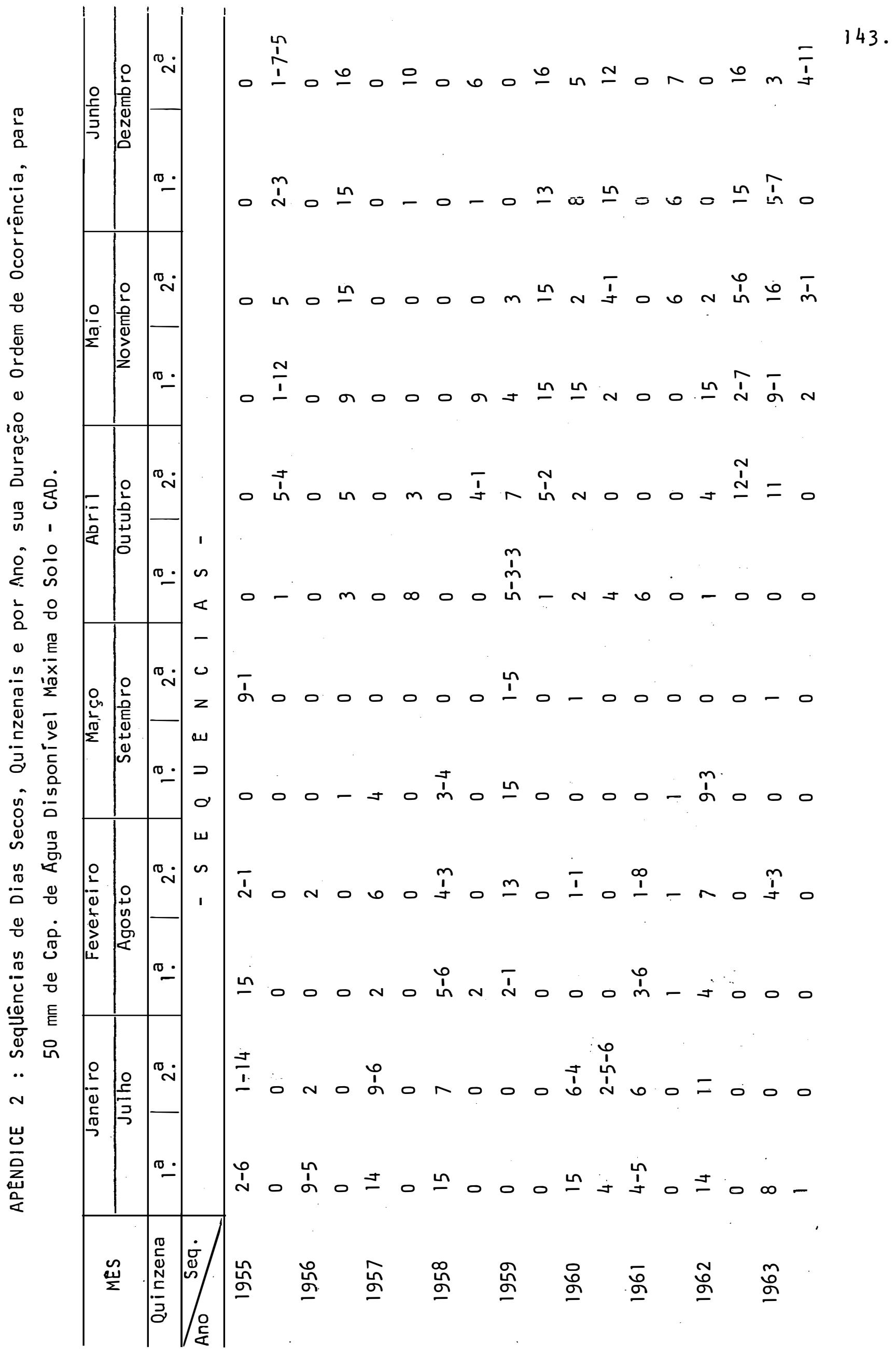




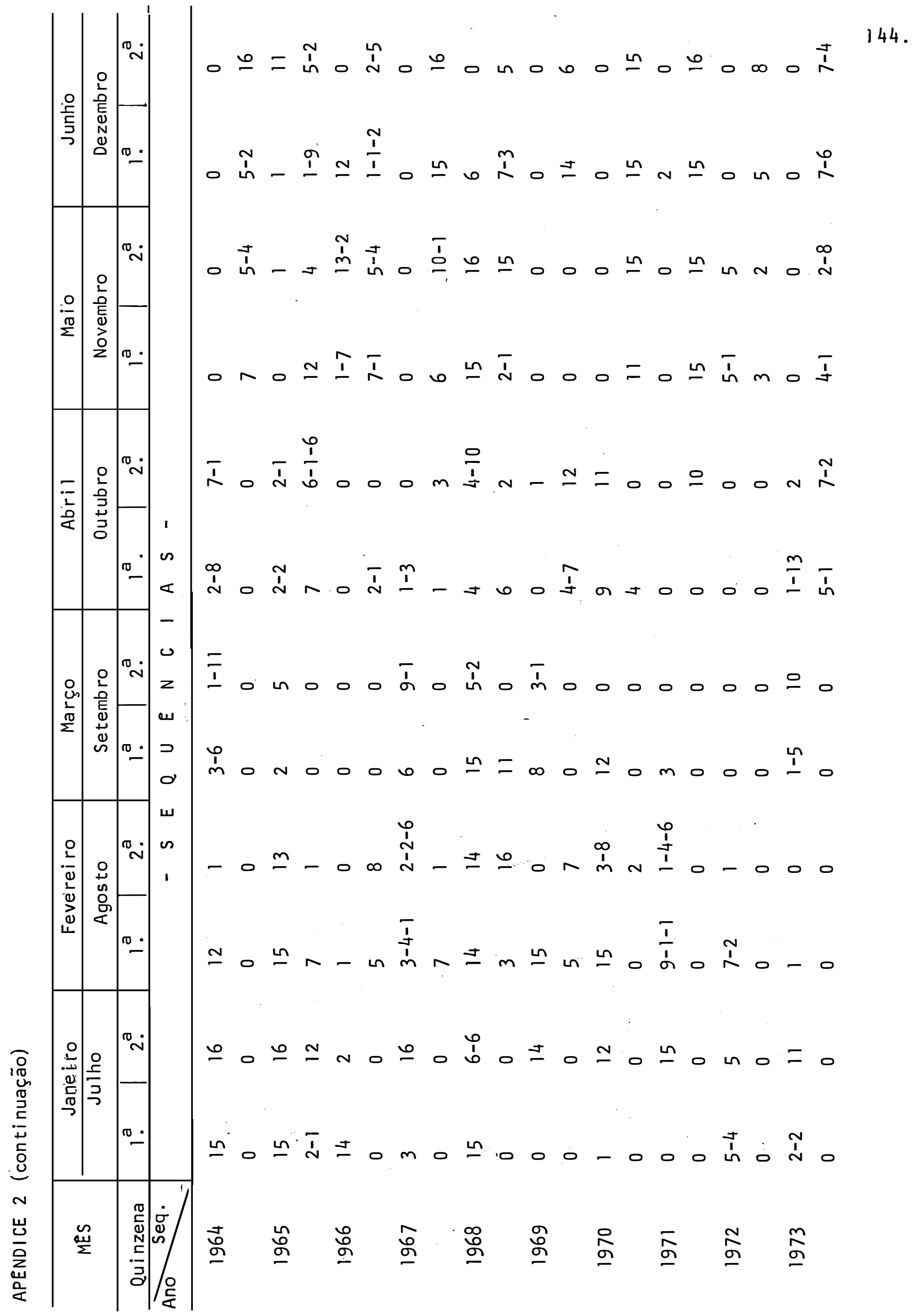




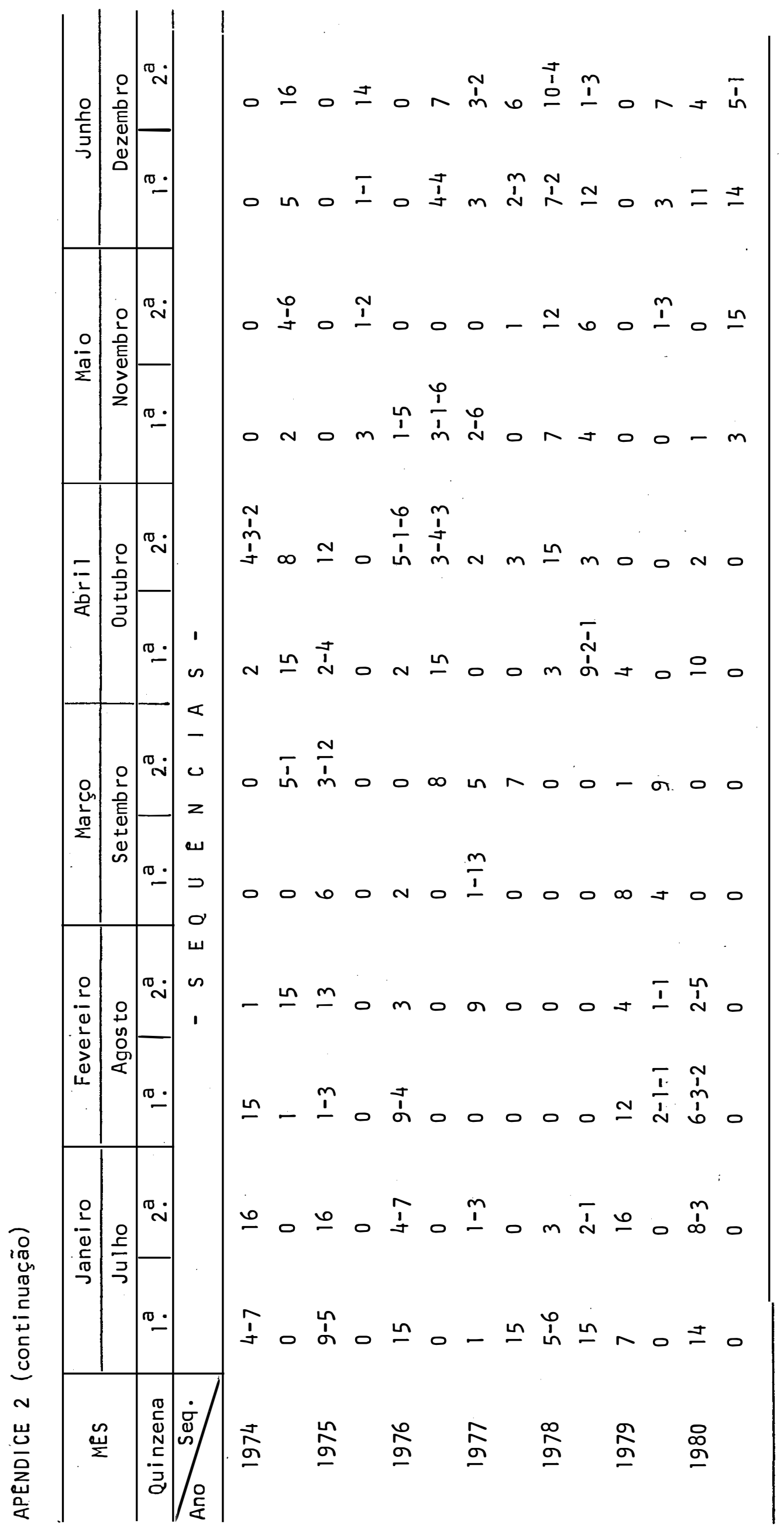

145. 
146.

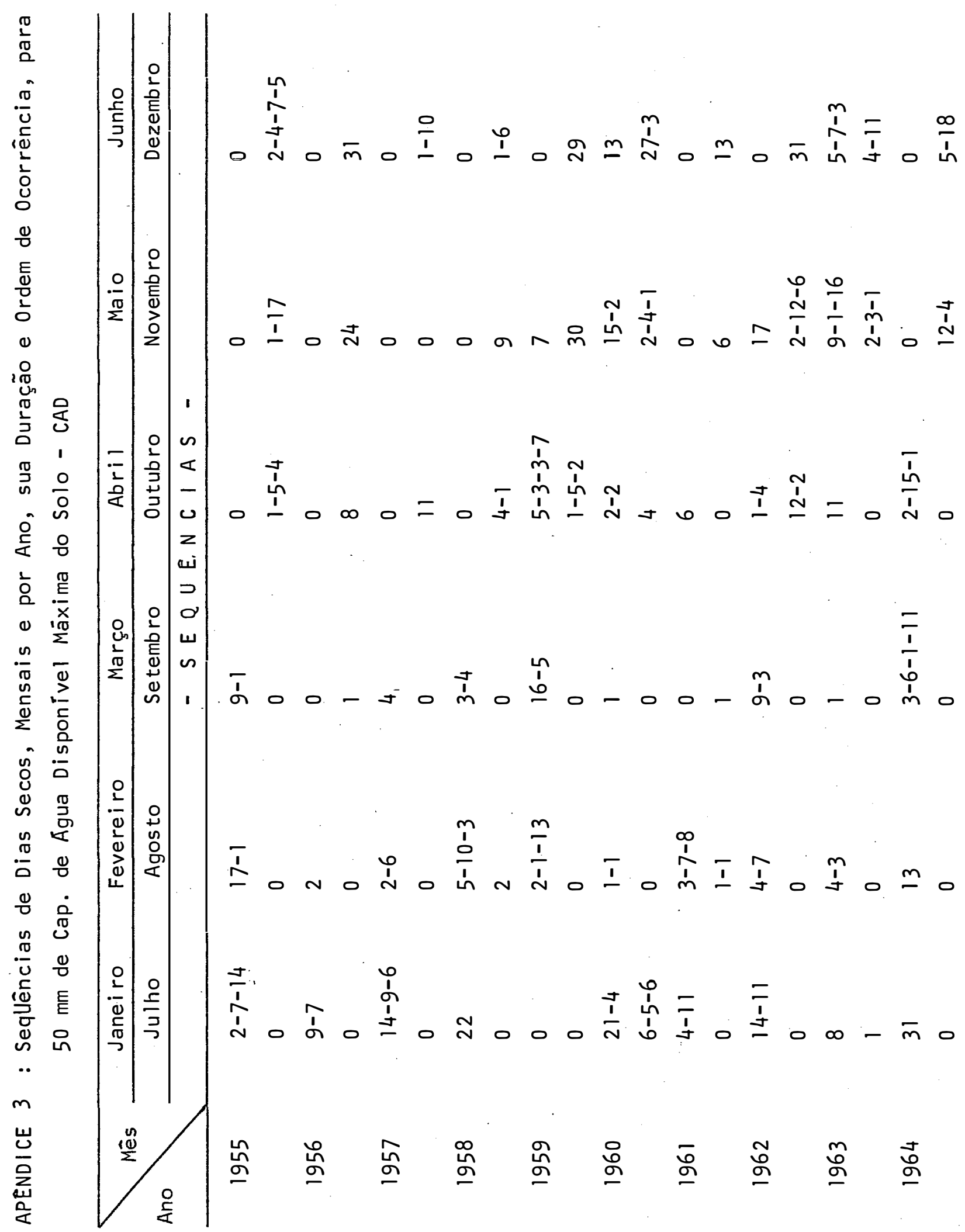


147.

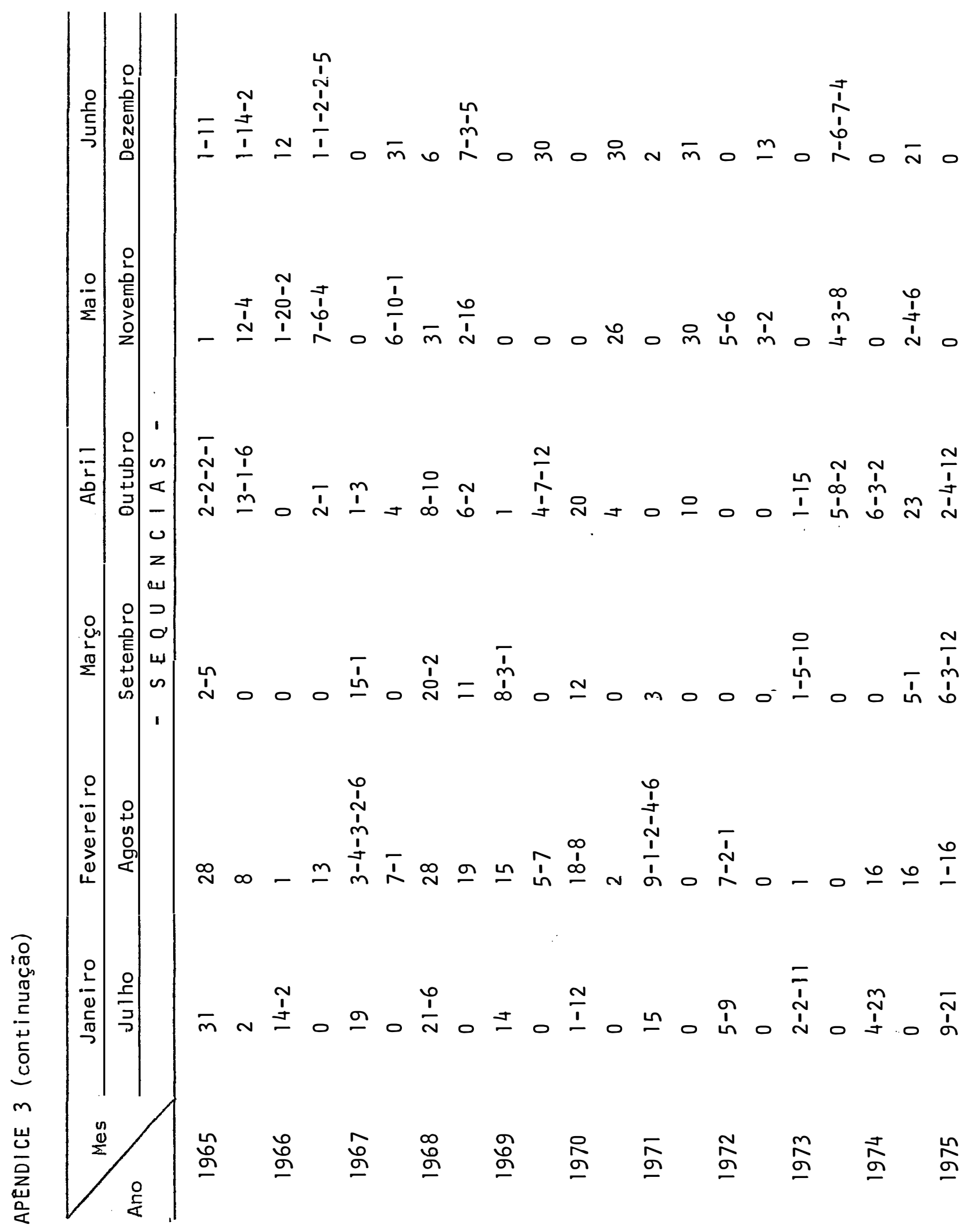


148.

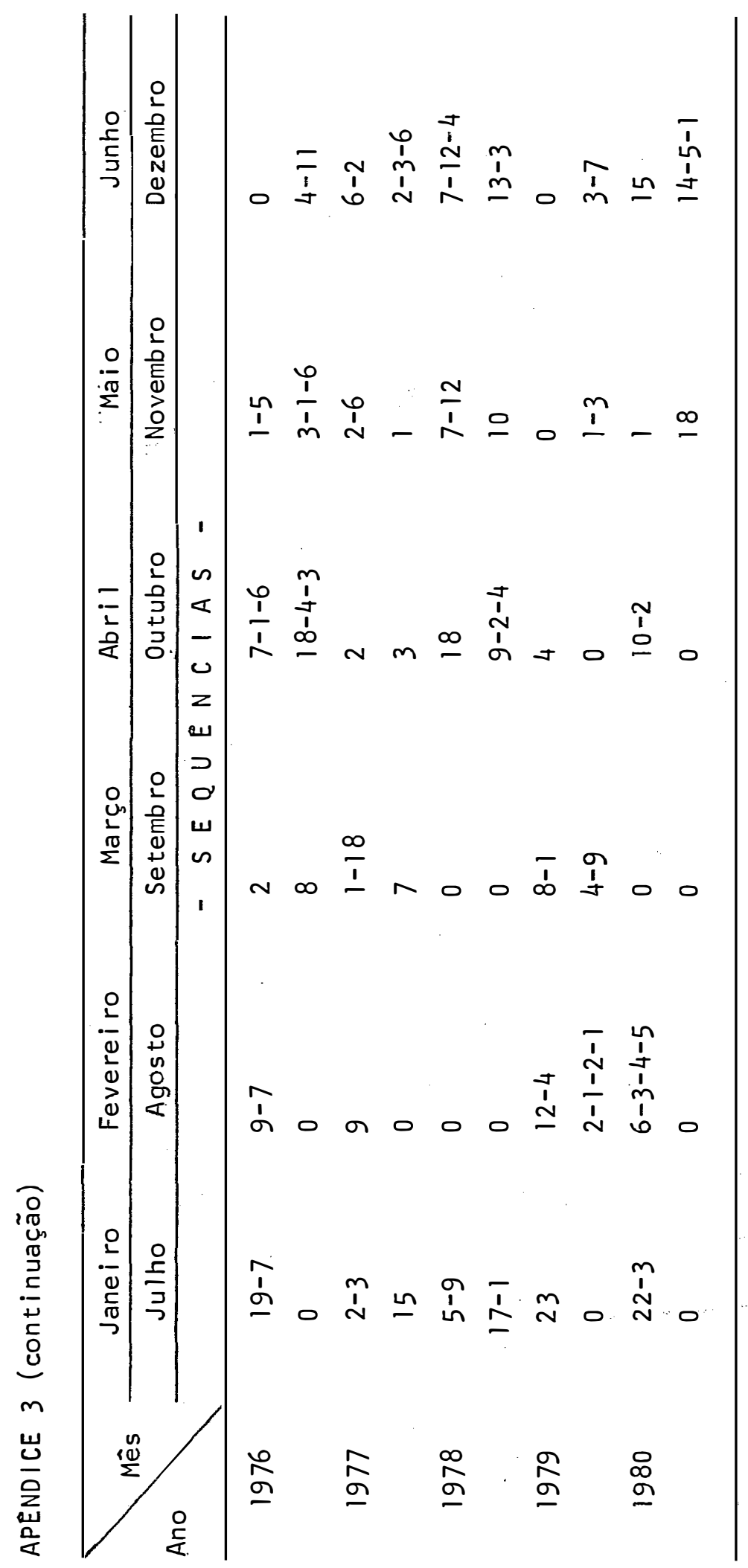




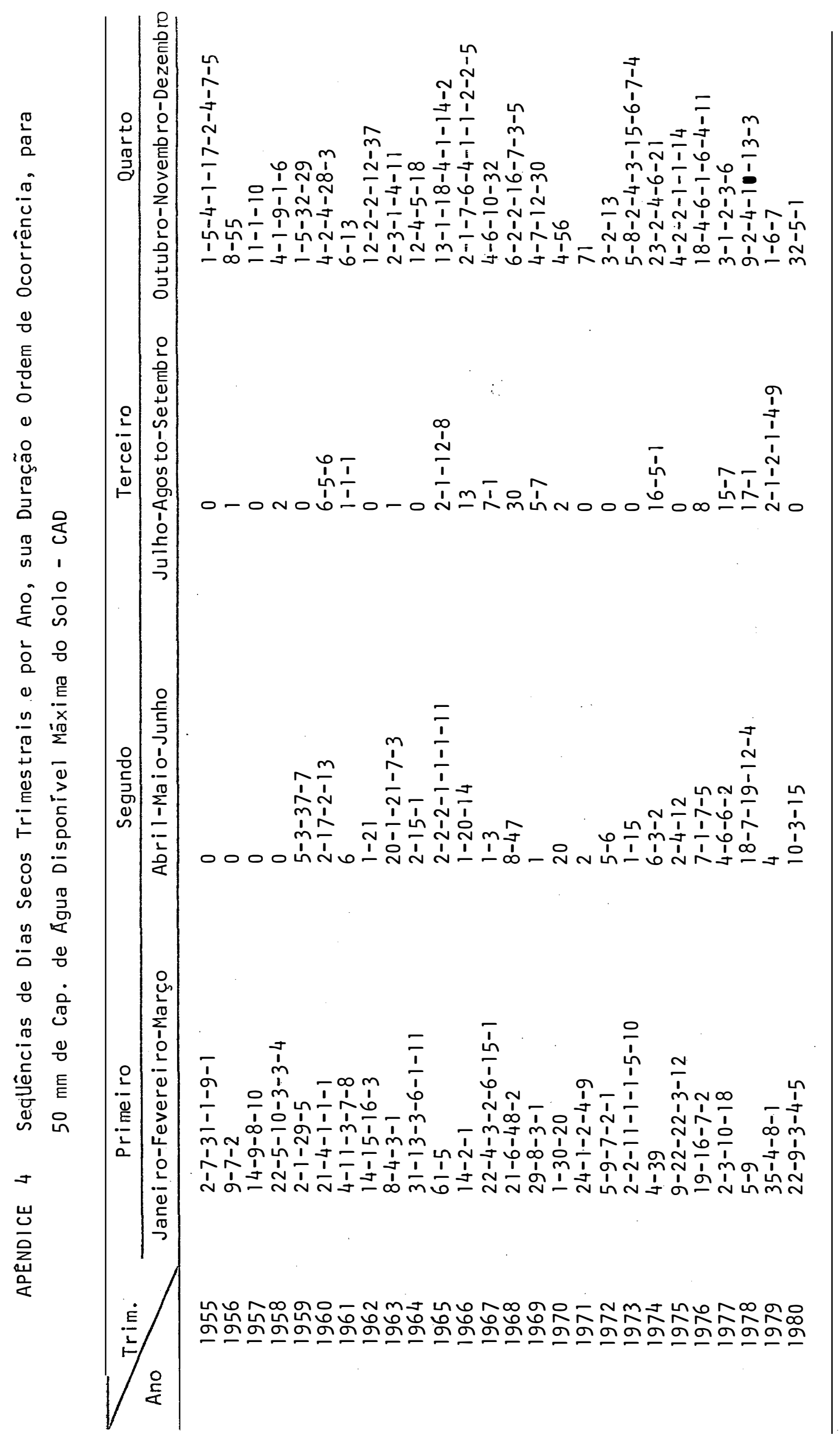

149. 
APENDICE 5 : Classes das Maiores SeqUências de Dias Secos em cada Quinzena, Frequência Absoluta, em \%, Frequência Acumulada Complemetar em Percentagem e Probabilidade Linear ( $P L)$, nos 26 anos, para $50 \mathrm{~mm}$ de Capacidade de Âgua Disponível Máxima - CAD

Mês: Janei ro $Q$ : 1 ?

\begin{tabular}{rrrl}
$F$ & $F \%$ & \multicolumn{1}{c}{$F A_{C} \%$} & \multicolumn{1}{l}{$P L$} \\
3 & 11,54 & 100,00 & - \\
3 & 11,54 & 88,46 & 12,88 \\
1 & 3,85 & 76,92 & 11,18 \\
4 & 15,38 & 73,07 & 10,74 \\
3 & 11,54 & 57,69 & 9,19 \\
2 & 7,69 & 46,15 & 8,12 \\
0 & 0,00 & 38,46 & 7,40 \\
4 & 15,38 & 38,46 & 7,40 \\
6 & 23,08 & 23,08 & 5,76
\end{tabular}

Mês: Feverei ro Q: $1^{a}$.

\begin{tabular}{rrrrc}
$F$ & \multicolumn{1}{c}{$F \%$} & \multicolumn{1}{l}{ FA ${ }_{c} \%$} & \multicolumn{1}{l}{ PL } & CLASSES \\
5 & 19,23 & 100,00 & \multicolumn{1}{l}{-} & zero \\
4 & 15,38 & 80,77 & 11,65 & $1-2$ \\
3 & 11,54 & 65,39 & 9,94 & $3-4$ \\
3 & 11,54 & 53,85 & 8,84 & $5-6$ \\
1 & 3,85 & 42,31 & 7,74 & $7-8$ \\
2 & 7,69 & 38,46 & 7,40 & $9-10$ \\
2 & 7,69 & 30,77 & 6,63 & $11-12$ \\
1 & 3,85 & 23,08 & 5,76 & $13-14$ \\
5 & 19,23 & 19,23 & 5,27 & $15-16$
\end{tabular}

Mês: Março Q: 1 a

\begin{tabular}{rrrc}
$F$ & $F \%$ & \multicolumn{1}{c}{$F A_{C \%}$} & $P L$ \\
10 & 38,46 & 100,00 & - \\
2 & 7,69 & 61,54 & 9,55 \\
3 & 11,54 & 53,85 & 8,84 \\
4 & 15,38 & 42,31 & 7,74 \\
2 & 7,69 & 26,93 & 6,19 \\
1 & 3,85 & 19,24 & 5,27 \\
1 & 3,85 & 15,39 & 4,78 \\
1 & 3,85 & 11,54 & 4,10 \\
2 & 7,69 & 7,69 & 3,23
\end{tabular}

Mês. Janei ro $Q: 2$ ?

\begin{tabular}{lrrrc} 
CLASSES & $F$ & \multicolumn{1}{c}{$F \%$} & \multicolumn{1}{c}{$F A_{C} \%$} & $\underline{P L}$ \\
zero & 2 & 7,69 & 100,00 & - \\
$.3-2$ & 2 & 7,69 & 92,31 & 13,67 \\
$3-4$ & 2 & 7,69 & 84,62 & 12,24 \\
$5-6$ & 4 & 15,38 & 76,93 & 11,18 \\
$7-8$ & 3 & 11,54 & 61,55 & 9,55 \\
$-9-10$ & 1 & 3,85 & 50,01 & 8,50 \\
$11-12$ & 3 & 11,54 & 46,16 & 8,12 \\
$13-14$ & 2 & 7,69 & 34,62 & 7,01 \\
$15-16$ & 7 & 26,92 & 26,93 & 6,19
\end{tabular}

Mês: Fevereiro $Q: 2^{\text {a }}$.

$\begin{array}{rrrc}F & F \% & F_{C A} \% & P L \\ 4 & 15,38 & 100,00 & - \\ 6 & 23,08 & 84,62 & 12,24 \\ 4 & 15,38 & 61,54 & 9,55 \\ 4 & 15,38 & 46,16 & 8,12 \\ 3 & 11,54 & 30,78 & 6,63 \\ 1 & 3,85 & 19,24 & 5,27 \\ 0 & 0,00 & 15,39 & 4,78 \\ 4 & 15,38 & 15,39 & 4,78 \\ 0 & 0,00 & - & -\end{array}$

CLASSES

ze ro

1-2

3-4

5-6

7-8

$9-10$

$11-12$

$13-14$

$15-16$
Mês : Março

$Q: 2^{a}$.

$\begin{array}{cccc}F & F \% & F_{C \%} & P L \\ & & & \\ 13 & 50,00 & 100,00 & - \\ 3 & 11,54 & 50,00 & 8,50 \\ 1 & 3,85 & 38,46 & 7,40 \\ 4 & 15,38 & 34,61 & 7,01 \\ 0 & 0,00 & 19,23 & 5,27 \\ 3 & 11,54 & 19,23 & 5,27 \\ 2 & 7,69 & 7,69 & 3,26 \\ 0 & - & - & - \\ 0 & - & - & -\end{array}$


151.

APENDICE 5 (continuação)

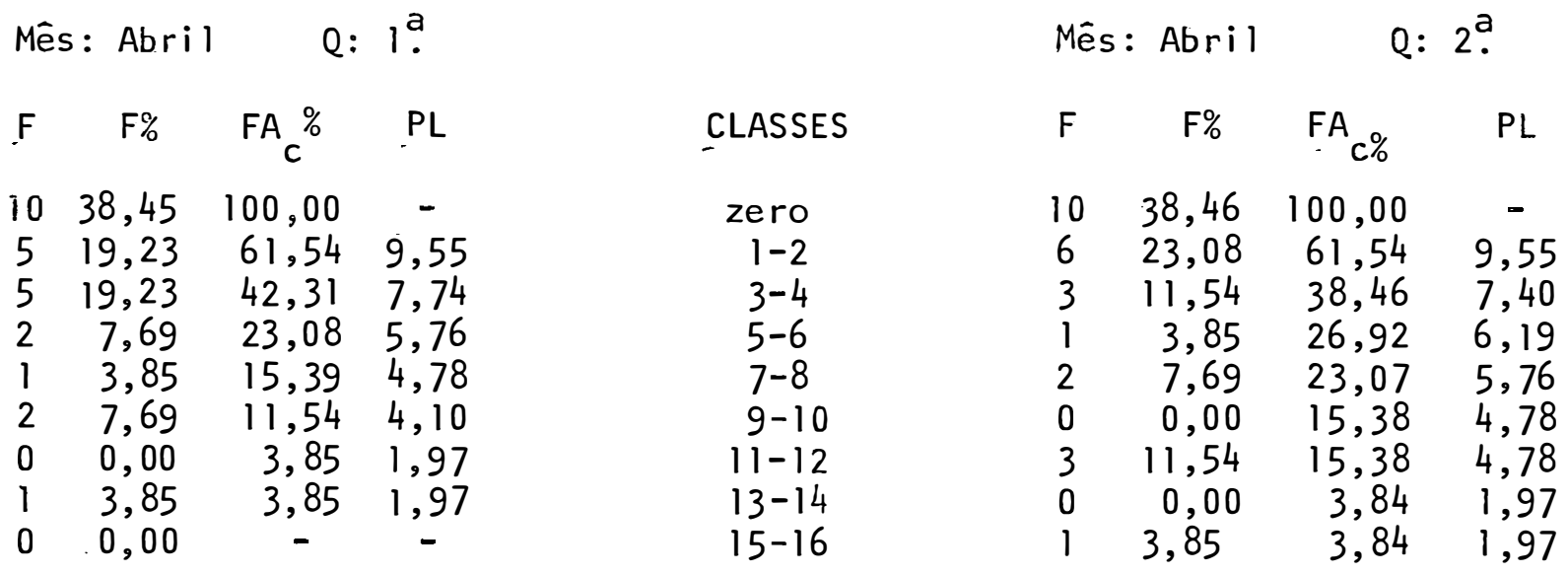

Mês: Maio Q: la $^{\circ}$

$\begin{array}{rrrc}\mathrm{F} & \mathrm{F} \% & \mathrm{FA} \% & \mathrm{PL} \\ 15 & 57,69 & 100,00 & - \\ 1 & 3,85 & 42,31 & 7,74 \\ 1 & 3,85 & 38,46 & 7,40 \\ 3 & 11,54 & 34,61 & 7,01 \\ 2 & 7,69 & 23,07 & 5,76 \\ 1 & 3,85 & 15,38 & 4,78 \\ 0 & 0,00 & 11,53 & 4,10 \\ 0 & 0,00 & 11,53 & 4,10 \\ 3 & 11,54 & 11,53 & 4,10\end{array}$

CLASSES
zero
$1-2$
$3-4$
$5-6$
$7-8$
$9-10$
$11-12$
$13-14$
$15-16$

Mês: Maio

$Q: 2^{a}$.

\begin{tabular}{cccc}
$F$ & $F \%$ & \multicolumn{1}{c}{$F{ }_{C} \%$} & $P L$ \\
17 & 65,38 & 100,00 & - \\
3 & 11,54 & 34,62 & 7,01 \\
1 & 3,85 & 23,08 & 5,76 \\
1 & 3,85 & 19,23 & 5,27 \\
0 & 0,00 & 15,38 & 4,78 \\
0 & 0,00 & 15,38 & 4,78 \\
1 & 3,85 & 15,38 & 4,78 \\
1 & 3,85 & 11,53 & 4,10 \\
2 & 7,69 & 7,69 & 4,26
\end{tabular}

Mês: Junho $Q:$ l.

\begin{tabular}{cccc}
$\mathrm{F}$ & $\mathrm{F} \%$ & $\mathrm{FA} \%$ & $\mathrm{PL}$ \\
& & \multicolumn{1}{c}{${ }^{2}$} & \\
17 & 65,38 & 100,00 & - \\
2 & 7,69 & 34,62 & 7,01 \\
1 & 3,85 & 26,93 & 6,19 \\
1 & 3,85 & 23,08 & 5,76 \\
3 & 11,54 & 19,23 & 5,27 \\
0 & 0,00 & 7,69 & 3,26 \\
2 & 7,69 & 7,69 & 3,26 \\
0 & 7,69 & - & - \\
0 & - & - & -
\end{tabular}

Mês: Junho

$Q: 2^{a}$

CLASSES
zero
$1-2$
$3-4$
$5-6$
$7-8$
$9-10$
$11-12$
$13-14$
$15-16$

$\begin{array}{cccc}F & F \% & F A_{C \%} \% & P L \\ 20 & 76,92 & 100,00 & - \\ 0 & 0,00 & 23,08 & 5,76 \\ 3 & 11,54 & 23,08 & 5,76 \\ 1 & 3,85 & 11,54 & 4,10 \\ 0 & 0,00 & 7,69 & 3,26 \\ 1 & 3,85 & 3,84 & 3,26 \\ 1 & 3,85 & - & 1,97 \\ 0 & - & - & - \\ 0 & - & & -\end{array}$


APENDICE 5 (continuação)

\begin{tabular}{|c|c|c|c|c|c|c|c|c|}
\hline \multicolumn{2}{|c|}{ Mês: Julho } & \multicolumn{2}{|c|}{$Q: 1^{a}$} & & \multicolumn{2}{|c|}{ Mês: Julho } & \multicolumn{2}{|c|}{$Q: 2^{a}$. } \\
\hline $\mathrm{F}$ & $\mathrm{F} \%$ & $F A_{c} \%$ & PL & CLASSES & $\mathrm{F}$ & $\mathrm{F} \%$ & $F A_{c} \%$ & PL \\
\hline 21 & 80,77 & 100,00 & - & zero & 23 & 88,46 & 100,00 & - \\
\hline 2 & 7,69 & 19,23 & 5,27 & $1-2$ & 1 & 3,85 & 11,54 & 4,10 \\
\hline 1 & 3,85 & 11,54 & 4,10 & $3-4$ & 0 & 0,00 & 7,69 & 3,26 \\
\hline 0 & 0,00 & 7,69 & 3,26 & $5-6$ & 1 & 3,85 & 7,69 & 3,26 \\
\hline 0 & 0,00 & 7,69 & - & $7-8$ & 0 & 0,00 & 3,84 & 1,97 \\
\hline 0 & 0,00 & 7,69 & - & $9-10$ & 0 & 0,00 & 3,84 & 1,97 \\
\hline 0 & 0,00 & 7,69 & - & $11-12$ & 1 & 3,85 & 3,85 & 1,97 \\
\hline 0 & 0,00 & 7,69 & - & $13-14$ & 0 & - & 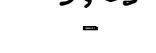 & - \\
\hline 2 & 7,69 & 7,69 & - & $15-16$ & 0 & - & - & - \\
\hline
\end{tabular}

Mês: Agos to Q: $1^{a}$

$\begin{array}{cccc}\mathrm{F} & \mathrm{F}_{-} \% & \mathrm{FA}_{\mathrm{c}} \% & \mathrm{PL} \\ 17 & 65,38 & 100,00 & - \\ 4 & 15,38 & 34,62 & 7,01 \\ 1 & 3,85 & 19,24 & 6,27 \\ 2 & 7,69 & 15,39 & 4,78 \\ 2 & 7,69 & 7,70 & 3,26 \\ 0 & - & - & - \\ 0 & - & - & - \\ 0 & - & - & - \\ 0 & - & - & -\end{array}$

Mês: Setembro Q: 1 .

$\begin{array}{cccc}\mathrm{F} & \mathrm{F} \% & -\mathrm{FA} \mathrm{c}^{\%} & -\mathrm{PL} \\ & & \\ 22 & 84,62 & 100,00 & - \\ 2 & 7,69 & 15,38 & 4,78 \\ 1 & 3,85 & 7,69 & 3,26 \\ 0 & 0,00 & 3,84 & 1,97 \\ 0 & 0,00 & 3,84 & - \\ 0 & 0,00 & 3,84 & - \\ 1 & 3,85 & 3,84 & - \\ 0 & 0,00 & - & - \\ 0 & 0,00 & - & -\end{array}$

CLASSES
zero
$1-2$
$3-4$
$5-6$
$7-8$
$9-10$
$11-12$
$13-14$
$15-16$

Mês: Agos to

Q: 2 .

\begin{tabular}{crrc} 
F. & F\% & \multicolumn{1}{c}{ EA ${ }^{\%}$} & PL \\
14 & 53,85 & 100,00 & - \\
5 & 19,23 & 46,15 & 8,12 \\
3 & 11,54 & 26,92 & 6,19 \\
0 & 0,00 & 15,38 & 4,78 \\
2 & 7,69 & 15,38 & 4,78 \\
0 & 0,00 & 7,69 & 3,26 \\
0 & 0,00 & 7,69 & $-3,26$ \\
0 & 0,00 & 7,69 & 3,26 \\
2 & 7,69 & 7,69 & 3,26
\end{tabular}

Mês: Setembro Q: 2 .

TLASSES

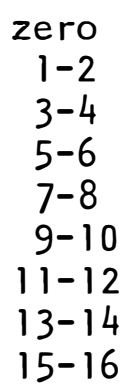

$\begin{array}{cccc}F & F \% & F_{c} \% & P L \\ 22 & 84,61 & 100,00 & - \\ 0 & 0,00 & 15,39 & 4,78 \\ 0 & 0,00 & 15,39 & 4,78 \\ 1 & 3,85 & 15,39 & 4,78 \\ 2 & 7,69 & 11,54 & 4,10 \\ 1 & 3,85 & 3,85 & 1,97 \\ 0 & - & - & - \\ 0 & - & - & - \\ 0 & - & & \end{array}$


APÉNDICE 5 (continuação) Mês: Outubro $Q:$ I.

$\begin{array}{rrrc}F & F \% & F A c \% & P L \\ 11 & 42,31 & 100,00 & - \\ 4 & 15,38 & 57,69 & 9,19 \\ 3 & 11,54 & 42,31 & 7,74 \\ 2 & 7,69 & 30,77 & 6,63 \\ 3 & 11,54 & 23,08 & 5,76 \\ 1 & 3,85 & 11,54 & 4,10 \\ 0 & 0,00 & 7,69 & 3,26 \\ 0 & 0,00 & 7,69 & - \\ 2 & 7,69 & 7,69 & -\end{array}$

Mês: Novembro Q: $1^{\text {a }}$

\begin{tabular}{rrrc}
$F$ & $F \%$ & \multicolumn{1}{c}{$F A \%$} & \multicolumn{1}{c}{$P L$} \\
5 & 19,23 & 100,00 & 11,65 \\
4 & 15,38 & 80,77 & 9,94 \\
5 & 19,23 & 65,39 & 8,12 \\
2 & 7,69 & 46,16 & 7,40 \\
3 & 11,54 & 38,47 & 6,19 \\
2 & 7,69 & 26,93 & 5,27 \\
3 & 11,54 & 19,24 & 3,26 \\
0 & 0,00 & 7,70 & 3,26 \\
2 & 7,69 & 7,70 & -
\end{tabular}

Mês: Dezembro $Q: l^{a}$

\begin{tabular}{rrrr}
$F$ & $F \%$ & $F A_{c} \%$ & \multicolumn{1}{l}{$P L$} \\
& & \multicolumn{1}{l}{} \\
1 & 3,85 & 100,00 & \multicolumn{1}{l}{-} \\
4 & 15,38 & 96,15 & 15,02 \\
4 & 15,38 & 80,77 & 11,65 \\
4 & 15,38 & 65,39 & 9,94 \\
2 & 7,69 & 50,01 & 8,50 \\
1 & 3,85 & 42,32 & 7,74 \\
1 & 3,85 & 38,47 & 7,40 \\
3 & 11,54 & 34,62 & 7,01 \\
6 & 23,08 & 23,08 & 5,76
\end{tabular}

Mês: Outubro $\quad$ : $2^{\text {a }}$.

CLASSES
ze ro
$1-2$
$3-4$
$5-6$
$7-8$
$9-10$
$11-12$
$13-14$
$15-16$

$\begin{array}{cccc}F & F \% & F A_{C} \% & P L \\ 10 & 38,46 & 100,00 & - \\ 1 & 3,85 & 61,54 & 9,55 \\ 6 & 23,08 & 57,69 & 9,19 \\ 4 & 15,38 & 34,61 & 7,01 \\ 2 & 7,69 & 19,23 & 5,27 \\ 1 & 3,85 & 11,54 & 4,10 \\ 2 & 7,69 & 7,69 & 3,26 \\ 0 & - & - & - \\ 0 & - & - & -\end{array}$

Mês: Novembro $Q: 2^{a}$.

\begin{tabular}{ccrrr} 
CLASSES & $\mathrm{F}$ & $\mathrm{F} \%$ & \multicolumn{1}{c}{$\mathrm{FA}_{\mathrm{C}} \%$} & $\mathrm{PL}$ \\
zero & 4 & 15,38 & 100,00 & 12,24 \\
$1-2$ & 3 & 11,54 & 84,62 & 10,74 \\
$3-4$ & 4 & 15,38 & 73,08 & 9,19 \\
$5-6$ & 7 & 26,92 & 57,70 & 6,63 \\
$7-8$ & 1 & 3,85 & 30,78 & 6,19 \\
$9-10$ & 1 & 3,85 & 26,93 & 5,76 \\
$11-12$ & 0 & 0,00 & 23,08 & - \\
$13-14$ & 0 & 0,00 & 23,08 & - \\
$15-16$ & 6 & 23,08 & 23,08 & -
\end{tabular}

Mês: Dezembro Q: $2^{a}$.

\begin{tabular}{crrrc} 
CLASSES & $F$ & $F \%$ & \multicolumn{1}{c}{$F A_{c} \%$} & $P L$ \\
zero & 0 & 0,00 & 100,00 & - \\
$1-2$ & 0 & 0,00 & 100,00 & - \\
$3-4$ & 1 & 3,85 & 100,00 & - \\
$5-6$ & 6 & 23,08 & 96,15 & 15,02 \\
$7-8$ & 6 & 23,08 & 73,07 & 10,74 \\
$9-10$ & 1 & 3,85 & 49,99 & 8,50 \\
$11-12$ & 2 & 7,69 & 46,14 & 8,12 \\
$13-14$ & 1 & 3,85 & 38,45 & 7,40 \\
$15-16$ & 9 & 34,61 & 34,60 & 7,01
\end{tabular}


APENDICE 6 : Classes das Maiores Sequências de Dias Secos em cada Mês, Fre qUência Absoluta, Percentagem, Frequência Acumulada Complemen tar em Percentagem e Probabilidade Linear, nos 26 anos, para $50 \mathrm{~mm}$ de CAD.

Mês: Janei ro

Mês: Feverei ro

\begin{tabular}{|c|c|c|c|c|c|c|c|}
\hline $\mathrm{F} \%$ & $F A_{C} \%$ & $P L$ & CLASSES & $F$ & $\mathrm{~F} \%$ & $F A_{C} \%$ & PL \\
\hline 3,85 & 100,00 & $=$ & zero & 1 & 3,85 & 100,00 & - \\
\hline 3,85 & 95,15 & 15,15 & $1-3$ & 4 & 15,38 & 96,15 & 15,02 \\
\hline 0,00 & 92,30 & 13,67 & $4-6$ & 4 & 15,38 & 80,77 & 11,65 \\
\hline 15,38 & 92,30 & 13,57 & $7-9$ & 6 & 23,08 & 65,39 & 9,94 \\
\hline 11,54 & 76,92 & 11,18 & $10-12$ & 2 & 7,69 & 42,31 & 7,74 \\
\hline 23,08 & 65,38 & 9,94 & $13-15$ & 3 & 11,54 & 34,62 & 7,01 \\
\hline 0,00 & 42,30 & 7,74 & $16-18$ & 4 & 15,38 & 23,08 & 5,76 \\
\hline 19,23 & 42,30 & 7,74 & $19-21$ & 0 & 0,00 & 7,7 & 3,26 \\
\hline 15,38 & 23,07 & 5,76 & $22-24$ & 0 & 0,00 & 7,7 & 3,26 \\
\hline 0,00 & 7,69 & 3,26 & $25-27$ & 0 & 0,00 & 7,7 & 3,26 \\
\hline 7,69 & 7,69 & 3,26 & $28-31$ & 2 & 7,69 & 7,7 & 3,26 \\
\hline
\end{tabular}

Mês: Março

Mês: Abril

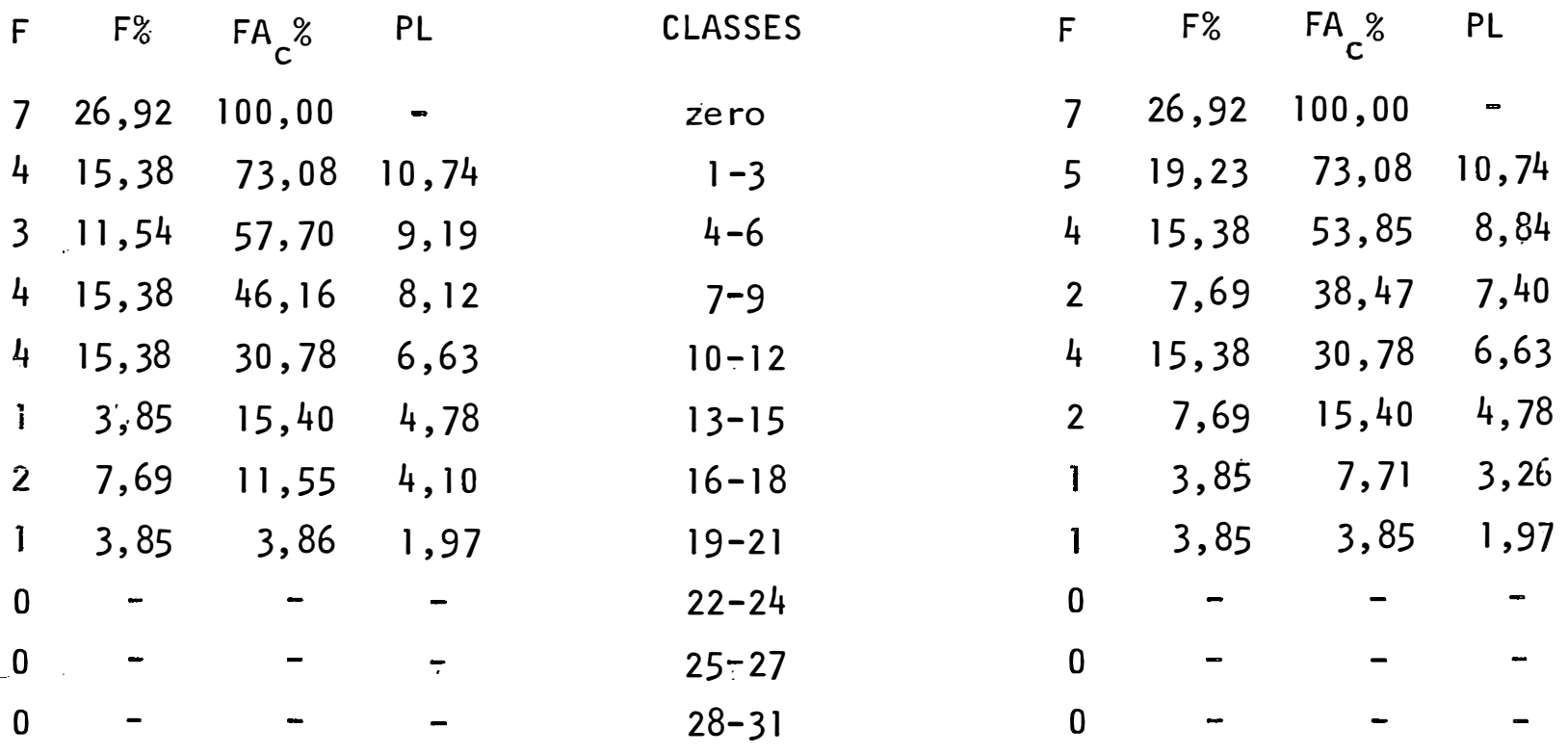


155.

\begin{tabular}{|c|c|c|c|c|c|c|c|c|}
\hline \multirow[b]{2}{*}{$F$} & \multicolumn{3}{|c|}{ Mês: Maio } & \multirow[b]{2}{*}{ CLASSES } & \multicolumn{4}{|c|}{ Mêș: Junho } \\
\hline & $\mathrm{F} \%$ & $F A_{c} \%$ & PL & & $F$ & $\mathrm{~F} \%$ & $F A_{C} \%$ & PL \\
\hline 14 & 53,85 & 100,00 & - & zero & 17 & 65,38 & 100,00 & - \\
\hline 2 & 7,69 & 46,15 & 8,12 & $1-3$ & 1 & 3,85 & 34,62 & 7,01 \\
\hline 3 & 11,54 & 38,46 & 7,40 & $4-6$ & 2 & 7,69 & 30,77 & 6,63 \\
\hline 1 & 3,85 & 26,92 & 6,19 & $7-9$ & 1 & 3,85 & 23,08 & 5,76 \\
\hline I & 3,85 & 23,07 & 5,76 & $10-12$ & 3 & 11,54 & 19,23 & 5,27 \\
\hline 1 & 3,85 & 19,22 & 5,27 & $13-15$ & 2 & 7,69 & 7,69 & 3,26 \\
\hline 2 & 7,69 & 15,37 & 4,78 & $16-18$ & 0 & 0,00 & - & - \\
\hline 1 & 3,85 & 7,68 & $3 ., 26$ & $19-21$ & 0 & - & - & - \\
\hline 0 & 0,00 & 3,83 & 1,97 & $22-24$ & 0 & - & - & - \\
\hline 0 & 0,00 & 3,83 & 1,97 & $25-27$ & 0 & - & - & - \\
\hline 1 & 3,85 & 3,83 & 1,97 & $28-31$ & 0 & - & - & - \\
\hline
\end{tabular}

Mês: Julho

$\begin{array}{cccc}F & F \% & F A_{C} \% & P L \\ 21 & 80,77 & 100,00 & - \\ 1 & 3,85 & 19,23 & 5,27 \\ 1 & 3,85 & 15,38 & 4,78 \\ 0 & 0,00 & 11,53 & 4,10 \\ 1 & 3,85 & 11,53 & 4,10 \\ 1 & 3,85 & 7,68 & 3,26 \\ 1 & 3,85 & 3,83 & 1,97 \\ 0 & - & - & - \\ 0 & - & - & - \\ 0 & - & - & - \\ 0 & - & - & -\end{array}$

Mês: Agos to

$\begin{array}{ccccc}\text { CLASSES } & F & F \% & F A_{C} \% & P L \\ \text { zero } & 16 & 61,54 & 100,00 & - \\ 1-3 & 4 & 15,38 & 38,46 & 7,40 \\ 4-6 & 0 & 0,00 & 23,08 & 5,76 \\ 7-9 & 3 & 11,54 & 23,08 & 5,76 \\ 10-12 & 0 & 0,00 & 11,54 & 4,10 \\ 13-15 & 1 & 3,85 & 11,54 & 4,10 \\ 16-18 & 1 & 3,85 & 7,69 & 3,26 \\ 19-21 & 1 & 3,85 & 3,84 & 1,97 \\ 22-24 & 0 & - & - & - \\ 25-27 & 0 & - & - & - \\ 28-31 & 0 & - & - & -\end{array}$


156.

\begin{tabular}{|c|c|c|c|c|c|c|c|c|}
\hline \multicolumn{5}{|c|}{ Mês: Setembro } & \multicolumn{4}{|c|}{ Mês: Outubro } \\
\hline $\mathrm{F}$ & $F \%$ & $F A_{c} \%$ &.$P L$ & CLASSES & $F$ & $\mathrm{~F} \%$ & $F A_{c} \%$ & $P L$ \\
\hline 19 & 73,08 & 100,00 & - & ze ro & 7 & 26,92 & 100,00 & - \\
\hline 2 & 7,69 & 26,92 & 6,19 & $1-3$ & 2 & 7,69 & 73,08 & 10,74 \\
\hline 1 & 3,85 & 19,23 & 5,76 & $4-6$ & 7 & 25,92 & 65,39 & 9,94 \\
\hline 3 & 11,54 & $1-5,38$ & 4,78 & $7-9$ & 3 & 11,54 & 38,47 & 7,40 \\
\hline 1 & 3,85 & 3,84 & 1,97 & $10-12$ & 4 & 15,38 & 26,93 & 6,19 \\
\hline 0 & - & - & - & $13-15$ & 1 & 3,85 & 11,55 & 4,10 \\
\hline 0 & - & - & - & $16-18$ & 1 & 3,85 & 7,70 & 3,26 \\
\hline 0 & - & - & - & $19-21$ & 0 & 0,00 & 3,85 & 1,97 \\
\hline 0 & - & - & - & $22-24$ & 1 & 3,85 & 3,85 & 1,97 \\
\hline 0 & - & - & - & $25-27$ & 0 & - & - & - \\
\hline 0 & - & - & - & $28-31$ & 0 & - & - & - \\
\hline
\end{tabular}

Mès: Novembro

Mês: Dezembro

\begin{tabular}{rrrcc}
$F$ & \multicolumn{1}{c}{$F \%$} & \multicolumn{1}{c}{$F A_{C} \%$} & \multicolumn{1}{l}{ PL } & .CLASSES \\
2 & 7,69 & 100,00 & - & ze ro \\
4 & 15,38 & 92,31 & 13,67 & $1-3$ \\
5 & 19,23 & 76,93 & 11,18 & $4-6$ \\
3 & 11,54 & 57,70 & 9,19 & $7-9$ \\
5 & 19,23 & 46,16 & 8,12 & $10-12$ \\
0 & 0,00 & 26,93 & 6,19 & $13-15$ \\
3 & 11,54 & 26,93 & 6,19 & $16-18$ \\
0 & 0,00 & 15,39 & 4,78 & $19-21$ \\
1 & 3,85 & 15,39 & 4,78 & $22-24$ \\
1 & 3,85 & 11,54 & 4,10 & $25-27$ \\
2 & 7,69 & 7,69 & 3,26 & $28-31$
\end{tabular}

\begin{tabular}{rrrc}
$F$ & \multicolumn{1}{c}{$F \%$} & $F_{C} \%$ & $P L$ \\
0 & 0,00 & 100,00 & - \\
0 & 0,00 & 100,00 & - \\
3 & 11,54 & 100,00 & - \\
4 & 15,38 & 88,46 & 12,88 \\
3 & 11,54 & 73,08 & 10,74 \\
6 & 23,08 & 61,54 & 9,55 \\
1 & 3,85 & 38,46 & 7,40 \\
1 & 3,85 & 34,61 & 7,01 \\
0 & 0,00 & 30,76 & 6,63 \\
1 & 3,85 & 30,76 & 6,63 \\
7 & 26,92 & 26,91 & 6,19
\end{tabular}


APENDICE 7 : Classes das Maiores Sequências de Dias Secos encada Trimestre, FreqUência Absoluta, Percentagem, FreqUéncia Acumulada Comple mentar em \% e Probabilidade Linear, nos 26 anos, para 50 mm de CAD.

Trimestre: 1 ?

$\begin{array}{rrrl}F & F \% & F A_{C} \% & P L \\ - & 0,00 & 100,00 & - \\ 4 & 15,38 & 100,00 & - \\ 7 & 26,92 & 84,62 & 12,24 \\ 6 & 23,08 & 57,70 & 9,19 \\ 6 & 23,08 & 34,62 & 7,01 \\ 1 & 3,85 & 11,54 & 4,10 \\ 1 & 3,85 & 7,69 & 3,26 \\ 1 & 3,84 & 3,84 & 1,97\end{array}$

Trimestre: 3 ?

\begin{tabular}{llrl}
$F$ & \multicolumn{1}{l}{$F \%$} & \multicolumn{1}{c}{$F A_{c} \%$} & $P L$ \\
10 & 38,46 & 100,00 & - \\
10 & 38,46 & 61,54 & 9,55 \\
5 & 19,23 & 23,08 & 5,76 \\
0 & 0,00 & 3,85 & 1,97 \\
1 & 3,85 & 3,85 &
\end{tabular}

Trimestre: 20

$\begin{array}{ccccc}\text { CLASSES } & F & F \% & F_{c} \% & P L \\ \text { zero } & 4 & 15,38 & 100,00 & - \\ 1-10 & 10 & 38,46 & 84,62 & 12,24 \\ 11-19 & 7 & 26,92 & 46,16 & 8,12 \\ 20-28 & 4 & 15,38 & 19,24 & 5,27 \\ 29-37 & 0 & 0,00 & 3,86 & 1,97 \\ 38-46 & 0 & 0,00 & 3,86 & 1,97 \\ 47-55 & 1 & 3,85 & 3,86 & 1,97 \\ 56-64 & & & & \\ 65-73 & & & & \\ 74-83 & & & & \\ 84-92 & & & & \end{array}$

Trimestre: 4 ?

$\begin{array}{ccrcc}\text { CLASSES } & F & F \% & F_{c} \% & P L \\ \text { zero } & 0 & 0,00 & 100,00 & - \\ 1-10 & 6 & 23,08 & 100,00 & - \\ 11-19 & 11 & 42,31 & 76,92 & 11,18 \\ 20-28 & 2 & 7,69 & 34,61 & 7,01 \\ 29-37 & 4 & 15,38 & 26,92 & 6,19 \\ 38-46 & 0 & 0,00 & 11,54 & 4,10 \\ 47-55 & 1 & 3,85 & 11,54 & 4,10 \\ 56-64 & 1 & 3,85 & 7,69 & 3,26 \\ 65-73 & 1 & 3,85 & 3,84 & 1,97 \\ 74-83 & & & & \\ 84-92 & & & & \end{array}$

